\title{
Office of Military Government for Bremen
}

\author{
Von
}

Andreas Röpcke 



\section{A. Historischer und verwaltungsgeschichtlicher Überblick*}

Vorbemerkung: Bei den Functional Histories wird in den Anmerkungen auf Angabe des Fundorts verzichtet. Hier eine detaillierte Beschreibung der Functional Histories:

Functional History of Military Government - Bremen Enclave

27.4.1945-30.6.1946

Part I: 487 S. (6/48-2/5)

Part II. 120 Appendices (6/48-2/6)

Functional History of Military Government in Land Bremen

1.7.1946-30.6.1947

Part I: 270 S. $(6 / 50-2 / 1)$

Part II: 94 Appendices (6/50-2/2)

Annual Functional History of Military Government in Land Bremen

1.1.1948-31.12.1948

Part I: 220 S. (6/51-2/9)

Part II: 70 Appendices (6/51-2/10)

Functional History of Military Government in the Bremen Enclave 26.4.1945-30.9.1945

Part I: 176 S. (6/48-2/1)

Part II: ca 40 Appendices (6/48-2/2)

Functional History of Military Government in the Bremen Enclave 1.10.1945-10.12.1945

Part I: 164 S. (6/48-2/3)

Part II: 40 Appendices (6/48-2/3)

Functional History of Military Government in the Bremen Enclave 10.12.1945-31.1.1946

Part I: 201 S. (6/48-2/8)

Part II: 81 Appendices (6/48-3/1)

Bremen Enclave, Functional History of Operations in the Military Government 1.2.1946-31.3.1946

Part I: 173 S. (6/48-3/2)

Part II: 52 Appendices (6/48-3/3)

Functional History of Military Government in the Bremen Enclave 1.7.1946-31.8.1946

Part I: 160 S. (6/48-3/6)

Part II: 48 Appendices $(6 / 48-3 / 7)$

* Dieser Teil wurde in gekürzter Form bereits veröffentlicht unter dem Titel: Entstehung, Status und Verwaltung der amerikanischen Enklave Bremen. In: Bremisches Jahrbuch 66 (1988), S.423-452. Das Manuskript für den Abschnitt Bremen wurde 1989 abgeschlossen. Jüngere Neuerscheinungen konnten nicht mehr in den Text eingearbeitet werden. 
Functional History of Military Government in the Bremen Enclave 1.9.1946-31.12.1946

Part I: 340 S. (6/49-1/1)

Part II: 133 Appendices (6/49-1/2)

Functional History of Military Government in the Bremen Enclave

1.1.1947-31.3.1947

Part I: 249 S. (6/49-1/5)

Part II: 102 Appendices (6/49-2/4)

Functional History of Military Government in Land Bremen

1.7.1947-30.9.1947

Part I: 170 S. (6/49-3/1)

Part II: 55 Appendices (6/49-3/3)

Functional History of Military Government in Land Bremen

1.10.1947-31.12.1947

Part I: 161 S. (6/49-3/4)

Part II: 73 Appendices (6/49-3/8)

Functional History of Military Government in Land Bremen

1.1.1948-31.3.1948

Part I: 145 S. $(6 / 49-3 / 10)$

Part II: 39 Appendices (6/49-3/11)

\section{Die Entstehung der Bremer Enklave}

Im September 1944 war der Gedanke eines amerikanischen Kontrollgebietes an der Unterweser Sprungstein über den Graben britisch-amerikanischer Meinungsverschiedenheiten bezüglich der Besatzungszonen im Nachkriegsdeutschland. Mit der „Bremer Klausel“ als Ergänzung zum Londoner Zonenprotokoll konnte eine zwölfmonatige Kontroverse der beiden Westalliierten beendet werden, doch barg der Kompromiß in sich Stoff für neue Differenzen. Um die Hintergründe der amerikanischen Präsenz an der Unterweser deutlich zu machen, ist es erforderlich, diese Auseinandersetzungen hier in groben Zügen darzustellen. ${ }^{1}$

Als Präsident Franklin D. Roosevelt und Premierminister Winston Churchill im August 1943 den unter rein militärischen Gesichtspunkten entwickelten Invasionsplänen OVERLORD und RANKIN ihr Plazet erteilt hatten, war eine schließlich maBgebliche Vorentscheidung über die künftigen Besatzungszonen gefallen, ohne daß sich der amerikanische Präsident dessen bewußt gewesen wäre. Beide Pläne sahen den Einsatz der amerikanischen Verbände auf dem rechten, der britischen auf dem linken Flügel der Invasionsarmee vor. RANKIN bestimmte ferner, daß bei einem plötzlichen Kollaps der nationalsozialistischen Herrschaft in Deutschland die Briten in den nordwestlichen, die Amerikaner in den südwestlichen Teil Deutschlands vorstoßen und diese „Sphären“ besetzen sollten. Ein von britischer Seite aus RANKIN entwickeltes Papier sah die Benelux-Länder, Dänemark und Norwegen samt Nordwestdeutschland in der britischen Sphäre, während Frankreich und Österreich mit dem deutschen Süden der amerikanischen Sphäre zugerechnet wurden.

${ }^{1}$ Dieser Abschnitt fußt, wenn nicht anders angemerkt, auf Sharp: Wartime Alliance, bes. Kap. II-IV. 
Dieses Papier diskutierte Roosevelt mit seinen Beratern am 19. November 1943 auf dem Weg zur Kairoer Konferenz. Es paßte ihm nicht. Er wollte die Vereinigten Staaten nicht in die Nachkriegsprobleme Frankreichs verstrickt sehen - das sei eine britische Aufgabe - und stieß sich an den langen Versorgungslinien für die in Süddeutschland stationierten Truppen, die wiederum durch Frankreich führen würden. Die Vereinigten Staaten sollten vielmehr Nordwestdeutschland besetzen und die Häfen in Hamburg und Bremerhaven für sich nutzen ebenso wie die in Dänemark, Norwegen und vermutlich den Niederlanden. Damit war der Konflikt programmiert.

Das Thema kam zwischen Churchill und Roosevelt erst auf der zweiten Kairoer Konferenz Anfang Dezember 1943 zur Sprache. Beide brachten zum Ausdruck, daB sie gern den deutschen Nordwesten hätten. Ein von amerikanischer Seite erarbeitetes Memorandum erklärte, daß der Seitenwechsel militärisch kein unübersteigbares Hindernis sei und nahm die Nordwestzone für die USA in Anspruch. Churchill und sein Außenminister Anthony Eden nahmen diese Forderung am 6. Dezember 1943 mit begreiflicher Zurückhaltung zur Kenntnis.

Von der Moskauer Außenministerkonferenz war die Europäische Beratende Kommission (EAC) in London 1943 unter anderem mit der Aufgabe betraut worden, die Besatzungszonen der drei Großmächte auszuhandeln. Amerika wurde durch Botschafter John G. Winant vertreten, die Sowjetunion durch Botschafter Fedor T. Gousev und GroBbritannien durch Sir William Strang vom Foreign Office. Von britischer Seite wurde am 15.Januar 1944 ein Vorschlag zur Einteilung der Besatzungszonen eingebracht, der weiterhin den Briten den Nordwesten, den Amerikanern den Süden Deutschlands zuwies. Die vorgeschlagene Grenze zur Ostzone entsprach mit geringen Änderungen der innerdeutschen Grenze, wie sie bis zur Wiedervereinigung bestand. Die Reaktion der Sowjets im Februar 1944 zeigte, daß der Vorschlag weitgehend ihren Vorstellungen entsprach. Von amerikanischer Seite jedoch wurde der Anspruch auf den Nordwesten erneuert mit dem Hinweis, daB dadurch die Ruckfuhrung der amerikanischen Truppen erleichtert würde. Das akzeptierten die Briten nicht als ausreichenden Grund für eine Veränderung der bisherigen Planung. Roosevelt erklärte sich gegenüber einem Mitglied der amerikanischen Delegation im April 1944 zwar bereit, die vorgeschlagene Grenze zur Ostzone anzuerkennen, beharrte aber weiterhin auf dem Nordwesten, so daß die Londoner Verhandlungen festsaBen. Die EAC wandte sich zunächst anderem zu, griff aber Anfang Juni das Zonenthema wieder auf und stellte bis Ende des Monats den Entwurf eines Zonenprotokolls fertig, in dem die Zuweisung der beiden beschriebenen Westzonen jedoch offengelassen war. Nach anfänglicher Weigerung der Sowjets, ein solches unfertiges Dokument zu unterzeichnen, kam es am 12. September 1944 doch noch zur Unterschrift der drei Verhandlungsführer in der EAC.

Inzwischen hatte es nicht an Versuchen gefehlt, Roosevelt zum Einlenken zu bewegen. Außenminister Edward R. Stettinius hatte ihm Ende Juli vorgeschlagen, doch den Süden zu nehmen, wenn dafür die Briten die Verantwortung für Frankreich, Italien und den Balkan übernähmen und die Vereinigten Staaten an Nutzung und Kontrolle der Häfen der Nordwestzone teilhaben ließen. Ohne Erfolg. Am Tage der Unterzeichnung des Londoner Protokolls, am 12. September 1944, erklärten sich die amerikanischen Stabschefs (Joint Chiefs of Staff) mit der Südwestzone einverstanden, sofern Vereinbarungen über die Nutzung der norddeutschen Häfen getroffen werden könnten. Die Klärung der Frage blieb jedoch einem persönlichen Gespräch auf höchster Ebene vorbehalten, das am 15. September in Quebec während der Octagon-Konferenz stattfand. Roosevelt gab nach, laut Churchill überzeugt von militärischen Gesichtspunkten und ,subject to the United States armies having a near-by direct outlet 
to the sea across the British zone". ${ }^{2}$ In einem Gespräch der Admirale Ernest J. King und Andrew Cunningham am selben Tag erklärte King, daB die US Navy die Häfen übernehmen werde, die sie nutzen müsse, $d$. h. sie werde einen Hafendirektor und entsprechendes Personal stellen. Ein ausgeklügeltes Gebilde wolle er nicht. ${ }^{3}$ Der Sitzung der amerikanischen Stabschefs am kommenden Tag (16. September 1944) lag ein Memorandum von Admiral William D. Leahy vor, in dem die neu festgelegte britische und amerikanische Zone beschrieben und die Notwendigkeit des Zugangs zu den Seehäfen und des Transits durch die britische Zone dargelegt wurden. General George C. Marshall hielt es für besser, in der Hafenfrage zu spezifizieren und einen bestimmten Hafen zu nennen, der von den Vereinigten Staaten kontrolliert werden wurde. Admiral King pflichtete ihm bei und brachte Bremen und Umgebung in Vorschlag. ${ }^{4}$ Marshall formulierte daraufhin für das Memorandum den zusätzlichen Absatz: „Control of the port of Bremen and the necessary staging areas in that immediate vicinity will be vested in the commander of the American zone".5 Dies war die Geburtsstunde der Bremer Enklave. Sie war der Zucker, mit dem Roosevelt die bittere Medizin des Verzichts auf die von ihm favorisierte Nordwestzone zu schlucken hatte.

Bei einem Treffen mit den britischen Kollegen am selben Tag erläuterte Admiral King, daB die amerikanische Kontrolle des Hafens Bremen die Kontrolle eines geeigneten Gebietes zur Vorbereitung und Abwicklung der Transporte einschließen müßte. Der britische Admiral Cunningham stimmte zu und schlug außerdem vor, das flußabwärts gelegene Bremerhaven hinzuzunehmen. Diese Ergänzung wurde in das Memorandum aufgenommen, das dann auch die Billigung von Roosevelt und Churchill fand. Die genaue Abgrenzung der britischen und amerikanischen Kontrollgebiete wurde auf einen späteren Zeitpunkt verschoben.

Damit war, wie eingangs erwähnt, der Streit um den deutschen Nordwesten begraben, doch bestand, wie sich bald zeigte, uber die Ausdeutung der KompromiBformel kein Einvernehmen. Was hatte man sich unter dem Begriff "control" vorzustellen? Waren mit „ports“ die Hafenanlagen oder die Hafenstädte gemeint?

Im am 19. September 1944 tagenden amerikanischen Joint Logistics Committee wurde der Vorschlag gemacht, das Land Bremen mit den Städten Bremen und Bremerhaven für die USA zu fordern. ${ }^{6}$ Winant telegraphierte am 3. Oktober an das State Department, man sei sich unsicher, wie „control of the ports of Bremen and Bremerhaven" zu verstehen sei - als (a) Kontrolle der Transporteinrichtungen bei ansonsten britischer Militärregierung, oder (b) Verantwortung für die Militärregierung, was eine Umschreibung des betreffenden Gebietes nötig machen würde. Winant hielt Lösung (a) für praktisch und nützlich und sah andernfalls Schwierigkeiten voraus. Für die amerikanischen Stabschefs aber war die Sache klar: akzeptabel sei nur die ausschließliche Kontrolle durch einen amerikanischen Kommandeur, der auch die Verantwortung für

${ }^{2}$ Churchill: Triumph and Tragedy, S.510. Als weiteres Motiv wurde von Konferenzteilnehmer Morgenthau genannt, daB damit die Briten als Besetzer von Ruhr und Saar die Hauptlast der Umsetzung des gerade beschlossenen Morgenthau-Planes zu tragen hätten; siehe Foreign Relations, Malta and Yalta 1945, S.136f.

3 "Admiral King said that the US Navy would take over such ports as they were using, providing a Port Director and staff. However, he did not want any elaborate organization set-up“ (Foreign Relations, Quebec 1944, S. 353; StA Bremen 16,1/3-1).

4 Wohl weil am nächsten zu Kassel, dem nördlichen Zipfel der amerikanischen Zone, gelegen.

${ }^{5}$ Foreign Relations, Quebec, S. 373; für das folgende ebenda, S. 375 und 392 sowie StA Bremen $16,1 / 3-1$.

${ }^{6}$ Ebenda. 
die Militärregierung haben müBte. 7 Das Joint Logistics Committee empfahl in einem am 8. Oktober 1944 vorgelegten Bericht die Einbeziehung in die amerikanische Zone und schlug als Areal das Land Bremen, Stadt und Landkreis Wesermünde sowie die Landkreise Osterholz und Wesermarsch vor. ${ }^{8}$ Der Vorschlag fand Eingang in das Memorandum vom 5. November 1944, in dem die Joint Chiefs of Staff den britischen Partnern ihre Vorstellungen über den Verlauf der Zonengrenzen näher darlegten. ${ }^{9}$ In der EAC vorgetragen, stießen die amerikanischen Wünsche sofort auf britische Bedenken.

Um nun die beschlossenen Änderungen möglichst rasch im Zonenprotokoll zu verankern (man fürchtete neue Komplikationen durch das Auftauchen eines französischen Delegierten bei der EAC), bot der US-Delegierte eine Interimslösung für die Bremen-Frage an, die beide Optionen offen hielt. Die Briten akzeptierten, und es kam am 14. November 1944 zur Unterzeichnung des revidierten Zonenprotokolls. Nach der Beschreibung der Südwestzone wurde eingefügt:

„For the purpose of facilitating communications between the South-Western Zone and the sea, the Commander-in-Chief of the United States forces in the South-Western Zone will

(a) exercise such control of the ports of Bremen and Bremerhaven and the necessary staging areas in the vicinity thereof as may be agreed hereafter by the United Kingdom and United States military authorities to be necessary to meet his requirements;

(b) enjoy such transit facilities through the North-Western Zone as may be agreed hereafter by the United Kingdom and United States military authorities to be necessary to meet his requirements." 10

Diese Interimslösung, die eine Festlegung bewußt vermeiden und künftigen Verhandlungen überlassen sollte, findet sich Wort für Wort wieder in der endgültigen Fassung des Zonenprotokolls vom 26. Juli 1945. Ein Vierteljahr nach Beginn der Besatzungsverwaltung war der Status der Amerikaner in ihrem Kontrollgebiet an der Unterweser also weiterhin ungewiß.

Roosevelt stimmte dem revidierten Zonenprotokoll am 4. Dezember $1944 \mathrm{zu}$, die Briten ratifizierten es am 5. Dezember, doch die förmliche Ratifizierung seitens der Amerikaner blieb aus. Sie sollte, wie aus Washington verlautete, erst erfolgen, wenn eine akzeptable Formel für das Kontrollgebiet um Bremen und die Transitrechte gefunden sei. Dieses Zögern konnte das ganze Zonenprotokoll in Gefahr bringen. Winant warnte aus London dringend davor, den ganzen Komplex neu aufzurollen. Um wenigstens noch vor der Konferenz von Jalta zu einer Lösung zu kommen, setzte sich John J. McCloy am 5.Januar 1945 im War Department mit den britischen Vertretern Lord Halifax und Gordon Macready zusammen und erarbeitete eine Kompromißformel, die noch am selben Tag nach London durchgegeben wurde. ${ }^{11}$ Bei ihrer Annahme durch die Briten stünde einer Ratifizierung des Zonenprotokolls nichts mehr im Wege. Während das Foreign Office Zustimmungsbereitschaft signalisierte, meldeten die Militärs in einigen Punkten Vorbehalte an und erbaten eine Bestätigung ihrer Auslegung. ${ }^{12}$ Das Drängen auf eine Einigung im Vorfeld der Konferenzen blieb vergeblich.

\footnotetext{
${ }^{7}$ Ebenda, Schreiben vom 4.10.1944.

8 Ebenda, JLC 196/3, auch JLC 196/4 vom 9.10.1944.

9 StA Bremen 16,1/3-2, CCS 320/29.

${ }^{10}$ Foreign Relations, Malta and Yalta 1945, S. $122 \mathrm{f}$.

11 Ebenda, S. 198.

12 Ebenda, S. 199 f.
} 
Bei einem Treffen der beiden Außenminister auf Malta am 1. Februar 1945 kam das Problem zur Sprache. Stettinius und Eden waren sich einig, daB die Zustimmung der Sowjets zum Zonenprotokoll von großer Bedeutung sei. So, wie sich die militärische Lage entwickeite, mochte die Sowjetunion das Interesse an der gefundenen Regelung verlieren und sich einfach nehmen, was sie bekommen konnte. Die im Zusammenhang mit Bremen und Bremerhaven noch offenen Fragen bedürften daher einer raschen Klärung. Sie wurde bereits beim Mittagessen mit Armeegeneral Marshall und Feldmarschall Sir Alan Brooke herbeigeführt, so daB umgehend die Zustimmung der amerikanischen Regierung zum revidierten Zonenprotokoll nach London telegraphiert werden konnte. ${ }^{13}$

Der sowjetische Delegierte bei der EAC gab die Zustimmung seiner Regierung zum Zonenprotokoll am 6. Februar 1945 bekannt, nachdem am Vortag Roosevelt und Churchill Stalin in Jalta darauf angesprochen hatten.

An diesem 5. Februar beschäftigten sich in Jalta auch die amerikanischen Stabschefs erneut mit den Problemen des Bremer Kontrollgebietes. Marshall wehrte sich gegen ein ins einzelne gehendes Abkommen. Nun, da über die große Linie entschieden sei, könnten Details den örtlichen Befehlshabern überlassen bleiben. Probleme, die aus überlappenden Hoheitsrechten entstünden, könnten zu gegebener Zeit den Combined Chiefs of Staff vorgelegt werden. ${ }^{14}$ Der Text, auf den man sich am kommenden Tag mit den britischen Kollegen abschließend verständigte, dokumentiert, daß man die Probleme zwar nicht gelöst hatte, aber vom Tisch haben wollte. ${ }^{15}$ Andere sollten später sehen, wie sie zurechtkamen. Immerhin, eine Enklave vollständig unter amerikanischer Kontrolle sollte es geben - in diesem Punkt hatten sich die USA durchgesetzt. Eine Eingliederung in die amerikanische Zone erfolgte jedoch nicht, sondern die Militärregierung der Enklave sollte entsprechend den Grundlinien der Politik der britischen Zone geführt werden. Wie das in der Praxis funktionieren sollte - darüber, wie gesagt, sollten andere sich Gedanken machen. Das fur die Enklave abgegrenzte Gebiet entsprach im übrigen der bereits Anfang Oktober 1944 vom Joint Logistics Committee vorgelegten Empfehlung: Land Bremen einschließlich Bremerhaven, Stadt und Landkreis Wesermünde, dazu rechts der Weser Landkreis OsterholzScharmbeck und links der Weser der Landkreis Wesermarsch.

13 Ebenda, S. 498f.

14 Ebenda, S.637f.; Sharp: Wartime Alliance, S. 113.

15 Der nachstehend wiedergegebene Wortlaut der Vereinbarung ist gedruckt in Foreign Relations, Malta and Yalta 1945, S.639, die darin genannte Karte der Enklave ebenda, nach S. 200; siehe auch Übersicht 1.

"The Bremen Enclave

1. The Bremen and Bremerhaven enclave as shown on the attached map will be under complete American control including military government and responsibility for disarmament and demilitarization. It is understood that the American military government will conform to the general policies pursued in the administration of the British zone subject always to the right of the American commander to vary the administration of the enclave in any particular that he may find necessary on military grounds.

2. The U.S. interest in transit passage from the Bremen area to the southwestern zone is so dominant and the British interest in possible movement through the American zone to Austria so evident that obligation to carry stores and personnel for the one government through the zone controlled by the other is mutually recognized. To better achieve responsive service, each military zone commander will accept a Deputy Controller for (United States/British) requirements of Movement and Transport from the other to assist in the coordination of the movement and transport involved in such essential traffic." 
Übersicht 1: Enklave Bremen und Bremerhaven

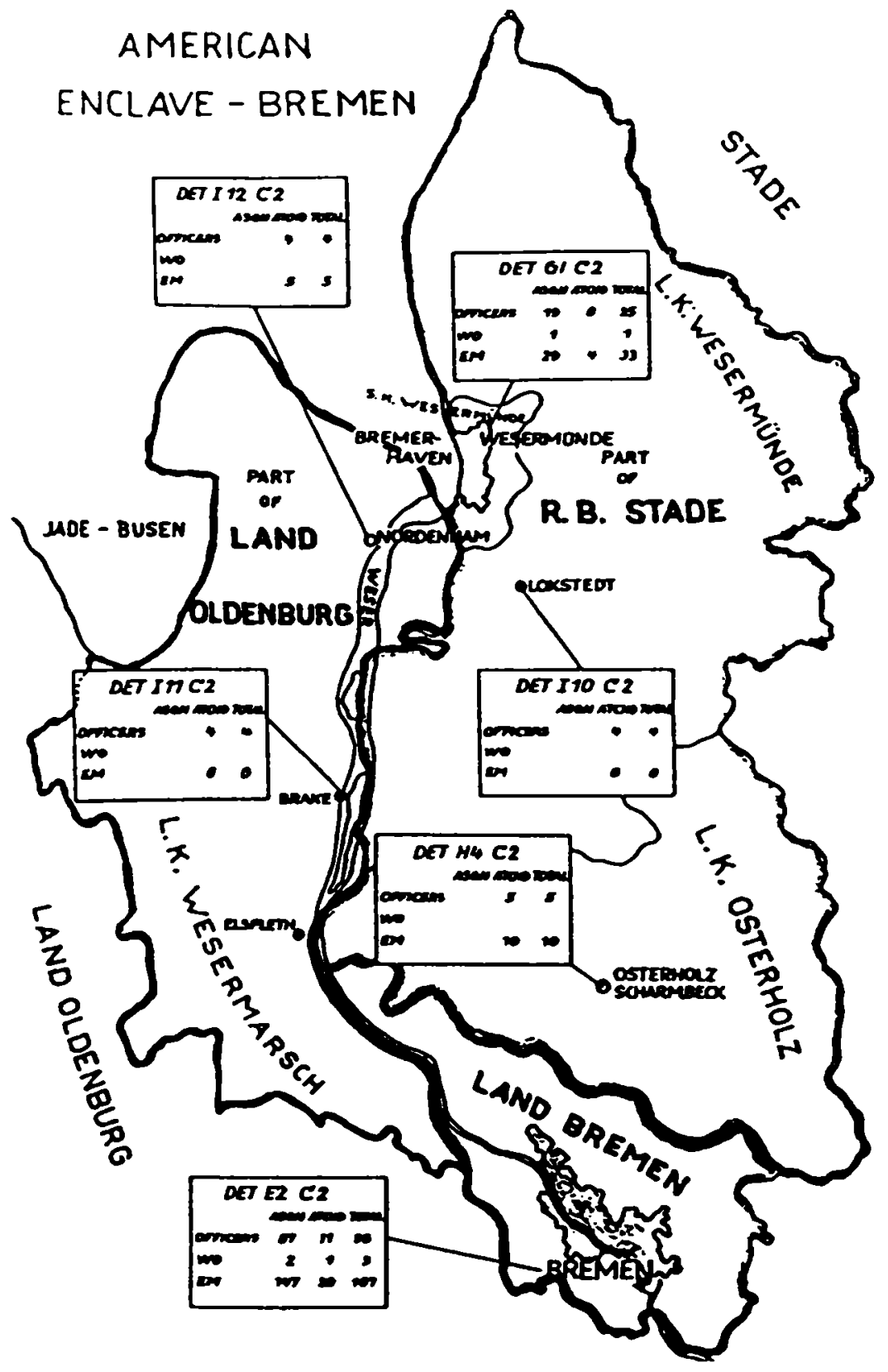


Die aus heutiger Sicht erstaunliche Tatsache, daß die amerikanische Diplomatie sich bei den Verhandlungen um die Besatzungszonen 1944 wesentlich intensiver um den Zugang nach Bremen bemühte als um den Zugang nach Berlin, ist treffend damit erklärt worden, daß es der amerikanischen Führung nach Beendigung des Krieges in Europa nicht so sehr um Zugangsrechte, sondern vielmehr um einen Ausgang aus Europa gegangen sei. ${ }^{16}$ Und den sollte die Bremer Enklave bieten. Wenn derselbe amerikanische Historiker jedoch die Enklave als „ein kurzlebiges Denkmal angloamerikanischer Streitlust während der Kriegszeit" charakterisiert, ${ }^{17}$ so mag das für Statusfragen und ihren territorialen Bestand zutreffen - übersehen wird dabei aber die fundamentale Bedeutung der Enklave für das Wiedererstehen eines selbständigen Landes Bremen nach dem Zusammenbruch 1945.

\section{Exkurs: Territoriale Probleme der Enklave}

\section{a) Hemelingen, Mahndorf und Bremerhaven}

Mit der Entscheidung für eine voll verantwortliche amerikanische Militärregierung im Kontrollgebiet hatte sich die Notwendigkeit der Abgrenzung von der britischen Zone ergeben. Die Grenzen der Enklave wurden von den amerikanischen Planern auf einer Karte festgehalten, die dann ausdrücklich Bestandteil des Abkommens von Jalta wurde, ein Vertragsdokument also. ${ }^{18}$ Diese Karte nun gibt die Bremer Landesgrenzen nicht nach dem seinerzeit aktuellen Stand wieder, sondern stellt den Zustand vor der Vierten Verordnung über den Neuaufbau des Reichs vom 28. September 1939 dar. Folglich liegen die Bremen am 1. November 1939 eingegliederten Ortschaften Hemelingen und Mahndorf am südöstlichen Stadtrand außerhalb der Enklave, und Bremerhaven besteht noch als eigene Stadt, während nach dem aktuellen Stand Bremerhaven in Wesermünde aufgegangen war und nur noch das zur Stadt Bremen eingemeindete Überseehafengebiet die Bezeichnung Bremerhaven trug. ${ }^{19}$ Das war geeignet, Verwirrung zu stiften, und hat es auch getan, zumal nach dem Zonenprotokoll die deutschen Grenzen nach dem 25. Juni 1941 maßgeblich waren. In der Praxis ist man dann ohne viel Aufhebens von der vorgegebenen Bremer Landesgrenze ausgegangen, nicht von der in Jalta vertraglich festgelegten. Der Direktor der Bremer Militärregierung erklärte auf Anfrage der Zentrale am 12. September 1945 lapidar, er habe die maßgebliche Karte noch nie gesehen. ${ }^{20}$ In Bezug auf Bremerhaven gab es in der Folge eine Panne beim britisch-amerikanischen Abkommen über die Militärregierung in der Bremer Enklave vom 10.Dezember 1945. Es knüpfte an den Wortlaut des Zonenprotokolls an, um dann festzulegen, daB die Militärregierung in der Enklave, abgesehen von Bremen und Bremerhaven, an die Briten zu übergeben sei. ${ }^{21} \mathrm{Da}$ wichtige amerikanische Versorgungseinrichtungen in Wesermünde stationiert waren, setzte sich der amerikanische Kommandeur, General Harry B. Vaughan, mit dem britischen Befehlshaber in Hannover, Brigadier J. Lingham in Verbindung und erwirkte das Zugeständnis, daß die Stadt Wesermünde unter amerikanischer Kontrolle verbleiben solle. Eine entspre-

${ }^{16}$ Ziemke: Occupation of Germany, S. 126.

17 Ebenda, S. 125.

18 Siehe Anm. 15 und Übersicht 1.

${ }^{19}$ RGBl. 1939 1, S. 2041; Grundriß zur deutschen Verwaltungsgeschichte, S. 57.

20 AG 1945-46/13A/5.

21 OMGBR: Functional History 27.4.1945 - 30.6.1946, II. Appendix 6a; OMGBR: Functional History 1.10. - 10.12.1945, II. Appendix 6, bzw. OMGBR: Functional History 10.12.194531.1.1946, II, Appendix 1; abgedruckt in Pollock u. a.: Germany under Occupation, S.121. 
chende schriftliche Abmachung wurde mit der Bitte um Zustimmung nach Berlin geschickt, wo sich herausstellte, daß es in der Tat in der Absicht der Verhandlungspartner gelegen hatte, die zum Hafen gehörende Stadt unter amerikanischer Kontrolle zu belassen. Man war jedoch der Meinung gewesen, Wesermünde gehöre zu Bremerhaven. Die Nachbesserung des Abkommens ging am 15. Januar 1946 glatt über die Bühne. 2

\section{b) Delmenhorst}

Delmenhorst gehörte nie zur Bremer Enklave. Da immer wieder, auch in seriösen Publikationen, das Gegenteil behauptet wird, ${ }^{23}$ müssen diesem Irrtum ein paar Sätze gewidmet werden. Er taucht erstmals bereits bei den Verhandlungen um das amerikanische Kontrollgebiet an der Unterweser im Winter 1944 auf. Unter den britischen Einwänden gegen die Enklavenpläne befand sich im Dezember auch der Hinweis auf das Flughafenbereichskommando in Delmenhorst, dessen Kontrolle durch die Amerikaner nicht wünschenswert sei, was von den Amerikanern kühl mit dem Hinweis gekontert wurde: „There appears to be no problem here, since Delmenhorst is not situated within the proposed U.S. controlled area, as may be seen by reference to the map". ${ }^{24}$ Die in Jalta am 6. Februar 1945 gefaBten Beschlüsse uber die Enklave hatten das zuständige Detachment noch nicht erreicht, als es Ende April in Bremen einrückte. Der in der Vorbereitungszeit an der Basis erarbeitete und im März auf verschiedenen Ebenen abgestimmte Einsatzplan sah die Stationierung eines amerikanischen Detachments in Delmenhorst vor. ${ }^{25}$ In der rückschauenden Berichterstattung heiBt es dazu, man sei um eine Stellungnahme gebeten worden und habe die Einbeziehung von Delmenhorst in die Enklave befürwortet, darauf jedoch keine Antwort mehr erhalten. Erst der Operationsplan der im Mai einrülckenden amerikanischen 29. Infanteriedivision habe Klarheit dartiber geschaffen, daß Delmenhorst nicht zur Enklave gehörte. ${ }^{26}$

Auf die verschiedenen Pläne zur Erweiterung oder Verkleinerung der Enklave, die in den kommenden 18 Monaten diskutiert wurden, kann und braucht hier nicht eingegangen werden. Bei den entscheidenden Gesprächen 1946 zwischen Austen Albu und Henry Parkman über die zukunftige Gestalt des Landes Bremen ist eine Variante unter Einschluß von Delmenhorst und den Landkreisen Hoya und Verden durchgespielt und verworfen worden. ${ }^{27}$ Die Generäle Lucius D. Clay und Brian Hubert Robertson, die aus dem Arbeitsergebnis von Parkman und Albu ein Abkommen ent-

22 OMGBR: Functional History 1.10. - 10.12.1945, I, S.2f;; OMGBR: Functional History 27.4.1945-30.6.1946, II, App. 6b und 6c.

${ }^{23}$ Z. B. Wulff: Im Jahrfünft, S. 10; Peters: Zwölf Jahre Bremen, S.41; Zuversicht und Beständigkeit, S. 136; Müller: Wider die hannoverschen Schrullen, S. 167; Kloos: Bremer Lexikon, S.97; Kleines Bremer Lexikon, in: Kurier am Sonntag, 8.1.1984, S. 13.

${ }^{24}$ StA Bremen 16,1/3-4, JLC 196/15.

25 6/125-3/24.

${ }^{26}$ OMGBR: Functional History 27.4.1945 - 30.6.1946, I, S. 27f. Die Planungsabteilung der Air Force ACOS A-3 unternahm am 15.3.1945 noch einen VorstoB, Delmenhorst in die Enklave einzubeziehen, weil der dortige Flugplatz für die US-Truppen benötigt würde. G-5, SHAEF, unterstützte im Antwortschreiben vom 23.3. das Ansinnen grundsätzlich, gab jedoch zu bedenken, daß die Frage den Combined Chiefs of Staff vorgetragen werden müsse, da diese die Grenze festgelegt hätten (5/358-3/9 und AGTS 8/11).

${ }^{27}$ 6/95-2/26. Parkman war Leiter der Civil Administration Division, OMGUS, Albu vertrat die britischen Interessen. 
wickelten, bewiesen - wie schon im Vorjahr im Falle Bremerhavens - in topographischen Fragen keine glückliche Hand: Die Formulierung in Absatz i) „GroBbritannien behält die Verantwortung für die Verwaltung der Militärregierung in dem Teil der Enklave, der beim Lande Niedersachsen bleibt, nämlich die Landkreise Wesermünde, Osterholz und Wesermarsch und der Stadtkreis Delmenhorst" kann, ja muB den irrigen Eindruck erwecken, Delmenhorst habe bis dahin zur Enklave gehört. Das Abkommen ist in einer Sonderausgabe des Weser-Kurier am 23.Januar 1947 veröffentlicht worden. Wilhelm Kaisen hat es in einer Bürgerschaftsrede am 30.Januar 1947 verlesen, die bald darauf in einem Buch publiziert wurde, ${ }^{28}$ und es hat natürlich Eingang in die Bremer Senatsakten gefunden: In einer Ausarbeitung „Wichtige Daten über die Bremer Enklave" wird gerade dieser fehlerhafte Passus der Vereinbarung referiert. ${ }^{29}$ Hier dürfte die bislang nicht auszutrocknende Quelle des Irrtums liegen.

\section{Besetzung und spezifische Probleme der Besatzungsverwaltung (1945)}

Die Detachments E2C2 und G1C2, die für die Militärregierung in Bremen und Wesermünde vorgesehen waren, wurden am 27 . Januar 1945 in Romilly (Frankreich) aufgestellt - zu einem Zeitpunkt also, als auf der obersten Ebene noch gar nicht endgültig entschieden war, ob es überhaupt eine Enklave mit amerikanischer Militärregierung an der Unterweser geben sollte. ${ }^{30}$ Die Detachments rückten noch am selben Tag in ihr Trainingsquartier in St. Savine bei Troyes ein, wo sie sich bis zum 5. April auf ihren Einsatz vorbereiteten. Dann erfolgte der Aufbruch. Bei Enschede traf man mit britischen Einheiten zusammen, in deren Gefolge sich der Vormarsch Richtung Bremen vollzog. Am 19. April wurde Quartier in der Jugendherberge Pestinghausen bei Syke bezogen, um dort die Einnahme der Stadt abzuwarten. Eine Vorausabteilung folgte dem Angriff der 52. Lowland Division auf dem Ostufer der Weser und gelangte am 26. April gegen Mittag ins Zentrum der Stadt. Zusammen mit dem britischen Obersten Lambert suchte Lt.Col. Bion C. Welker, Kommandeur des Detachments E2C2, das Polizeipräsidium auf, während sein Executive Officer Joseph W. Shamel auf Quartiersuche ging. Lambert setzte den amtierenden Bürgermeister Richard Duckwitz ab und übertrug das Amt vorläufig dem Polizeipräsidenten Generalmajor Johannes Schroers, Parteigenosse seit 1932, Beisitzer im Volksgerichtshof seit 1935 und SS-Brigadeführer seit 1942, der allerdings schon am 30. April den Bürgermeistersessel wieder räumen und seinen Weg in ein Internierungslager antreten mußte. ${ }^{31}$ Shamel hatte inzwischen als Hauptquartier der Militärregierung das Gebäude Contrescarpe 22/23 ausgewählt, in dem heute der Senator für Inneres residiert. Quartiere für Offiziere und Mann-

${ }^{28}$ Kaisen: Bereitschaft und Zuversicht, S. $86 \mathrm{f}$.

${ }^{29}$ StA Bremen 3-B.10.a.Nr.2 [1], Bd. 1.

${ }^{30}$ Das folgende nach OMGBR: Functional History 27.4.1945-30.6.1946, I, S. 1 ff. Eine gründliche Darstellung der letzten Kampfhandlungen bis zur Kapitulation liefert Schwarzwälder: Kampf um Bremen, Kap. I und II, sowie ders.: Das Ende an der Unterweser, Kap. II. Für die Zeit danach fehlt eine umfassende Studie. Heranzuziehen sind vor allem Brandt: Antifaschismus und Arbeiterbewegung, S. 68 ff.; Adamietz: Das erste Kapitel; Zuversicht und Beständigkeit, S. 74 ff.; ferner die Examensarbeiten von Buchholz: Wiederaufbau in Bremen und Wenzlau: Entstehungsgeschichte; für Bremerhaven Scheper: Bremerhaven, S. $345 \mathrm{ff}$.

${ }^{31}$ Schwarzwälder: Kampf um Bremen, S. 103 f. 
schaften wurden später in der unmittelbaren Nachbarschaft requiriert. ${ }^{32}$ Am darauffolgenden Tag rückte das Detachment ein. Am 27. April 1945 um 11 Uhr begann in Bremen offiziell die Besatzungszeit.

Während an den ersten beiden Tagen noch der britische Verbindungsoffizier, Oberstleutnant Kennedy, das Kommando führte, konnte sich Welker vom 29. April an als Chef der Militärregierung in Bremen fühlen, direkt unterstellt dem britischen Divisionskommandeur Generalmajor Edmund Hakewell-Smith. Um den 1. Mai herum überschritt eine kleine Gruppe unter Major Harold R. Bechtel die Lesum und errichtete in der Vegesacker Polizeistation ihr Hauptquartier. ${ }^{33}$ Wesermünde wurde am 7. Mai kampflos eingenommen. Eine Vorausabteilung des Detachments G1C2 hatte die Pestalozzischule, den Amtssitz des Oberbürgermeisters, als Hauptquartier ausgesucht, von dem aus die Regierungsverantwortung am 8. Mai 1945 übernommen wurde. Quartier fanden die Offiziere in der Hafenstraße 36, die Mannschafen in der Wiener Straße, wo auch die Messe eingerichtet wurde. ${ }^{34}$

Die Zuständigkeit für die militärische Sicherheit in der Enklave ging am 20. Mai 1945 offiziell von den Briten auf die nachgerückte 29. Infanteriedivision über. ${ }^{35}$ Etwa zum gleichen Zeitpunkt wurde klar, daß für die Verwaltung der Enklave weitere Detachments zu bilden und schwerpunktmäßig zu stationieren waren. Bis zum Monatsende waren Detachments für Osterholz-Scharmbeck, Brake und den Landkreis Wesermünde formiert und an der Arbeit. Im Juni erhielt der Landkreis Wesermarsch ein zweites Detachment in Nordenham. ${ }^{36}$

Die Vertreter der Militärregierung hatten es schwerer als andernorts, wo man wenigstens die vorhandenen Behördenstrukturen und eingespielte Verwaltungsabläufe nut-

${ }^{32}$ Nach dem Telefonverzeichnis vom 1.3.1946 wohnten die Mannschaftsdienstgrade in den Häusem Contrescarpe Nr.17, 34 und 35, die Offiziere in den Häusern Kohlhökerstr. Nr. 26, 44, 45, 46, 47, 48, Rutenstr. Nr. 3, 7, 29, Contrescarpe Nr. 15 und 18.

${ }^{33}$ OMGBR: Functional History 27.4.1945 - 30.6.1946, I, S.8f.; Vegesack lag noch am 3. Mai unter leichtem Artilleriebeschuß und wurde erst nach dem 5.Mai von britischen Truppen besetzt (siehe Schwarzwälder: Kampf um Bremen, S. 116f.). Es ist das Kuriosum zu verzeichnen, daB die Besatzungsverwaltung durch das siebenköpfige amerikanische Detachment in Vegesack schon begonnen hatte, bevor es dort zu Kapitulation und Besetzung gekommen war!

34 OMGBR: Functional History 27.4.1945 - 30.6.1946, I, S. 11 und 25; vgl. Scheper: Bremerhaven, S. 341 f. und Schwarzwälder: Das Ende an der Unterweser, S. $128 \mathrm{ff}$., die beide die amerikanische Militärregierung fälschlich am 9.5.1945 beginnen lassen. Das Wesermünder Hauptquartier zog am 19.6.1945 von der Pestalozzischule um ins Gebäude der ehemaligen Gauwirtschaftskammer am Hohenzollerning (OMGBR: Functional History 27.4.1945 30.6.1946, I, S. 13).

${ }^{35}$ Siehe OMGUS-Hb, Bremen A., Anm.154. Die britische Siegesparade in Wesermünde, die Schwarzwälder einmal richtig auf den 12.5. (Kampf um Bremen, S. 124), einmal falsch auf den 8.5. datiert (Das Ende an der Unterweser, S.130f.; danach auch Scheper, Bremerhaven, S.345), hat entgegen den Angaben von Schwarzwälder und Scheper mit der Übergabe der militärischen Verantwortung an die 29. Infanteriedivision nichts zu tun. Völlig falsch ist die Feststellung von Gulgowski (American Military Government, S.43), Bremen sei am 12.12.1945 eine amerikanische Enklave geworden.

36 Vgl. Röpcke: Dienstberichte, S. 294; am 31.5.1945 leitete Det. H4C2 Osterholz Major Joseph Reed, Det. I1 A9 (später I10C2) Landkreis Wesermünde, später stationiert in Loxstedt, Capt. James F. Flynn, Det. I2A9 (später I11C2) Brake Capt. Martin L. Krauss (6/105-1/4). Die Angabe in OMGBR: Functional History 27.4.1945 - 30.6.1946, I, S. 15, die Detachments hätten am 29.6.1945 ihre Tätigkeit aufgenommen, kann nur für Nordenham zutreffen; wahrscheinlich ist es das Datum der Umbenennung in $\mathrm{I1}_{1 \mathrm{C} 2}$ bzw. $112 \mathrm{C} 2$. 
zen konnte. Der Zuschnitt der Enklave warf administrative Probleme auf, denen vor Ort niemand so recht gewachsen war. Der Landkreis Wesermarsch links der Weser war Teil des Landes Oldenburg und in seinen Verwaltungsziugen dorthin orientiert. Stadt und Landkreis Wesermïnde sowie der Landkreis Osterholz-Scharmbeck rechts der Weser gehörten zum ehemals preuBischen Regierungsbezirk Stade der Provinz Hannover und waren in ihrer Verwaltungsstruktur entsprechend ausgelegt. Sollten die gewohnten Geleise befahren werden, mußten ungeheure Umwege in Kauf genommen werden, wenn z. B. eine vorgesetzte Behörde in Oldenburg mit einer nachgeordneten Stelle in Brake Dienstgeschäfte abzuwickeln hatte. ${ }^{37}$ Um die alten Verbindungen rigoros zu unterbrechen und neue, auf Bremen ausgerichtete herzustellen, fehlte es an politischer und administrativer Kraft und institutionellen Voraussetzungen. Für die meisten in Politik und Verwaltung Tätigen war es gelinde gesagt unangenehm, sich mit solchen Fragen alter und/oder neuer Zuständigkeiten immer wieder befassen zu müssen in einer Zeit, in der die Befriedigung der elementarsten Lebensbedürfnisse der Bevölkerung die Anspannung aller Kräfte erforderte. Eine USFET-Kommission, die Ende Juli 1945 die Wirtschaftsverwaltung der Enklave untersuchte, zog das Fazit: „All authorities and agencies interviewed, American, British, and German, were as one in the statement that the situation was fluid and obscure and that clear directives were needed from the top" ${ }^{38}$ Die Besatzungsoffiziere vor Ort waren in diesen Dingen überfordert. Anschaulich wird das in einem Gespräch zwischen Wirtschaftssenator Dr. Hermann Apelt und dem Fachreferenten bei der Militärregierung, Capt. Osborne M. Taylor, am 28. Juli 1945. Von deutscher Seite wurde der Vorschlag gemacht, dem Landeswirtschaftsamt die Verteilung der Güter zu übertragen: „Es sei dringend erwünscht, daß das Landeswirtschaftsamt für die gesamte Enklave für zuständig erklärt würde, um wenigstens innerhalb der Enklave einheitliche Verhältnisse zu schaffen. Hptm. Taylor erkundigte sich, in welcher Weise eine derartige Regelung formell geregelt werden músse. Ihm wurde erwidert, daß es dazu lediglich einer Anordnung der Militärregierung bedürfe. Hptm. Taylor erklärte, daß er sich mit diesem Plan schon länger befasse und daß er die Angelegenheit prüfen wolle". Später erklärte Taylor sich einverstanden und versprach, entsprechende Anordnungen schleunigst auf den Weg zu bringen. ${ }^{39}$ Die Unregierbarkeit der Enklave in der gegebenen Form zwang zu Überlegungen, ob die Verwaltungsstrukturen den neuen Herrschaftsverhältnissen oder die Herrschaftsverhältnisse den Verwaltungsstrukturen angepaßt werden sollten. Mit dem Abkommen vom 10. Dezember 1945, in dem die Landkreise Wesermarsch, Wesermünde und Osterholz-Scharmbeck der britischen Besatzungsverwaltung überlassen wurden, entschieden sich die Vereinigten Staaten für die zweite der beiden Möglichkeiten. Schwierigkeiten bereiteten aber nicht nur die Strukturen der deutschen Verwaltung in den unterschiedlichen Segmenten der Enklave - die ganze Ausgangslage der amerikanischen Detachments an der Unterweser war ungewöhnlich schwierig. Um ihr Aufgabenfeld zu beackern, mußten sie es erst gegenüber dem Hafenkommando, den Streitkräften und der Marine abstecken und dann auch noch die britischen Interessen berücksichtigen..$^{40}$ Übergeordnete Instanzen, die um Entscheidungshilfen hätten an-

37 Oldenburg hatte sich an die britische Militärbehörde zu wenden, die reichte den Vorgang an Det. E2C2 Bremen weiter, von dort ging er an das Braker Detachment, von dort an die deutsche Dienststelle in Brake; siehe Beispiel in OMGBR: Functional History 10.12.194531.1.1946, I, S. 9; auch Latour/Vogelsang: Okkupation und Wiederaufbau, S. 102.

${ }^{38}$ Economic Branch, G-5, USFET, 28.7.1945 (11/32-1).

${ }^{39}$ Gesprächsvermerk in StA Bremen 4,92-H.1.b.1.[5].

${ }^{40}$ Die geheime Planungsdirektive zur Besetzung der Enklave für die 15. Armee vom 7.3.1945 
gegangen werden können, saßen weit entfernt und wechselten mehrfach. „Probably no other Military Government Detachment ever had as many administrative difficulties due to the many shifts of command, which endlessly complicated problems, interrupted the flow of cummunications and likewise complicated the flow of personnel through all the various channels" - mit diesem Seufzer beginnt im ersten Jahresbericht der Bremer Militärregierung der Abschnitt über Organisation. ${ }^{41}$ Die weiten Wege zum Armeehauptquartier in Süddeutschland hatten zur Folge, daB Anordnungen oder Aufforderungen zum Bericht verspätet oder gar so spät eintrafen, daß sich die Angelegenheit schon erledigt hatte. ${ }^{42}$ Manche Verfügungen und Erlasse waren auf die Verhältnisse in der Enklave überhaupt nicht anwendbar, und das Gefühl setzte sich fest, man würde bei den Überlegungen und Planungen auf oberster Ebene manchmal regelrecht vergessen. ${ }^{43}$ Das war das eine. Das andere, in der täglichen Praxis noch gravierendere Problem waren die teils mehrfach gespaltenen Verantwortlichkeiten zwischen Bremen Port Command, U.S. Navy, und der Militärregierung sowie Reibereien mit den Einheiten der 29. Infanteriedivision. Der von auswärts angereiste Untersuchungsausschuß, der, aufgescheucht durch zwei Zeitungsartikel des Joumalisten Russell Hill in der Pariser Ausgabe der New York Herald Tribune, Ende Juli 1945 die Mitglieder der Bremer Militärregierung einer ausfuhrlichen Befragung unterzog, schloB seinen Untersuchungsbericht an den stellvertretenden amerikanischen Militärgouverneur Clay am 25. Juli 1945 mit der Empfehlung: „The political structure of Enclave Bremen requires a definite study of overlapping administrative responsibilities and the development of clear cut operating procedures".4 Bei der Befragung hatte sich z.B. herausgestellt, daB im Verkehrsbereich das Detachment E2C2 für den StraBenverkehr verantwortlich zeichnete, das Transportation Corps von Bremen Port Command für die Bahn und für die Binnenschifffahrt die Civil Operations Section von Bremen Port Command in Abstimmung mit der U.S. Navy. Eine amerikanische Instanz, die alle drei Teilbereiche Uberblickte, war in der Enklave nicht vorhanden. ${ }^{45}$ Unter Bezugnahme auf den Bericht wurde am 30. Juli 1945 die Einsetzung einer britischamerikanischen Kommission in die Wege geleitet, die Verbesserungsvorschläge für die Enklavenverwaltung erarbeiten sollte. ${ }^{46}$

Das Bremer Hafenkommando (Bremen Port Command), das den Hafenbetrieb gewährleisten und Nachschub und Versorgungseinrichtungen für die amerikanischen Truppen bereitstellen sollte, war von den zu erfullenden Aufgaben her fraglos eine notwendige und zweckmäßige Einrichtung. Es gelang den Spezialeinheiten, die von Kriegszerstörungen nicht so betroffenen Hafenanlagen in Bremerhaven in wenigen Wochen betriebsbereit zu machen, so daB bereits am 22 . Juni 1945 das erste amerikanische Frachtschiff dort festmachen konnte. ${ }^{47}$ Unglücklich aus der Sicht der Militär-

läBt die komplizierten Beziehungen und Abläufe bereits erkennen: die Operationspläne der betroffenen amerikanischen Land-, See- und Luftstreitkräfte sowie der technischen Einheiten muBten koordiniert werden, ihre Verantwortlichkeiten muBten abgegrenzt, das Verhältnis zu den Briten festgelegt werden (AG 1945-46/13A/5).

41 OMGBR: Functional History 27.4.1945 - 30.6.1946, I, S.13.

${ }^{42}$ Ebenda, S. 15.

43 OMGBR: Functional History 10.12.1945 - 31.1.1946, I, S.7f.

44 Special Report, Conclusions (StA Bremen 16,1/4; AG 1945-46/79/7).

${ }^{45}$ Ebenda, S. 31.

46 AG 1945-46/13A/5.

${ }^{47}$ History of Bremen Port Command, Bd. 2, Preface (StA Bremen 16,1/4); vgl. Peters: Zwölf Jahre Bremen, S. 16. Schwarzwälder: Das Ende an der Unterweser, S. 150 nennt fälschlich den 6. Juni. 
regierung war nur die Tatsache, daß der Befehlshaber des Hafenkommandos, Generalmajor Harry $\mathrm{B}$. Vaughan, ${ }^{48}$ selbständig und ranggleich neben dem militärischen $\mathrm{Be}$ fehlshaber der Enklave, Generalmajor Charles H. Gerhardt von der 29. Infanteriedivision, operieren konnte. Ein einheitliches Oberkommando für beide gab es nicht, da das Hafenkommando direkt in die Nachschuborganisation der Theater Service Forces eingebunden war, während die Division einen Teil der 9., dann der 7. Armee bildete. Hinzu kam noch die Marine mit der US Naval Advanced Base Weser River in Bremerhaven und Bremen. ${ }^{49}$ Da eine erreichbare Entscheidungsinstanz fehlte, bestand bei konkurrierenden Interessen, z. B. in der Nutzung von Materialien, Gebäuden oder Arbeitskräften, Einigungszwang. Die Militärregierung hatte dabei meist das Nachsehen, auch wenn sie sachlich überzeugend argumentierte, da dem Hafenbetrieb höchste Priorität zukam, und in zweiter Linie sich die Sicherheitsinteressen der taktischen Truppen durchzusetzen pflegten, wobei auch der Umstand eine Rolle spielte, daB an der Spitze der Militärregierung mit Oberstleutnant Welker ein rangniedrigerer Offizier stand. ${ }^{50}$ Das Hafenkommando hatte sein Hauptquartier im Haus des Reichs am Richtweg aufgeschlagen, wohin die Militärregierung erst nach Auflösung des Kommandos im Laufe des Jahres 1946 übersiedelte, und es sicherte sich im Juni 1945 den Bremer Ratskeller als Offizierskasino. ${ }^{51}$ Anfang August 1945 unterstanden Bremen Port Command 11000 Mann - der Militärregierung in der ganzen Enklave zum Vergleich ca. $370 .{ }^{52}$

Oberstleutnant Welker als Kommandeur des Bremer Detachments E2C2 sollte, so war es besprochen, auch die ubrigen Detachments der Enklave kommandieren. Er war zwar der militärischen Führung des Distrikts verantwortlich, d.h. Generalmajor Gerhardt von der 29. Infanteriedivision, die ihr Hauptquartier in der Grohner Kaserne hatte, aber die nachgeordneten Truppenführer der taktischen Einheiten waren der Militärregierung gegenüber nicht weisungsberechtigt, sondern hatten sie zu unterstützen. ${ }^{53}$ In der Praxis sah das öfters anders aus. ${ }^{54}$ In Vegesack, wo eine Abordnung des Bremer Detachments deutschen Soldaten die Waffen nicht abgenommen, sondern sie als Sicherheitskräfte zu Patrouillengängen eingesetzt hatte, kam es zu Zwischenfällen, die der erste Jahresbericht wie folgt schildert: „No trouble whatsoever was experienced until our troops came in. About two weeks later when our forces arrived, they wanted to start the war all over again; and some German soldiers were shot. The patrols had to be called in. “55 An anderer Stelle heißt es: „Wieder und wieder mußten

48 Vorher in England eingesetzt als Befehlshaber von den Vereinigten Staaten genutzter Häfen am Bristol Channel, sowie dann der amerikanischen Sektion von Mulberry Port, einem Behelfshafen in der Normandie; siehe Stars \& Stripes, 23.5.1945 (StA Bremen 7,58 Meyer).

49 Telefonverzeichnisse vom März 1946, die Aufbau und Umfang des Marinestützpunktes recht gut erkennen lassen (5/372-3/16).

so OMGBR: Functional History 10.12.1945 - 31.1.1946, I, S. 4 ff.; der Berichterstatter (ebenda, S.5) hebt nicht ohne Stolz hervor, daß alle Konflikte auf lokaler Ebene ausgetragen und schlieBlich bereinigt worden seien; vgl. dazu Gulgowski: American Military Government, S. 260.

51 History of Bremen Port Command, Bd. 2, S. 150 (StA Bremen 16,1/4); bis Dezember 1945 wurden knapp 73000 Essen für Offiziere im Ratskeller ausgegeben (Report of Operations, Bd. 1, S.11, ebenda).

52 History of Bremen Port Command, Bd. 2, Preface (StA Bremen 16,1/4); OMGBR: Functional History 26.4.1945 - 30.9.1945, II, Appendix 1.

53 OMGBR: Functional History 27.4.1945 - 30.6.1946, I, S. 14 und 16.

54 Vgl. OMGBR: Functional History 10.12.1945 - 31.1.1946, I, S. 6f.; OMGBR: Functional History 27.4.1945 - 30.6.1946, I, S. 486.

55 Ebenda, S.9. 
die Detachments feststellen, daß sie ihre Energie mehr darauf zu richten hatten, mit den Einheiten der kämpfenden Truppe ein einigermaßen brauchbares Verhältnis zu bewahren, als darauf, mit den Deutschen zu Rande zu kommen."56

Es ist kein Zufall, daß unmittelbar nach Abschluß der Überprüfung durch den Untersuchungsausschuß der Versuch gemacht wurde, durch eine Reorganisation die Arbeit der Militärregierung übersichtlicher und effektiver zu gestalten. Auf Anordnung des Kommandierenden Generals der 7. Armee wurde am 5. August 1945 eine zweistufige Verwaltung eingeführt, so da $B$ die lokalen Militärregierungseinheiten künftig unter einem für die gesamte Enklave zuständigen Detachment arbeiteten, dem Welker vorstand. Änderungen ergab das vor allem für Bremen, wo eine für die lokale Verwaltung verantwortliche Mannschaft vom regional zuständigen Detachment abgesondert werden mußte. Überzeugen konnte diese Lösung nicht, denn sie wurde bereits Mitte November wieder aufgegeben. ${ }^{77}$

Bei einer der wichtigsten Aufgaben der ersten Wochen, der Regierungsbildung, erhielt das Bremer Detachment maßgebliche Hilfe von außen durch den Sonderbeauftragten Walter Dorn, der Anfang Mai in Bremen eintraf und Gespräche mit potentiellen Regierungsmitgliedern führte, zu denen auch das legendenumwobene Treffen mit Wilhelm Kaisen auf der Siedlerstelle in Borgfeld zählt. ${ }^{58}$ Welker, seit dem 29. April 1945 für die Bremer Militärregierung voll verantwortlich, hatte am 30. April den zunächst zum Bürgermeister ernannten ehemaligen Polizeichef Johannes Schroers wieder aus dem Amt genommen ${ }^{59}$ und am 2.Mai - der britische Befehlshaber General Hakewell-Smith drängte auf eine Entscheidung ${ }^{60}$ - den deutschnationalen Politiker Erich Vagts als Regierenden Bürgermeister eingesetzt. ${ }^{61}$ Dorn war uber diese Wahl gar nicht glücklich und hielt Vagts wegen dessen politischer Vergangenheit für ungeeignet. ${ }^{62}$ Welker hielt jedoch an ihm fest und war offenbar nicht unzufrieden mit ihm. ${ }^{63}$ Er stattete ihn sogar mit außerordentlichen Vollmachten aus, die die Ermächtigung einschlossen, bestehende Gesetze zu mißachten, sofern nur die Anweisungen der Militärregierung stets befolgt würden. ${ }^{64}$ Auch gegenüber dem neuen Senat war Vagts' Stellung als Regierender Bürgermeister stärker, als dies bremischer Tradition entsprach, was manchem miBfiel. Der Senat hatte am 6. Juni sein Amt angetreten. Er setzte sich, abgesehen vom Regierungschef, aus drei burgerlichen und drei sozialdemokratischen Politikern zusammen; dazu kam mit Hermann Wolters ein Kommunist, gegen

${ }^{56}$ Zit. nach Latour/Vogelsang: Okkupation und Wiederaufbau, S. 79.

57 Ebenda, S. 16 und $51 \mathrm{f}$.

${ }^{58}$ Müller: Begegnungen mit Kaisen, S. 179 ff.; Kaisen: Meine Arbeit, S. 175 f. und 203.

59 Siehe OMGUS-Hb, Bremen A., Anm. 31.

60 OMGBR: Functional History 27.4.1945 - 30.6.1946, I, S. 6f. Die Hervorhebung des britischen Drängens in der Berichterstattung hat offensichtlich die Funktion, mildernde Umstände für Welkers Fehlentscheidung zu schaffen. Gulgowski: American Military Government, S. 231 ist dadurch zu dem irrigen Schluß verleitet worden, Hakewell-Smith habe Vagts eingesetzt.

${ }^{61}$ Erich Vagts (1896-1980) war deutschnationaler Abgeordneter der Bürgerschaft seit 1928, 1933 Senator und 1935-1945 bremischer Vertreter in Berlin. Er war Freimaurer und nicht Mitglied der NSDAP; vgl. Buchholz: Wiederaufbau in Bremen, S.16f. und Adamietz: Das erste Kapitel, S. $43 \mathrm{f}$.

62 Dorn: Inspektionsreisen, S. $41 \mathrm{f}$.

63 So Vagts' eigener Eindruck (StA Bremen 7,29-5), der von Spittas Tagebuch bestätigt wird; vgl. Wenzlau: Entstehungsgeschichte, S. 27.

${ }^{64}$ Schreiben Welkers vom 22.6.1945: „When the urgency of the situation requires the Reigning Lord Mayor is authorized and directed to disregard the provisions of Reich and Land laws and regulations and customary German procedure" (StA Bremen 3-S. 1.a.Nr.363). 
dessen Einbeziehung Vagts sich vergeblich gesträubt hatte und der ihm auch Scherereien machte: ${ }^{65}$ Wolters war Informant des Journalisten Russell Hill, dessen Artikel über die Bremer Senatsbildung und „Nazism Carries on in Bremen" 66 Staub aufwirbelten und zur bereits mehrfach genannten Untersuchung führten, ${ }^{67}$ in der die erhobenen Vorwürfe zwar entkräftet wurden, aber es fällt doch auf, daß die Entlassung von Vagts praktisch auf dem Fuße folgte. Welker konnte oder wollte ihn nun nicht mehr halten und ersetzte ihn am 1. August 1945 durch den Sozialdemokraten Wilhelm Kaisen, der Bremen dann zwanzig Jahre lang regiert hat.

\section{Amerikanische Besatzung nach britischen Richtlinien (1946)}

Gute Beziehungen zu den Briten gehörten von Anbeginn zu den Lebensbedingungen der Enklave an der Unterweser, denn die Versorgung der Hafenstädte mit Nahrungsmitteln und Rohstoffen war vom britisch kontrollierten Umland abhängig. Für die amerikanische Besatzungstruppe war die Notwendigkeit, ständig als Bittsteller auftreten zu müssen, natürlich nicht angenehm; ${ }^{68}$ aber das Problem war der Enklavensituation immanent und lieB sich nicht ändern. Bei anderen administrativen Schwierigkeiten der Militärregierung hingegen, die ihren Ursprung in der gespaltenen Befehlsgewalt und im Zuschnitt des Kontrollgebietes hatten, ${ }^{69}$ war Abhilfe möglich. Brigadegeneral Clarence L. Adcock von G-5, USFET, empfahl im August von mehreren denkbaren Möglichkeiten die Reduzierung der Enklave auf die Kontrolle der Hafenbereiche von Bremen und Bremerhaven. ${ }^{70}$ Im September 1945 tauchte eine von USFET und Kontrollrat gebildete Kommission in Brake auf, um sich vor Ort einen Eindruck von den Verwaltungsproblemen zu verschaffen. ${ }^{71}$ James K. Pollock, Leiter der Government Structure Branch der Militärregierung, verfaßte am 26. September 1945 ein Memorandum, in dem die Wiederherstellung der herkömmlichen deutschen Verwaltungsstrukturen als beste Lösung empfohlen wurde, verbunden mit einer Reduzierung der Enklave auf die Stadt Bremen und den Hafenbereich von Bremerhaven. Pollocks Studie wurde vom Deutschlandberater Robert D. Murphy dem amerikanischen Außenminister zugeleitet. ${ }^{72}$ Einen Mo-

65 StA Bremen 7,29-5; Buchholz: Wiederaufbau in Bremen, S. $19 \mathrm{ff}$.; Welker erklärte vor dem AusschuB, er habe auf Wolters bestanden, um ihn in die Verantwortung einzubinden, siehe Special Report, S.43 (StA Bremen 16,1/4).

${ }^{66}$ Texte der Artikel vom 8. und 14.6.1946 in StA Bremen 7,29-4 und 7.

${ }^{67}$ Special Report (StA Bremen 16,1/4). Vorsitzender des Untersuchungsausschusses war Brigadegeneral Luther S. Smith. Bei der Vernehmung von Lt.Col. Welker ergab sich folgender, für das Verhältnis von Theorie und Praxis der Besatzungsverwaltung sehr aufschluBreicher Tatbestand. Frage: „Have the JCS series of papers No. 1067 been brought to your attention?" Antwort: "I have been told that the directives based on the 1067 series are in our possession but I have not yet had opportunity to read them" (ebenda, S.44). Und das nach beinahe einem Vierteljahr an der Spitze der Militärregierung der Enklave. Zweck und Ergebnis der Untersuchung sind in der Bremer Militärregierung übrigens bis Jahresende nicht bekannt geworden; vgl. OMGBR: Functional History 10.12.1945-31.1.1946, I, S. 16.

68 OMGBR: Functional History 10.12.1945-31.1.1946, I, S.8f.

${ }^{69}$ Siehe OMGUS-Hb, Bremen A.2.

${ }^{70}$ Schreiben an den Chief of Staff, G-5, USFET, vom 11. und 27.8.1945 (11/32-1).

7 National Archives, Washington, RG 59740.00119 (Control Germany)/10-845; Murphys Schreiben gedruckt in Foreign Relations 1945 III, S. $976 \mathrm{f}$.

72 AG 1945-46/13A/5; AG 1945-46/73/3. 
nat später hatte ein neues britisch-amerikanisches Abkommen über die Militärregierung in der Bremer Enklave bereits Konturen angenommen. Der mit General G. W. R. Templer auf britischer Seite abgestimmte Entwurf war Gegenstand einer Besprechung zwischen Clay und Eisenhower am Rande der Kontrollratssitzung vom 30. Oktober 1945 in Berlin. Clay wurde autorisiert, das Abkommen in der vorgesehenen Form mit den Briten zu schließen, und zwar ohne daB es noch General Vaughan, dem Port Commander, der davon hauptsächlich betroffen war, zur Stellungnahme zugehen sollte. ${ }^{73}$

Erste Ergebnisse der britisch-amerikanischen Verhandlungen über die künftige Gestalt der Enklave gelangten im Oktober an die Presse. Die Bremer Militärregierung wurde an diesen Verhandlungen auf höherer Ebene nicht beteiligt. Als Wilhelm Kaisen am 22. Oktober 1945 den zuständigen Offizier nach dem Wahrheitsgehalt einer Zeitungsmeldung fragte, in der die Rückkehr des Landkreises Wesermarsch zum Land Oldenburg angekündigt wurde, konnte der Befragte nur versprechen, Erkundigungen einzuziehen. Am 26. Oktober trug er Kaisen inoffiziell die Ergebnisse der Vereinbarungen vor, doch aufgetretene Komplikationen, die keine rasche Lösung erwarten ließen, zögerten den Zeitpunkt des Inkrafttretens noch bis zum 10. Dezember 1945 hinaus. ${ }^{74}$

Kern der Vereinbarung zwischen den beiden stellvertretenden Militärgouverneuren Clay und Robertson war die Übergabe der Militärregierung in der Enklave mit Ausnahme von Bremen und Bremerhaven an die Briten. ${ }^{75}$ Die amerikanischen Detachments wurden abgezogen und durch britische ersetzt. In Brake waren bereits Mitte November wieder Briten erschienen in Erwartung der bevorstehenden Ablösung der Amerikaner. $^{76}$

Belange der militärischen Sicherheit waren weiterhin Sache der Amerikaner. Auch die Weserhafenbehörde blieb unter amerikanischer Kontrolle, ebenso - bis auf weiteres - der Schienenverkehr, Küsten- und Binnenschiffahrt und die Fischerei. Verbindungsoffiziere huben wie druben sollten die Kommunikation verbessern und die Versorgung der Hafenstädte mit Nahrungsmitteln, Rohstoffen und auch Arbeitskräften erleichtern.

Damit kehrte der Landkreis Wesermarsch wieder zum Land Oldenburg, die Kreise Osterholz-Scharmbeck und Wesermünde wieder zum Regierungsbezirk Stade zurück. Die gewohnten Verwaltungszusammenhänge waren wieder hergestellt. Die Stadt Wesermünde bildete einen Sonderfall. Während man bei der Bremer Militärregierung nach dem Wortlaut der Vereinbarung davon ausging, daß die Briten Wesermünde übernehmen wiirden, ${ }^{n}$ setzte sich der Befehlshaber von Bremen Port Command, Generalmajor Vaughan, im Interesse des Hafenbetriebs und der Versorgungseinrichtungen dafür ein, die Stadt Wesermünde unter amerikanischer Kontrolle zu belassen. Wie sich herausstellte, war das durchaus im Sinne der Vertragspartner. ${ }^{78}$ Der PferdefuB der

${ }^{73}$ OMGBR: Functional History 10.12.1945 - 31.1.1946, I, S. 12.

${ }^{74}$ Protokolle der Besprechungen zwischen Captain Bard und Wilhelm Kaisen (StA Bremen 3-R.1.m. Nr. 390); am 6.11. werden Kapazitätsprobleme beim Abtransport der 29. Infanteriedivision erwähnt und Meinungsverschiedenheiten zwischen Militärregierung und Hafenkommando angedeutet.

75 Siehe OMGUS-Hb, Bremen A., Anm. 21.

${ }^{76}$ Gespräch am 15.11.1945 (StA Bremen 3-R.1.m. Nr.390).

${ }^{77}$ So trug Bard es Kaisen am 26.10.1945 vor (ebenda), so lautet es in einer Presseerklärung der Militärregierung im Weser-Kurier am 1.12.1945, und so erläutert auch die laufende Functional History das Abkommen (OMGBR: Functional History 1.10.1945 - 10.12.1945, I, S.2).

${ }^{78}$ Ebenda, S. $2 f$. 
Vereinbarung steckte in der Klausel, daB die amerikanische Militärregierung in Bremen und Bremerhaven mit dem Vorbehalt gewisser Ausnahmeregelungen nach den Richtlinien britischer Besatzungspolitik, nach britischen Instruktionen zu verfahren habe. ${ }^{79}$ Diese Formulierung präzisierte die vage Vereinbarung von Jalta, nach der lediglich Konformität mit der britischen Besatzungspolitik im allgemeinen gefordert war, was praktisch keine Konsequenzen gehabt hatte. Rückschauend bleibt nur Verwunderung darüber, daß eine solche Regelung für praktikabel gehalten wurde. Wer vorsätzlich unter den amerikanischen Besatzungstruppen hätte Verwirrung stiften und Mißtrauen und Zwietracht unter den Alliierten säen wollen, hätte kaum geschickter vorgehen können. Der Schlußparagraph, der von künftigen Revisionen des Abkommens im Lichte der dann vorliegenden Erfahrungen spricht, deutet allerdings an, da $\beta$ man sich bewuBt war, keine dauerhafte Lösung gefunden zu haben. Tatsächlich setzten Verhandlungen zur Ergänzung und Nachbesserung des Abkommens sofort ein, und die bald reifende Erkenntnis, daB Besatzungsverwaltung nach diesem Grundmuster nicht sinnvoll zu realisieren war, zwang dazu, die Statusfrage der Enklave einer grundsätzlichen Klärung zuzuführen.

Neben den zwangsläufig engen Kontakten zu den Briten gab es bei der Bremer Militärregierung auch Verbindungsoffiziere anderer Nationen. Das Telefonverzeichnis vom 1.März 1946 registriert einen Holländer, zwei Franzosen und einen Polen, die vermutlich mit der Rückführung im Kriege verschleppter Personen bzw. mit Reparationen und Demontage befaßt waren.

Mit Wirkung vom 10. Dezember 1945 war aus den Komplikationen der ersten Monate von amerikanischer Seite eine weitere Konsequenz gezogen worden, indem die vorher getrennten Befehlsstränge beim Hafenkommando zusammengefaßt wurden. Bereits zum 1. Dezember hatte Generalmajor Vaughan die Verantwortung für die militärische Sicherheit in der Enklave von der 29. Infanteriedivision übernommen, die abgezogen wurde. ${ }^{80}$ Das in Grohn verbleibende 29. Infanterieregiment vertrat in Bremen zukunftig die Streitkräfte. ${ }^{81}$ Zum 10 . Dezember wurde dann auch die Militärregierung dem Hafenkommando unterstellt. Nachteil dieser Lösung war, daß die Spezialeinheiten vom Port Command mit Besatzungspolitik und Militärregierung sonst überhaupt nicht befaßt waren. So mußte zunächst aus erfahrenen Leuten der Militärregierung ein Stab gebildet werden, dem die Detachments in Bremen und Wesermünde unterstellt wurden, was sich bis in den Januar 1946 hinzog. ${ }^{82}$ Im Zusammenhang mit der Auflösung des Bremer Hafenkommandos entstand am 15. April 1946 schließlich eine Militärregierungsbehörde, die der Berliner OMGUS-Zentrale unmittelbar verantwortlich war, aber weiterhin britische Besatzungspolitik umzusetzen hatte: das Office

79 Paragraph 4 Absatz (b) „The United States Military Government teams at Bremen and Bremerhaven, as well as the British Military Government teams to be stationed in the Enclave, will follow the policy instructions issued by the British Government authorities, subject to the condition that if the team receives instructions from the British which interfere with the carrying out of the effective operation of the Bremen Port, or interfere with area security, all Military Government teams may, and upon the request of the US-Sub-District Commander, will suspend action on such instructions but will promptly notify the British authority which issued the instruction and Commanding General, United States Forces, European Theater." (OMGBR: Functional History 27.4.1945-30.6.1946, II, Appendix 6a; OMGBR: Functional History 1.10.1945 - 10.12.1945, II, Appendix 6, bzw. OMGBR: Functional History 10.12. 1945 - 31.1.1946, II, Appendix 1.)

80 Report of Operations 1945 Oct - Dec (StA Bremen 16,1/4).

81 OMGBR: Functional History 27.4.1945 - 30.6.1946, I, S. $486 \mathrm{f}$.

${ }^{82}$ Ebenda, S. 18; siehe OMGUS-Hb, Bremen A.5.a. 
of Military Government for Bremen Enclave (US) unter Führung von Oberst Welker. ${ }^{83}$ Mit der Übernahme der Hafenaufsicht in Bremen sowie einiger Funktionen der Marine in den Bereichen Werften und Schiffahrt durch die Militärregierung ${ }^{84}$ hatten die Amerikaner hinsichtlich der Zusammenfassung der Verantwortlichkeiten ihrer Besatzungsverwaltung im Vergleich zum Vorjahr viel erreicht.

Für die Enklave begann das Jahr 1946 mit einem Eklat. Der Gebietsrat in Hannover setzte ein mit den Amerikanern vereinbartes Gespräch über die Zukunft der in Bremen ansässigen Reichsmittelbehörden kurzerhand ab und teilte stattdessen die Entschlüsse mit, zu denen man aus technischen und politischen Gründen bereits gekommen sei. Sie betrafen zunächst Rolle und Zuständigkeit des Landesarbeitsamtes, Landesernährungsamtes und Landeswirtschaftsamtes sowie des Oberfinanzpräsidenten in Bremen. Tendenz war einerseits die Beschränkung der Zuständigkeit auf das Gebiet der amerikanischen Restenklave, andererseits die Unterwerfung unter hannoversche Oberaufsicht. ${ }^{85}$ In Bremen herrschten auf amerikanischer wie deutscher Seite Verwirrung, Aufregung und Empörung über Stil und Inhalt der Anweisung. Kaisen ging mit einem Zeitungsartikel gegen die Gefahren des Zentralismus an die Öffentlichkeit und schrieb am 10. Januar 1946 einen persönlichen Brief an Hinrich Wilhelm Kopf, der in seiner Anschaulichkeit hier auszugsweise mitgeteilt werden soll:

„Seit mehreren Tagen beginnt mein Tagewerk damit, daB irgendeine Verwaltungsstelle bei mir erscheint und irgendeine Aufforderung einer Verwaltungsstelle von Hannover vorlegt, der sie Folge geben soll. Gestern morgen begann es damit, daß mir der Leiter der Kriminalpolizei Bremen eine Anweisung der Kriminalpolizeizentrale Region Hannover vorlegt, wonach Bremen sofort 4 Beamte zu einem Lehrgang nach Hannover schicken solle. Eben ist dieser Herr aus der Tür, kommt eine andere Meldung von derselben Stelle an den Chef der Polizei, daß der Leiter der Kriminalpolizei sich sofort nach Stade begeben soll. Inzwischen weckt der Präsident des Landesgesundheitsamtes Bremen an mit der Frage, was denn jetzt los sei. Die Ärztekammer Hannover wünsche plötzlich zu wissen, wie die Eingliederung der bremischen Ärztekammer in die der hannoverschen vor sich gehen solle. Außerdem wünsche die I.G. Farbenindustrie plötzlich zu wissen, ob sie nach wie vor das dringend nötige Insulin direkt an Bremen schicken solle oder ob sie einem Ersuchen Bielefelds stattzugeben hätte, das sich plötzlich in der Verteilung von Insulin für die englische Zone auch für Bremen eingeschaltet habe. Eben ist das erledigt, ruft der Oberfinanzpräsident an und teilt mir mit, daß der Oberpräsident von Hannover plötzlich verlange, Rechenschaft darüber abzulegen, warum er kein Geld nach Hannover schicke. Nachdem wir uns von unserem Heiterkeitsausbruch erholt hatten, telefoniert die bremische Eisenbahndirektion an, ob wir nun englisch oder amerikanisch seien. Sie hätte da unverständliche Anweisungen aus Hannover und möchte von mir wissen, was denn los sei. Eben ist diese Sache abgetan, weckt der Vorsitzer des Arbeitsamtes von Brake an, ob ich nicht wuBte, ob er noch zum Landesarbeitsamt Bremen oder Oldenburg gehöre. Er hätte jetzt von allen Seiten Anweisungen vor sich liegen und wüßte nicht, welchen Herren er dienen soll. Vom Wirtschaftsamt Wesermünde wird angefragt, ob Anweisungen des Landeswirtschaftsamts Bremen noch Verbindlichkeit hätten oder was da eigentlich los sei. Kurzum, das ist so ein Ausschnitt von dem, was mir hier am Tag über den Weg läuft.

Meine Militärregierung hat Anweisung gegeben, nur das zu befolgen, was von ihr angeordnet wird. Aber immerhin ist dieser Zustand so unbefriedigend, er stört erheblich

83 OMGBR: Functional History 27.4.1945 - 30.6.1946, I, S. 19 f.

84 Siehe OMGUS-Hb, Bremen B.7; vgl. StA Bremen 4,116-24.

${ }^{85}$ OMGBR: Functional History 10.12.1945 - 31.1.1946, II, Appendix 3. 
die Verwaltungsarbeit, vergiftet unnötigerweise die Atmosphäre zwischen Bremen und Hannover und bringt die einzelnen Verwaltungsstellen in Konflikte, weil die Fragen der Zuständigkeiten nicht geklärt sind. [. . .] Ich kann unmöglich sowohl von der amerikanischen als auch von der englischen Militärregierung sowie von der Provinzregion in Hannover Anweisungen entgegennehmen und mir gleichzeitig noch gefallen lassen, daB die Sachbearbeiter des Oberpräsidenten auf eigene Faust in meine Verwaltung andauernd hineinfunken.“86

Die amerikanische Militärregierung, an sich gehalten, britischen Instruktionen Folge zu leisten, schrieb am 22. Januar 1946 nach Hannover, sie habe die deutschen Behörden angewiesen, die Direktive vom 2. Januar nicht zu befolgen, da zu diesem Thema keine britisch-amerikanische Vereinbarung vorliege. ${ }^{87}$ Ein am 1 . Februar von den Generälen Vaughan und Templer unterzeichnetes KompromiBpapier, gefolgt von einer Reihe von Sondervereinbarungen, ${ }^{88}$ schaffte zwar erst einmal Luft, doch bestanden bei den amerikanischen Fachoffizieren Bedenken gegen verschiedene britische Vorschriften fort. Um die Ablehnung jeweils formal einwandfrei zu begründen, mußte die Beeinträchtigung des Hafenbetriebs und/oder die Gefährdung der Sicherheit strapaziert werden. ${ }^{89}$ Im Jahresbericht erklärte der für das Gesundheitswesen zuständige Offizier, er habe bei der Bekämpfung von Geschlechtskrankheiten an den amerikanischen Direktiven festgehalten, da Penizillin nur aus amerikanischen Quellen erhältlich gewesen sei, ${ }^{90}$ um sich bei anderer Gelegenheit für die alleinige Anwendung amerikanischer Standards einzusetzen, da sie amerikanischen wie deutschen Interessen am besten diene, und die Gültigkeit sowohl britischer als auch amerikanischer Direktiven keine effektive Arbeit ermögliche. ${ }^{91}$ Ähnliches war von der Special Branch zu hören. In den Entnazifizierungsverfahren waren die amerikanischen Maßstäbe strenger als die britischen. Man konnte es doch nicht zulassen, daB etwa die zahlreichen deutschen Mitarbeiter der Militärregierung nach anderen als den eigenen Standards beurteilt wurden. Diese waren aus Sicherheitsgrunden auch für Arbeiter im Bereich militärischer Einrichtungen anzuwenden usw. ${ }^{92}$ Die Fiscal Branch beunruhigte im Januar 1946 die Anweisung, die vom Bremer Oberfinanzpräsidenten eingezogenen Reichssteuern, die Rundfunkgebühren und das bei der Reichsbankhauptstelle Bremen eingefrorene Vermögen der Nationalsozialistischen Volkswohlfahrt nach Hannover zu überweisen. Zur Deckung der Besatzungskosten sollten dann monatlich Anträge auf Mittelzuweisung in Hannover gestellt werden. Die sofort dem Chef der Bremer Militärregierung vorgetragenen Einwände des Fiscal Officer Major Bechtel lassen deutlich Unmut darüber erkennen, daB „someone in Hannover" darüber entscheiden solle, welches Geld in Bremen wozu gebraucht würde. ${ }^{93}$ Wie bockbeinig man sich in

${ }^{86}$ StA Bremen 3-B.10.a.Nr.3, Abdruck in Müller: Wider die hannoverschen Schrullen, S. $168 \mathrm{ff}$.; vgl. auch OMGBR: Functional History 27.4.1945 - 30.6.1946, I, S. 431: „It became apparent that confusion existed as a result of the agreement transferring the Enclave to British Control".

87 OMGBR: Functional History 10.12.1945-31.1.1946, II, Appendix 4.

${ }^{88}$ Ebenda, Appendix 5 .

${ }^{89}$ Beispiele ebenda, Appendix 4; desgl. bei der Ablehnung parteipolitisch ausgerichteter Jugendorganisationen später im Jahr (6/54-1/36).

90 OMGBR: Functional History 27.4.1945 - 30.6.1946, I, S.131.

$916 / 42-3 / 7$.

92 OMGBR: Functional History 10.12.1945 - 31.1.1946, II, Appendix 4, Denazification.

${ }^{93}$ Schreiben vom 23.1.1946 (ebenda), u. a.: „If the British are willing to agree that they will pay all expenses of the port operation, meeting promptly without question all demands for funds from Bremen Port Command, then they are more than welcome to the funds collected here. 
dieser Sache stellte, geht daraus hervor, daß Anfang Mai General Robertson Gelegenheit nahm, deswegen bei Clay vorstellig zu werden. Dieser antwortete am 25. Mai, daB natürlich die Schwierigkeiten der Militärregierung in Bremen offenkundig seien, er aber nunmehr als Interimslösung anordnen wolle, versuchsweise die bislang zurückgehaltenen Gelder nach Hannover zu überweisen und von dort bei Bedarf wieder anzufordern. ${ }^{94}$ Die entsprechende Direktive erging gegen Widerstand aus der Finanzabteilung am 16. Juli, wurde jedoch schlicht nicht befolgt, so daB noch im September alles beim Alten war. ${ }^{95}$ Unbehagen über die Bremer Verhältnisse spricht aus einem Vermerk Clays für Parkman vom 16. Juni 1946, in dem er deutlich macht, daß er die Amerikaner nicht in einer Lage sehen möchte, in der sie den Ruin von Bremens Rang und Ansehen zu verantworten hätten, und seine Bitte um Sondierungsgespräche bei den Briten schließt mit der Bemerkung: „Maybe we need another ,Boston Tea Party “. .0

Hatte Bremen bei dem Streit um die Kompetenzen der Reichsmittelbehörden zuruckstecken müssen, so war im Windschatten dieser Auseinandersetzung ein erster Schritt zur administrativen Angliederung Wesermündes vollzogen worden. Mit Wirkung vom 15. März 1946 gehörte das Amtsgericht Wesermünde wie Bremen in den Bezirk des Hanseatischen Oberlandesgerichts in Hamburg." Proteste aus Celle fruchteten nichts.

„British policy continued to be applied in the Bremen area until the beginning of 1947 , but actually it was more or less suspended during the period of uncertainty preceding the creation of the new Land Bremen“, konstatiert der zweite Jahresbericht vieldeutig. ${ }^{98}$ Verwirrung am Anfang, Meinungsverschiedenheiten und Ausnahmeregelungen, Aussetzung des Vollzugs am Ende - die Frage drängt sich auf, welche Auswirkungen die Verwaltung nach britischen Richtlinien in der Bremer Enklave uberhaupt hatte. Eine Antwort fällt nicht leicht. Erhebliche Komplikationen gab es, wie angedeutet, in der Finanzverwaltung und bei der Abrechnung der Besatzungskosten. Das ohnehin problematische Entnazifizierungsverfahren wurde durch Unsicherheit in der Bewertung und wechselnde Standards zusätzlich belastet. ${ }^{99}$ SchlieBlich fielen als Folge des

Otherwise it is obvious that to conduct an effecient port operation adequate funds must be available, without the necessity of persuading someone in Hannover or any other place that money should be provided for that expense“.

94 OMGBR: Functional History 27.4.1945 - 30.6.1946, II, Appendix 61.

95 Gailey, Chief of Staff, gesteht am 22.9. ein, daß er eine Überprifung des Vollzugs unterlassen habe, weil ihm die Möglichkeit, daB eine Direktive einfach nicht befolgt würde, nicht in den Sinn gekommen sei (AG 1945-46/67/5 und FIN 6/3, siehe auch AG 1945-46/46/8, Memo von Chatters vom 13.6.1946).

96 AG 1945-46/13A/5.

97 Wenzlau: Wiederaufbau der Justiz, S. $185 \mathrm{f}$.

98 OMGBR: Functional History 1.7.1946 - 30.6.1947, I, S.4. Dazu passen zwei Äußerungen aus der Bremer Intelligence Branch. Am 15.11.1946 wurde der bestehende Zustand als ,arbitrary mixture of U.S. and British regulations" beschrieben und die sich abzeichnende Klärung begrüBt. Am 25.1.1947 erklärte Metal auf telefonische Anfrage, daB die Militärregierung in der Enklave zwar theoretisch habe nach britischen Richtlinien arbeiten sollen, in der Praxis jedoch - mit britischer Billigung - im wesentlichen amerikanischer Besatzungspolitik gefolgt sei. Deshalb gebe es jetzt nach der Eingliederung in die amerikanische Zone de facto keine Änderung in der praktischen Politik (5/243-1/24).

99 Z. B. war eine Gruppe von politisch belasteten Bürgern nach britischen Richtlinien bei der Bürgerschaftswahl 1946 wahlberechtigt, die ein Jahr später nach amerikanischen Standards nicht mit abstimmen durften. - DaB die Praxis der Verordnungslage nicht entsprechen mußte, zeigt das Beispiel der Post. Der 1945 eingesetzte britische Verbindungsoffizier Major Hines, an sich nur für den Sprengel der Oberpostdirektion auBerhalb der Enklave zuständig, war 
Richtlinienwechsels die für das Frühjahr 1946 in Aussicht gestellten Wahlen aus. Die Briten zogen zunächst eine ernannte Volksvertretung vor, ${ }^{100}$ die am 17. April zu ihrer ersten Sitzung zusammentrat. Wahlen, bei denen britische Grundsätze des Mehrheitswahlrechts zum Tragen kamen, fanden erst im Oktober 1946 statt. ${ }^{101}$

Im Sommer 1946 trat die Diskussion um die Neugliederung der britischen Zone und damit auch um die künftige staatliche Existenz Bremens in ein entscheidendes Stadium. Harold H. Crabill, Leiter der Bremer Civil Government Division, erfuhr am 19. Juni auf einer Konferenz in Hannover, daB die britische Planung ein Vier-LänderModell favorisierte, in dem Bremen Teil Niedersachsens war. Er verfaßte daraufhin ein umfangreiches Memorandum, das die Empfehlung enthielt, die Bremer Enklave - eventuell mit erweitertem Territorium - als Land zu etablieren und in die amerikanische Zone einzubeziehen. Die Vereinigten Staaten als anerkannte Vorkämpfer von Freiheit und Unabhängigkeit - so ein tragendes Argument - würden bei den Deutschen schlecht aussehen, wenn die traditionellen bremischen Freiheiten unter ihrer Mitverantwortung verloren gingen. ${ }^{102}$ In dieselbe Kerbe schlug Erwin Bard, der die Bremer Situation aus eigener Erfahrung bestens kannte, in einem Memorandum für Henry Parkman, den Direktor der Civil Administration Division, OMGUS, ${ }^{103}$ und der Bremer Direktor Welker äußerte sich Parkman gegenüber ganz entschieden in demselben Sinne: Den Briten dürfe die Kontrolle nicht überlassen werden, da diese bevorzugt Hamburg förderten. ${ }^{104}$ Ein Gutachten der Rechtsabteilung der Bremer Militärregierung vom 1.Juli empfahı hingegen Zurückhaltung in der Statusfrage und hielt den gegebenen Zustand bei möglichen Verbesserungen im Detail für akzeptabel. ${ }^{105}$

Kaisen hatte auf der Eröffnungssitzung der Bürgerschaft Bremens Stellung als „sehr eigenartig" charakterisiert. Es sei im Gebietsrat der Region Hannover vertreten, im Gebietsrat der britischen Zone und im Hamburger Zonenbeirat, aber auch im Stuttgarter Länderrat der amerikanischen Zone. ${ }^{106}$ Eine Mitteilung des Senats vom 9. Juli 1946 , die mit den trotzigen Worten beginnt „1. Bremen ist nach wie vor ein deutsches Land“, versuchte, die Frage der Zugehörigkeit zu und der Zuständigkeit von zonalen Gremien und Behörden gegliedert darzulegen und traf dabei die interessante Feststellung, daB die amerikanische Militärregierung in Bremen bei der Durchführung ihrer

selbst engagierter Postler. Die zuständigen amerikanischen Fachoffiziere überließen ihm daher das Feld und mischten sich kaum ein. Für Hines lag die Priorität klar bei einem funktionierenden Postbetrieb; die Entnazifizierung wurde zurückgestellt und später in groBzügiger Manier in Zusammenarbeit mit der betroffenen deutschen Behörde gehandhabt. Verstärkte Einflußnahme der amerikanischen Entnazifizierungsabteilung wurde ab Februar 1946 spürbar, nach personellen Veränderungen (Ausscheiden von Hines) hörte im Laufe des Jahres die britische Mitwirkung bei der Entnazifizierung auf. Vgl. StA Bremen 5,1/2: Wiederaufbau des Post- und Fernmeldewesens nach dem Kriege, H. 2, Bericht des Postrates Michaelis vom 7.1.1949, S. 14-29.

100 OMGBR: Functional History 27.4.1945 - 30.6.1946, I, S.68f.

101 Peters: Zwölf Jahre Bremen, S. 53 und 65.

102 6/90-1/3, auch 6/54-1/32; Übersetzung in StA Bremen 3-B.10.a.Nr.2(1) II.

${ }^{103}$ Memo vom 19.8.1946 (17/256-2/10).

104 AG 1945-46/46/8.

105 6/95-2/35. Robert W. Johnson von der Bremer Rechtsabteilung führte am 17.12.1946 gegenüber der Zentrale aus, der Mißerfolg der britisch-amerikanischen Enklavenverwaltung habe nicht am System gelegen, sondern an der Unfähigkeit beider Seiten, damit richtig umzugehen - eine sehr theoretische Sichtweise (3/162-3/15).

106 Zuversicht und Beständigkeit, S.140f. 
Aufgaben teils nach amerikanischen, teils nach britischen Gesetzen, Richtlinien und Verwaltungsgrundsätzen verfahre und deshalb „Bremen sowohl in der britischen, als auch in der amerikanischen Zone zuständig" sei. ${ }^{107}$ Nach der Bildung des Landes Nordrhein-Westfalen am 18. Juli sah Kaisen den Zeitpunkt für gekommen, in der Neuordnungsdiskussion eindeutig Stellung zu beziehen. In einem Schriftsatz an die amerikanische Militärregierung in Bremen legte er am 25. Juli dar, da $B$ es zwingend geboten sei, eine Entscheidung für die eine oder die andere Besatzungsmacht zu treffen. Der gegenwärtige amerikanisch-britische Dualismus könne auch bei bestem Willen aller Beteiligten nicht aufgehoben werden, und man könne, wie er es bildlich ausdrückte, nicht gleichzeitig gehen und laufen. Aus der Sicht des Senats stelle die Wiedereingliederung in das amerikanische Besatzungsgebiet die einzige erfolgversprechende Möglichkeit dar. ${ }^{108}$ Die Allianz bremischer und amerikanischer Interessen blieb nicht ohne Wirkung. Henry Parkman, Leiter der Civil Administration Division, OMGUS, erhielt von Clay den Auftrag, sich über die Enklave Gedanken zu machen. Im August 1946 arbeitete er an einer Studie, deren Tendenzen sich abzeichneten, ${ }^{109}$ im September lag das Ergebnis vor: er war zu der Überzeugung gekommen, daß die Übernahme der gesamten Verantwortung in Bremen und Bremerhaven den unmittelbaren und langfristigen Interessen der USA am meisten diene, ${ }^{110}$ und drang mit seiner Auffassung bei Clay durch, obwohl Chief of Staff Charles K. Gailey dazu riet, aus Kostengründen den Briten die Enklave zu uberlassen und sich auf den reinen Hafenbetrieb zu beschränken. ${ }^{11}$ Bei einer Ansprache aus AnlaB der Bremer Interzonenkonferenz verkündete der Direktor der Bremer Militärregierung am 4. Oktober 1946, daß Bremen als reichsunmittelbare Hansestadt erhalten bleiben werde. ${ }^{112}$ Der Oldenburger Theodor Tantzen, eben von einem Gespräch mit Robertson aus Berlin kommend, war mit seinem gleichgelagerten Anliegen auf ein bevorstehendes Treffen mit Außenminister Bevin verwiesen und beschieden worden, daB voraussichtlich bald die Entscheidung falle. ${ }^{113}$ Ende Oktober war es so weit. Es gab die Umrisse einer britisch-amerikanischen Vereinbarung über die Zukunft der Enklave, und bei der Grünung des Landes Niedersachsen am 1.November 1946 gehörte Bremen nicht dazu.

\section{Die Bremer Enklave wird Teil der amerikanischen Zone (1947)}

Den Auftrag, einen Lösungsvorschlag für die Probleme der Bremer Enklave zu erarbeiten, hatten Austen Albu (Deputy President, Governmental Sub-Commission, Control Council Germany, British Element) und Henry Parkman, der schon mehrfach ge-

${ }^{107}$ StA Bremen 3-B. 10.a. Nr.2 (1) I; dies ist ein weiterer unverdächtiger Beleg dafür, daß entgegen dem Abkommen vom 10.12.1945 in erheblichem Umfang nach amerikanischen Direktiven gehandelt wurde.

108 Zuversicht und Beständigkeit, S. $145 \mathrm{ff}$.

109 POLAD 748/30.

110 Stelllungnahme vom 18.9.1946 (AG 1945-46/46/8).

111 Memo vom 22.9.1946 (AG 1945-46/67/5). Auch noch nach dem Albu/Parkman-Agreement vom 29.10.1946 wurden bei OMGUS parallel zu den laufenden Vertragsverhandlungen Modelle entwickelt, die im Kern die Aufgabe der Enklavenverwaltung durch die USA vorsahen, so z. B. Alternativplan von William Whipple, Secretary General, 9.12.1946 (AG 194546/13A/5).

112 Zuversicht und Beständigkeit, S. 150, falsch datiert auf den 3.10.1946; ebenso auch Peters: Zwölf Jahre Bremen, S. 65.

113 Akten zur Vorgeschichte der Bundesrepublik 1, S.884. 
nannte Direktor der Civil Administration Division, OMGUS, erhalten. ${ }^{114}$ Sie hörten sich die Meinung der Betroffenen vor Ort an, Parkman sprach auch mehrfach mit Kaisen. ${ }^{115}$ Am 29. Oktober 1946 waren gemeinsame Empfehlungen für Clay und Robertson fertiggestellt, die am kommenden Tag gebilligt wurden, verbunden mit dem Auftrag, sie in ein Abkommen umzusetzen. ${ }^{16}$ Das Memorandum geht davon aus, daB die ursprüglichen Grenzen der Enklave keine besondere Bedeutung mehr hätten, daß amerikanische Kontrolle der Unterweserhäfen wegen ihrer Bedeutung für die ganze amerikanische Besatzungszone weiterhin winschenswert sei und mit den bizonalen Einrichtungen für den wirtschaftlichen Bereich wesentliche Gründe für eine britische Militärregierung entfielen. Hinsichtlich der Beziehung zur Region Hannover müsse der Tatsache Rechnung getragen werden, da $B$ die britische Militärregierung Bremen provisorisch als Stadtstaat mit unabhängiger Regierungsgewalt wiederhergestellt habe - offenbar eine Bezugnahme auf die britische Direktive vom 5. Dezember 1945 anläßlich der Übernahme der Militärregierung in der Enklave. ${ }^{117}$ Empfohlen wird deshalb ein Land Bremen, das aus Bremen und der Stadt Wesermünde besteht und von Amerikanern nach amerikanischen Richtlinien verwaltet wird. Es sollte im Hamburger Zonenbeirat direkt vertreten sein, im Stuttgarter Länderrat informell, in bizonalen Gremien so wie Hamburg. Die Frage der Besatzungskosten wird zunächst ausgeklammert, von der Ausdehnung der US-Hoheit auf die anderen Weserhäfen wegen der Verwaltungsprobleme abgeraten.

Der Bremer Senat wurde am 5. November 1946 vom Inhalt des Memorandums durch den Direktor der Bremer Militärregierung mündlich in Kenntnis gesetzt, ${ }^{118}$ doch der Vollzug ließ auf sich warten, so daB schließlich Kaisen am 8. Januar 1947 in Stuttgart noch einmal Clay auf die Angelegenheit ansprach. ${ }^{119}$ Clay versicherte, daß Bremen Land der amerikanischen Zone und vollberechtigtes Mitglied des Länderrates sein werde, und mit einer entsprechenden Proklamation in wenigen Tagen zu rechnen sei. Sie erfolgte als Proklamation Nr. 3 am 22. Januar 1947 unter dem Datum des Vortages, unterzeichnet von General Joseph T. McNarney, Militärgouverneur in Deutschland und Oberbefehlshaber der US-Truppen in Europa. Unter Bezugnahme auf eine Vereinbarung der Militärregierung der Vereinigten Staaten und der Militärregierung GroBbritanniens wurden Stadt und Landgebiet von Bremen, Bremerhaven und der Stadtkreis Wesermünde als Staat im amerikanischen Kontrollgebiet proklamiert und die gegenwärtige Stadtregierung von Bremen als vorläufige Staatsregierung einge-

114 Das Entstehen des Abkommens ist in Parkmans Akten gut dokumentiert, siehe besonders $3 / 157-1 / 13$ und $3 / 162-3 / 15$.

115 StA Bremen 3-B.10.a.Nr.2 (1) II, S. 106, 124, 186f.; Albu wollte erst nach Fertigstellung des Gutachtens mit Kaisen sprechen (ebenda, S. 108).

116 6/90-1/3, auch StA Bremen 3-B.10.a.Nr.2 (1) II, S. 186 ff.; keineswegs wurde das fertige Abkommen am 30.10.1946 von Clay und Robertson unterzeichnet, wie es in Zuversicht und Beständigkeit, S.151 heißt - das geschah erst am 22.1.1947. Parkman selbst hat in einem Schreiben am 27.12.1946 noch einmal daran erinnert, daB die Empfehlungen nicht als Abkommen aufzufassen und zu behandeln seien, sondern daB sie den Ausgangspunkt für das zu erarbeitende Abkommen bildeten (3/157-1/13).

117 Directive on Assumption of Military Government Responsibility in the Bremen Enclave von Robertson an das Hauptquartier des 30. Corps (OMGBR: Functional History 10.12.194531.1.1946, II, Appendix 4). Entscheidend ist Abs. 12 (d) „Land Bremen will become an autonomous city-state, equivalent in status to Land Braunschweig or Land Oldenburg, and will not be subordinate in any way to the German civil administration of Provinz Hannover".

118 StA Bremen 3-B.10.a.Nr.2 (1) II, S. 193.

119 Zuversicht und Beständigkeit, S. $155 \mathrm{ff}$. 
setzt. ${ }^{120}$ Der Text des zitierten Abkommens, das ebenso wie die Proklamation erst am 22. Januar unterzeichnet worden war, ${ }^{121}$ wurde nun ebenfalls veröffentlicht. ${ }^{12}$ Es nahm seinerseits Bezug auf die Empfehlungen von Albu und Parkman und regelte in neun Punkten den künftigen Status Bremens als Land. Es sollte rückwirkend vom 1.Januar 1947 an wirksam sein. Clay und Robertson waren den Empfehlungen nicht überall gefolgt: bei Bremens Vertretung im Zonenbeirat und Länderrat z. B. wurde die Rolle getauscht, und amerikanische Kontrollrechte bei der Weserhafenbehörde blieben vorbehalten. Neu war die Beibehaltung der ursprünglichen Enklave als militärischer Zuständigkeitsbereich der Vereinigten Staaten, und auch die mißverständliche Erwähnung Delmenhorsts fehlt in der Vorlage. Das Abkommen, das an die Stelle der Vereinbarung vom 10. Dezember 1945 trat, beschrieb die Stellung des neuen Landes mit ,quasi-Zugehörigkeit“ zur US-Zone: Es sei hinsichtlich der Militärregierung so zu behandeln, als $o b$ es Teil der amerikanischen Besatzungszone wäre. ${ }^{123}$ Die Formulierung kehrt wortwörtlich wieder in der britischen Ordinance $\mathrm{Nr} .76$, die schon vom 31. Dezember 1946 an wirksam sein sollte. ${ }^{124}$

Mit ihr wurde offiziell die Stadt Wesermünde aus Niedersachsen herausgenommen und in das Land Bremen eingegliedert, das gleichzeitig in seinen heutigen Grenzen gegründet wurde. ${ }^{125}$ Man steht also vor der kuriosen Tatsache, daß die britisch-amerikanische Vereinbarung, die die Gründung des Landes Bremen vorsah, erst einen Tag später in Kraft trat als die britische Verordnung, mit der als Folge dieser Vereinbarung die Gründung bereits vollzogen wurde - eine der diversen Ungereimtheiten und Merkwürdigkeiten der Bremer Nachkriegsgeschichte. Zu ihnen muß man auch die Tatsache zählen, daB das Clay-Robertson-Agreement, welches nicht die Einbeziehung in die US-Zone, sondern einen „als ob"-Status für Bremen vorsah, am selben Tag unterzeichnet wurde wie die genannte Proklamation Nr. 3 McNarneys, mit der sich die Eingliederung vollzog. Ein zeitlicher Abstand zwischen beiden Vorgängen ist durch die rúckwirkende Inkraftsetzung zum 1. bzw. 21. Januar 1947 im Nachhinein wieder-

120 Amtsblatt der Militärregierung Deutschland - Amerikanisches Kontrollgebiet, Ausgabe C, 1.4.1947; auch Zuversicht und Beständigkeit, S. $158 \mathrm{f}$. und $182 \mathrm{f}$., Weser Kurier vom 23.1.1947, der die Proklamation irrefürend auf den 22.1. datiert; dasselbe Datum auch bei Meyer: Wesermulnde, S.218 und Dorn: Inspektionsreisen, S. 40; nicht zutreffend die Angabe bei Peters: Zwölf Jahre Bremen, S.74, Stichtag für die Eingliederung sei der 1.1.1947 gewesen (richtig:21.1.1947).

121 Mitteilung von Charles D. Winning vom Regional Govemment Coordinating Office, 31.1.1947 (StA Bremen 3-B.10.a.Nr.2 (1) II, S.252; in Zuversicht und Beständigkeit, S. 158 wird irrtiumlich der 21.1.1947 als Unterzeichnungsdatum der Proklamation genannt. Clay mußte noch am 21.1. Vorbehalte McNarneys gegen den Wortlaut ausräumen und auf unverzügliche Veröffentlichung des Textes drängen (AG 1947/19/4).

122 Weser-Kurier 23.1.1947, der englische Text in StA Bremen 3-B.10.a.Nr.2 (1) II, S. 244.

123 Abs. (c): „Land Bremen which shall be treated for the purposes of Military Government as if it were part and parcel of the U.S. Zone of Occupation".

124 Amtsblatt der Militärregierung Deutschland, Britisches Kontrollgebiet, Nr. 16, S.411; u. a. auch Scheper: Bremerhaven, S. 394.

125 Amtsblatt der Militärregierung Deutschland, Britisches Kontrollgebiet, Nr. 16, S. 41 1, Artikel II: „are hereby established as a land to be known as Land Bremen“. Zur Eingliederung Wesermündes ausfühlich Meyer: Wesermünde, und Scheper: Bremerhaven, S. $378 \mathrm{ff}$. DaB die Abtretung Wesermündes den Briten keineswegs leicht fiel, veranschaulicht ein handschriftlicher Vermerk Parkmans vom 1.12.1946: Weitere territoriale Forderungen sollen nicht in die Verhandlungen eingebracht werden. „Even with respect to Wesermünde we shall have difficulty in holding our ground, as Albu feels in hot water over his agreement to include it in Land Bremen"(3/162-3/15). 
hergestellt worden, wobei man für das Agreement besser einen Zeitpunkt noch vor dem Inkrafttreten der britischen Verordnung Nr. 76 gewählt hätte.

In Wesermünde fand aus AnlaB der Eingliederung der Stadt in das Land Bremen am 7. Februar 1947 ein Festakt statt im Rahmen einer feierlichen Sitzung der Stadtverordneten, auf der einstimmig beschlossen wurde, die Stadt in „Bremerhaven“ umzubenennen. ${ }^{126}$

Für die Militärregierung brachten diese Veränderungen endlich klare Verhältnisse. Es entstand ein Land Office, das nach eigenen amerikanischen Richtlinien und Grundsätzen arbeiten konnte. Der Bremerhavener Ableger wurde als Liaison \& Security Detachment etabliert. Im Sommer 1947 wurde auch die Hafenaufsicht in Bremerhaven größtenteils der Bremer Militärregierung übertragen, während der Stủtzpunkt Bremerhaven Port of Embarkation sich im wesentlichen auf die Abwicklung des Personenverkehrs über See beschränkte. ${ }^{12 n}$

Da sich die Aufgaben der Besatzungsbehörden 1947 schon in stärkerem Maße von der direkten Einwirkung zur beobachtenden Kontrolle hin verschoben hatten, ${ }^{128}$ konnten sie aus der bereinigten Lage nicht mehr so viel Nutzen ziehen, wie dies zu einem früheren Zeitpunkt der Fall gewesen wäre. In den ersten Monaten des Jahres 1948 wurden Aufgaben aus den Bereichen Wirtschaft und Verkehr aus der Verantwortlichkeit der Militärregierung in die bizonaler Einrichtungen überführt und eine Geschäftsstelle der JEIA in Bremen eröffnet, ${ }^{129}$ die Devisenwirtschaft und Außenhandel zu überwachen hatte. Gleichzeitig vollzog sich ein rasanter Personalabbau, der nahezu zu einer Halbierung des US-Personals innerhalb von sechs Monaten führte. ${ }^{130}$ Es war deshalb eine in ihrer Wirksamkeit bereits sehr eingeschränkte Militärregierung, die im Herbst 1949 ihre Tätigkeit einstellte und verbliebene Aufgaben samt Personal an die mit Inkrafttreten des Besatzungsstatuts am 21. September neu gebildete Behörde des Landeskommissars abgab.

Am Ende dieses Überblicks sollen einige Bemerkungen uber das Verhältnis zwischen Kontrolleuren und Kontrollierten, zwischen den Mitgliedern der amerikanischen Militärregierung und der Bremer Zivilverwaltung stehen. Der erste Militärgouverneur, Bion C. Welker, mußte mit Erich Vagts einen Mann seines Vertrauens aus politischen Gründen nach drei Monaten entlassen. ${ }^{131}$ Diese Hypothek lastete auf seinem Verhältnis zu Kaisen, das - auch aus anderen Gründen - eher von kühler Reserve gekennzeichnet blieb. Das änderte sich Ende 1946 grundlegend unter seinen Nachfolgern Thomas F. Dunn und Charles R. Jeffs, unter denen sich ein sehr konstruktives, von gegenseitiger menschlicher Achtung geprägtes Arbeitsverhältnis entwickelte. ${ }^{132}$ Kaisens schlichte, direkte Art kam bei Amerikanern gewöhnlich gut an - obwohl er kein Englisch sprach. Auch mit Clay und McCloy hat er noch gelegentliche Kontakte gepflegt, als dienstliche und politische Notwendigkeiten dafür längst nicht mehr bestanden. ${ }^{133}$ Aus Äußerungen von Angehörigen der Bremer Mili-

${ }^{126}$ Scheper: Bremerhaven, S. 396ff.; Zuversicht und Beständigkeit, S. $167 \mathrm{ff}$.

127 Siehe OMGUS-Hb, Bremen B.11.

128 Vgl. OMGBR: Functional History 1.7.1946 - 30.6.1947, I, S. 5.

${ }^{129}$ Siehe OMGUS-Hb, Bremen A.5.a.

${ }^{130}$ Siehe OMGUS-Hb, Bremen A.5.b, Anm. 182.

131 Siehe OMGUS-Hb, Bremen A.2.

132 Müller: Begegnungen mit Kaisen, S. $183 \mathrm{ff}$.

133 Ebenda, S. 192 ff.; Kaisen stellte Clay als Vater der Bremer Unabhängigkeit heraus, McCloy pries Kaisen 1977 ,as one of the wisest of counsellors and finest statesmen with whom I came in contact during that critical period" (ebenda, S. 194). 
tärregierung spricht Achtung, ja Bewunderung für seine Persönlichkeit und Leistung. ${ }^{134}$

Clay sah im Juni 1946 Veranlassung, die Militärregierungen der Länder zu einem distanzierten und geschäftsmäßigen Umgang mit Deutschen anzuhalten. Persönliche Freundschaften und gesellschaftliche Kontakte seien zu vermeiden. Der daraufhin aus Bremen eingehende Geheimbericht wirft ein Schlaglicht auf die deutsch-amerikanischen Probleme des Besatzungsalltags und läßt die Vorbehalte erkennen, die Welker gegenüber Deutschen hegte: „for we are dealing with people who can be ingratiating, have been versed and skilled in intrigue, double crossing and double dealing through the centuries“! Mädchen waren natürlich ein Problem, die als Tanzpartnerinnen in den Soldatenclubs zugelassen waren, wobei alles mit formaler Höflichkeit abgewickelt werden sollte. DaB in dem Zusammenhang einige Rügen nötig wurden, deutet an, daß es in der Praxis so nicht immer zuging. Ein Offizier mußte laut Welkers Bericht wegen seiner Beziehungen zu deutschen Mädchen den Dienst quittieren, ein anderer wegen zu enger Verbindungen zu einem einflußreichen Deutschen. Deutsche Mitarbeiter der Militärregierung müBten genau beobachtet werden, damit sie ihre Position nicht zur persönlichen Vorteilsannahme ausnutzten, wie geschehen. Als offensichtlich mustergültig wird geschildert, wie eine Abendeinladung der Handelskammer an die Wirtschaftsabteilung unter Hinweis auf die Bürozeiten zurückgewiesen wurde. ${ }^{135}$

Felix von Eckardt bezeichnet in seinen Erinnerungen die Fachoffiziere, die ihn als Journalisten beim Weser-Kurier hätten uberwachen sollen, als seine Freunde. ${ }^{136}$ Hafensenator Apelt nannte in einem Nachruf den amerikanischen Hafendirektor Stanley A. Clem seinen persönlichen Freund, ${ }^{137}$ und als Freundschaftsverhältnis gestaltete sich bereits während der Zeit der Zusammenarbeit in Bremen die Beziehung zwischen dem Leiter der Erziehungsabteilung, Harold H. Crabill, und seinem Verbindungsmann zur Bremer Schulverwaltung, Wilhelm Berger. ${ }^{138}$ Wenn schlieBlich der zu Kritik durchaus fähige Leiter der Entnazifizierungsabteilung, Joseph F. Napoli, rückblickend den Bremer Senator für politische Befreiung, Dr. Alexander Lifschult, neben Wilhelm Kaisen als ,absolutely outstanding in German public life“ - und zwar im positiven Sinne - beurteilte, ${ }^{139}$ so verwundert es nicht, daB der Jahresbericht für 1948 von amerikanischer Seite das summarische Urteil enthält: „Relationship between Military Government and German authorities has been generally excellent throughout the year". 140 So war es in den ersten Monaten der Besatzungszeit sicherlich nicht - Verbitterung über Plünderungen und Übergriffe amerikanischer Soldaten auf der einen Seite und Verärgerung über die mangelnde Flexibilität und Kooperationsbereitschaft deutscher Behörden auf der anderen Seite trübten die Beziehungen. Aber nach Stabilisierung der allgemeinen Lage war Kooperation, nicht Konfrontation atmosphärisch bestimmend. Zudem begünstigten ungeklärte Kompetenzfragen zwischen britischer und amerikanischer Militärregierung ein frühes $\mathrm{Zu}$ -

134 Ebenda, S. $189 \mathrm{f}$.

135 AG 1945-46/15/1.

136 Eckardt: Lebenserinnerungen, S. 125.

137 Apelt: Reden und Schriften, S. 282.

138 Siehe OMGUS-Hb, Bremen B.10, Anm. 225; vgl. Wulff: Im Jahrfünft, S. 20 f.

139 Müller: Begegnungen mit Kaisen, S. 190.

140 OMGBR: Annual Functional History 1.1. - 31.12.1948, I, S. 10; beinahe identisches Vokabular (,im allgemeinen ausgezeichnet“) benutzt von Eckardt: Lebenserinnerungen, S. 125, um aus seiner Sicht das Verhältnis zu den Amerikanern zu charakterisieren. 
sammengehen von bremischen und amerikanischen Interessen. ${ }^{141}$ Lediglich die Entnazifizierungspolitik konnte mit MiBbilligung in den Fachverwaltungen rechnen.

Die kleinräumigen Verhältnisse in Bremen haben eine Verwurzelung der Besatzungsoffiziere in der Stadt offenbar erleichtert. Jeffs, 1945 als Marineoffizier an die Weser gekommen, trat später in die Militärregierung ein und wurde ihr Direktor, dann Landeskommissar. „Er sorgte für Bremen wie ein Landesvater“, erinnert sich von Eckardt, und „den Hafen empfand er wie sein persönliches Eigentum“. ${ }^{142}$ Jeffs heiratete eine Bremerin - wie es auch Napoli und Ladd taten (letzterer Fachoffizier für Jugend und Sport),${ }^{143}$ neben mehreren hundert weiteren Amerikanern, die in der Enklave stationiert waren ${ }^{144}$ - und wurde nach dem Ausscheiden aus dem Dienst in Bremen ansässig. In Deutschland FuB faBte auch Wolf Citron, zustăndig für Radio Bremen, der später für das deutsche Fernsehen arbeitete. ${ }^{145}$ Clarence P. Oakes, von 1949 bis 1952 als politischer Berater von Jeffs in Bremen, hatte wie jener die Stadt zunăchst als Marineoffizier kennengelernt. Er verlieB Bremen u.a. als Ehrenmitglied des „Plattdütschen Vereens“ und mit einem stattlichen Repertoire deutscher Volkslieder, die er in seiner Freizeit zur Gitarre sang; sein Lieblingslied: „Wo die Nordseewellen ziehen an den Strand. . “..146

So wie Hamburg sich traditionell England verbunden fühlt, so hat Bremen sich stets etwas auf seine Beziehungen zu den Vereinigten Staaten zugute gehalten, seit George Washington 1796 das erste amerikanische Konsulat in Bremen einrichtete. ${ }^{147}$ Die amerikanische Enklave an der Unterweser hat diesen Beziehungen in einer kurzen historischen Zeitspanne ein vorher wie nachher nicht gekanntes Gewicht gegeben und wesentlich dazu beigetragen. Bremen nach dem Krieg als Stadtstaat wieder neu entstehen und seine Häfen zu neuer Geltung sich entwickeln zu lassen.

\section{Organisation und Personal der Bremer Militärregierung als Ganzes}

\section{a) Die Entwicklung der Organisationsstruktur}

Die für die Militärregierung in Bremen vorgesehene Einheit wurde am 27. Januar 1945 als Detachment E2C2, European Civil Affairs Division (Prov), in Frankreich aufgestellt zusammen mit Detachment G1C2, ECAD (Prov), das in Wesermünde/Bre-

141 Justizsenator Spitta sollte z. B. schon am 2.7.1945 für seinen Fachoffizier eine Denkschrift konzipieren, für die jener lediglich die Stichworte vorgab (Wenzlau: Wiederaufbau der Justiz, S. 178, Anm.8).

142 Eckardt: Lebenserinnerungen, S. 125.

143 Siehe OMGUS-Hb, Bremen A.5.a und B.3; Ladd war ein 28-jähriger Lehrer (Wulff: Im Jahrfünft, S. 44).

144 Zahl der EheschlieBungen zwischen Amerikanern und Deutschen in Bremen/Bremerhaven 1945: 0/2, 1946: 8/1, 1947: 115/64, 1948: 272/234, 1949: 96/64 (ermittelt mit freundlicher Unterstützung der Standesämter Bremen-Mitte, Bremen-Nord und Bremerhaven). Unter den Besatzungsangehörigen, die eine Deutsche heirateten, war 1947 auch der spätere Bestsellerautor Mario F. Puzo („Der Pate“, 1969); seine Erfahrungen aus der Bremer Nachkriegszeit fanden 1955 in einem Roman ihren Niederschlag (,The Dark Arena“, dt. „Die dunkle Arena", 1975). - Eine amerikanische Untersuchung ergab bereits 1945 , daß bis August über $50 \%$ der amerikanischen Soldaten sexuelle Kontakte mit deutschen Mädchen gehabt hatten; mehr als die Hälfte der geborenen unehelichen Kinder hatte amerikanische Besatzungssoldaten als Văter, siehe Schmidt/Fichter: Der erzwungene Kapitalismus, S. 114.

145 Eckardt: Lebenserinnerungen, S. 127.

146 Weser-Kurier 21.3.1952; siehe OMGUS-Hb, Bremen B.2, Anm. 61.

147 Das Konsulat wurde aus finanziellen Gründen zum 30.6.1986 geschlossen. 
merhaven tätig werden sollte. Eine am 16. März 1945 verfügte Reorganisation ersetzte „(Prov)“ in der Bezeichnung der Einheit durch „(Special)“.'148 Während der Vorbereitungszeit in Frankreich erarbeitete sich das Detachment einen Einsatzplan auf der Grundlage des von SHAEF herausgegebenen Handbuches für die Militärregierung. Dieser „Operational Plan“ enthält auch ein Organisationsschema des Detachments E2C2, das die vorgesehene Aufgabengliederung deutlich macht.

Ubersicht 2: Organisation des Detachments E2C2, OMGBR, Entwurf März 1945 (nach 6/125-2/24)

Other Detachments in Enclave

Military Govemment

Officer

1

Deputy

Mil. Gov. Officer

I

$\begin{array}{cc}\text { Headquarters - } & \text { Administrative } \\ \text { Commandant } & \text { Officer } \\ \text { । } & \vdots \\ \text { Troop Branch } & \begin{array}{c}\text { Administrative } \\ \text { Branch }\end{array}\end{array}$

Personnel Message Center

Supply Central File

Mail Stenographers

Post Exchange Receptionist

Mess Interpreters

Motor Pool Drafting

Special Service Switchboard

Office Supplies

Library

\begin{tabular}{lllll|l|}
\hline $\begin{array}{l}\text { Public } \\
\text { Safety }\end{array}$ & Economics & Legal & Fiscal & $\begin{array}{l}\text { Property } \\
\text { Control }\end{array}$ & $\begin{array}{l}\text { Displaced } \\
\text { Persons }\end{array}$
\end{tabular}

\begin{tabular}{|c|c|c|c|c|c|c|}
\hline $\begin{array}{l}\text { Police } \\
\text { Prisons } \\
\text { Fire } \\
\text { Civilian Defense }\end{array}$ & $\begin{array}{l}\text { Food, Fuel \& } \\
\text { Clothing } \\
\text { Trade \& } \\
\text { Industry } \\
\text { Agriculture } \\
\text { Fisheries } \\
\text { Labor } \\
\text { Communi- } \\
\text { cations } \\
\text { Public Works \& } \\
\text { Utilities } \\
\text { Transpor- } \\
\text { tation }\end{array}$ & $\begin{array}{l}\text { Laws \& } \\
\text { Ordinances } \\
\text { Courts } \\
\text { Legal } \\
\text { Problems } \\
\text { Official } \\
\text { Gazette }\end{array}$ & $\begin{array}{l}\text { Finance } \\
\text { Banks - } \\
\text { Financial } \\
\text { Institutions } \\
\text { Accounting } \\
\text { Public } \\
\text { Finance }\end{array}$ & $\begin{array}{l}\text { Seized } \\
\text { Property } \\
\text { Property } \\
\text { Custodian }\end{array}$ & $\begin{array}{l}\text { Refugees } \\
\text { Displaced } \\
\text { Persons } \\
\text { Repatriation } \\
\text { Red Cross } \\
\text { UNRRA } \\
\text { Public } \\
\text { Welfare }\end{array}$ & $\begin{array}{l}\text { Public } \\
\text { Health } \\
\text { Sanitation } \\
\text { Veterinary } \\
\text { Preventative } \\
\text { Medicine } \\
\text { D.P. Hospi- } \\
\text { talization } \\
\text { Medical } \\
\text { Supplies }\end{array}$ \\
\hline
\end{tabular}

Über den projizierten Fachabteilungen Public Safety, Economics, Legal, Fiscal, Property Control, Displaced Persons und Public Health sind Leitungs- und Verwaltungsfunktionen sowie die Außenkontakte angeordnet. Es fällt auf, daß Civil Administration nicht neben den übrigen Fachabteilungen steht, sondern direkt dem stellvertretenden Befehlshaber des Detachments unterstellt ist, und der Kulturbereich

148 OMGBR: Functional History 27.4.1945 - 30.6.1946, I, S. 1 f.; OMGBR: Functional History 27.4.1945 - 30.6.1946, II, App. 1, 2. 
(Arts \& Monuments, Education \& Religion) mit anderen Dingen in das Aufgabenfeld des Executive Officer integriert wurde. Vielleicht waren für diese ungewöhnliche Zuweisung besondere Qualifikationen des zunächst in Aussicht genommenen Offiziers maßgeblich. Realisiert wurde sie nicht. Der Organisationsplan des Detachments vom 1.Juli 1945, der anläßlich einer vom Chief of Staff, US Group Control Council, angeordneten Inspektion vorgelegt wurde, ${ }^{149}$ weist die beiden genannten Auffälligkeiten nicht mehr auf, kommt sonst im Grundmuster dem Konzept aber noch recht nahe.

Úbersicht 3: Organisation des Detachment E2C2, Enclave Military District, Bremen Germany, 1. Juli 1945 (nach StAB 16,1/4, FB 707, Special Report)

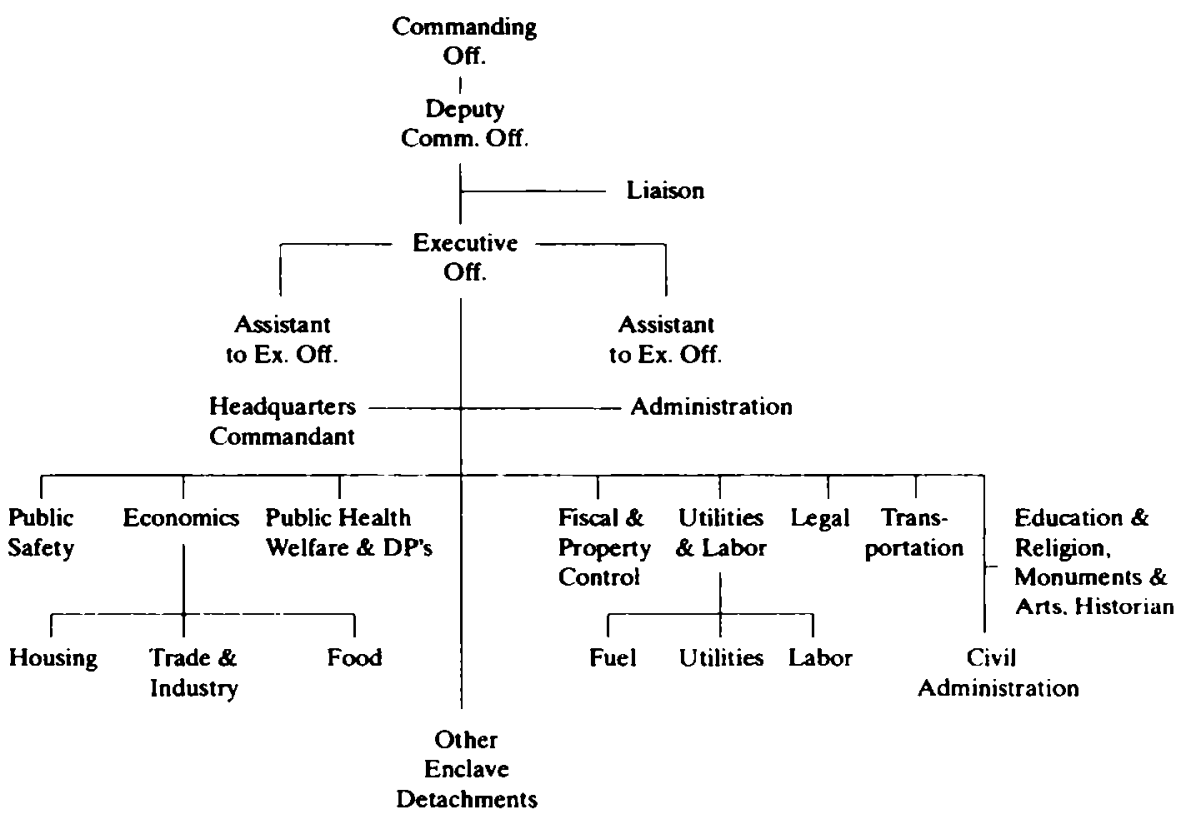

Läßt man einmal die Zivilverwaltung und den Kultursektor beiseite, die zu gewöhnlichen Fachbereichen geworden sind, so stehen die Leitungs- und Verwaltungsfunktionen weiterhin über sieben Fachreferaten (Branches), von denen Public Safety, Economics und Legal auch im Entwurf zu finden sind, während Fiscal \& Property Control nun ebenso wie Public Health, Welfare \& DPs aus vorher je zwei Referaten zusammengezogen wurden. Neu als eigene Referate sind dafür Transportation und Utilities \& Labor entstanden, die als Teilbereiche von Economics konzipiert waren. Dies sind aber eher Modifikationen als grundlegende Änderungen. Der Einsatzplan hatte sich im Organisatorischen offenkundig bis dahin als durchaus brauchbar erwiesen. Mit Interesse zu vermerken ist das Bestreben, die Aufgabenverteilung in den Fachreferaten der Geschäftsverteilung im Bremer Senat anzupassen ${ }^{150}$ - nicht etwa umgekehrt. Neugestaltungswille im Bereich der deutschen Verwaltungsorganisation ist hier nicht zu spüren.

149 OMGUS-Hb, Bremen, Übersicht 3 (National Archives RG 332 USFET G-5, box 11 080-31, file 014.4, Protokoll vom 21.7.1945 [Mikrofilm StA Bremen, FB 707]).

150 Aussage von Douglas W. Meservey, stellv. Kommandeur des Detachments: „Our administrative set-up parallels, where practicable, the local Bremen governmental set-up"(ebenda). 
Im Unterstellungverhältnis gab es für die Bremer Detachments mehrfachen Wechsel, was nicht gerade zur Vereinfachung der Verwaltungstätigkeit beitrug. ${ }^{151}$ Am 4. April 1945 der 21. Armeegruppe zugeordnet, wurden sie am 26. Mai der 12. Armeegruppe überstellt. ${ }^{152}$ Am 15.Juni wechselte die Zuständigkeit für den Militärbezirk West mit Bremen von der 9. zur 7. US-Armee. ${ }^{153}$ Die Lage der Enklave im britischen Operationsgebiet machte es notwendig, die amerikanischen Detachments in den Wochen vor dem Einmarsch und unmittelbar danach einer britischen Einheit, dem 30. Corps, zuzuordnen. Der Kommandeur des Detachment E2C2, Oberstleutnant Welker, unterstand während der Zeit Generalmajor Hakewell-Smith von der 52. Lowland Division, bis am 24. Mai die amerikanische 29. Infanteriedivision die Briten in dieser Funktion ablöste. ${ }^{154}$ Der führenden Rolle des Bremer Detachments E2C2 in der Enklave wurde Ende Juni/Anfang Juli durch die formale Anbindung bzw. Integration der übrigen fünf Rechnung getragen, die de facto bereits bis dahin unter dem Kommando von Lt.Col. Welker gearbeitet hatten. ${ }^{155}$ Damit kam sinngemäß die ETOUSA-Direktive vom 13. Mai 1945 zur Anwendung, die eine hierarchische Gliederung nach dem Muster vorsah, daß die in Städten und Landkreisen arbeitenden Detachments der Einheit auf Regierungsbezirksebene unterstellt werden sollten. ${ }^{156}$ Eine Reorganisation auf Anordnung des kommandierenden Generals der 7. Armee machte Welker mit Wirkung vom 5. August 1945 für die Militärregierung in der gesamten Enklave unmittelbar verantwortlich. Ein Enklave-Detachment wurde gebildet mit zentraler Zuständigkeit, darunter ein Bremen-Team und funf weitere Detachments. ${ }^{157}$

Eine spezifische Komplikation ergab sich daraus, daB sich in der Enklave neben der Militärregierung und dem Divisionsstab der 29. Infanteriedivision eine weitere, gleichrangige Kommandozentrale der amerikanischen Besatzungstruppe etablierte: Bremen Port Command, das vor allem Instandsetzung und Funktionieren der bremischen Nachschubhäfen gewährleisten sollte und nicht der 7. Armee, sondern direkt der Nachschubtruppe Theater Service Forces unterstand. Diese zweigleisige Befehlsgewalt (dual command) ${ }^{158}$ ließ in besonderem MaBe Kompetenzprobleme entstehen, die im übrigen auch anderen Teilen der US-Zone nicht fremd waren. ${ }^{159}$ Die verbreitete und wohlbegrundete Auffassung, daB der administrative Wirrwarr in der Enklave

151 OMGBR: Functional History 27.4.1945 - 30.6.1946, I, S. 13.

152 OMGBR: Functional History 27.4.1945 - 30.6.1946, II, Appendix 2a und 4 a, ECAD Troop Attachment Order Nr.59 und 93.

153 Vgl. Latour/Vogelsang: Okkupation und Wiederaufbau, S. 72.

154 Die militärische Kontrolle der Enklave ging bereits am 20.5.1945 formell von den Briten auf die amerikanischen Einheiten über, denen am 24.5. auch die Detachments der Militärregierung zugeordnet wurden (OMGBR: Functional History 27.4.1945 - 30.6.1946, I, S. 7 und $13 \mathrm{f}$., Latour/Vogelsang: Okkupation und Wiederaufbau, S.103). Brandt: Antifaschismus und Arbeiterbewegung, S.69 verwechselt die Vorgänge und Daten.

155 OMGBR: Functional History 27.4.1945 - 30.6.1946, I, S. 15 f.

156 Vgl. Latour/Vogelsang: Okkupation und Wiederaufbau, S. 75.

157 OMGBR: Functional History 27.4.1945 - 30.6.1946, I, S.15f.

158 Ebenda, S. 8; bei Latour/Vogelsang: Okkupation und Wiederaufbau, S. $101 \mathrm{f}$. wird der nicht ganz zutreffende Eindruck erweckt, mit Bremen Port Command, Militärregierung und 29. Infanteriedivision hătten drei voneinander unabhängige amerikanische Einheiten in der Enklave operiert. Da die Militärregierung zunächst der Divisionsführung untergeordnet war (vgl. OMGBR: Functional History 27.4.1945 - 30.6.1946, I, S. 14), waren es tatsächlich nur zwei separate Befehlsstränge.

159 Vgl. Latour/Vogelsang: Okkupation und Wiederaufbau, S. 69 und 79; Gulgowski: American Military Government, S. 260. 
effektiver Arbeit im Wege stand, wurde zur Triebfeder für umstrukturierende Maßnahmen.

Das Abkommen vom 10. November 1945 brachte für die Organisationsstruktur der amerikanischen Militärregierung in der Enklave zwei bedeutsame Veränderungen mit sich. Die erste war die Beschränkung des amerikanisch verwalteten Gebietes auf Bremerhaven/Wesermünde und Stadt und Landgebiet von Bremen. Die drei zur Enklave gezählten Landkreise Osterholz-Scharmbeck, Wesermünde und Wesermarsch rechts und links der Unterweser wurden den Briten uberlassen, die dort stationierten Detachments abgezogen. Die zweite Veränderung betraf einen Wechsel im Unterstellungverhältnis, denn nicht mehr die 7. Armee, sondem Bremen Port Command (BPC) unter Generalmajor Harry B. Vaughan sollte für die Militärregierung zuständig sein. Eine kompetente G-5 Sektion muBte dort allerdings erst im Laufe des Monats Dezember aufgebaut werden, da BPC bisher mit Militärregierungsaufgaben nicht befaBt gewesen war. Unter dem Dach eines Office of Military Government, Detachment Bremen Port Command, sollte eine Militärregierung in Bremen und eine in Bremerhaven und Wesermünde operieren. ${ }^{160}$ Der von einem längeren Heimaturlaub zurückkehrende Welker übernahm am 12. Februar 1946 das Kommando als Direktor der Militärregierung und G-5 Mitglied des Stabes von Bremen Port Command. Die Konstruktion hatte keine Zeit, ihre Arbeitsfähigkeit unter Beweis zu stellen. Bereits am 23. Februar 1946 wurde das Military Government Detachment Bremen Port Command (Provisional) aufgelöst und durch ein neues Provisorium ersetzt, das Office of Military Government for Bremen Detachment (Non T/O). ${ }^{161}$

Eine dauerhaftere Organisationsform wurde erst gefunden mit der Einrichtung des Office of Military Government for Bremen Enclave (US) am 15. April 1946, das der Berliner OMGUS-Zentrale direkt unterstellt war. OMGUS-Teams, die in den Wochen und Monaten zuvor unabhängig von der örtlichen Militärregierung in Bremen gearbeitet hatten - z. B. Spezialisten für Wasserstraßen, Nahrungsmittel, Im- und Export -, wurden ihr nun unterstellt. Bei der Aufsicht über den Hafenbetrieb verständigte man sich so, daß die bremischen Häfen von der Militärregierung, die in Bremerhaven von der Nachschubtruppe 17th Major Port zu kontrollieren waren. ${ }^{162}$

Die strukturelle Instabilität der Militärregierung in den ersten zwölf Monaten Besatzungszeit spiegelt sich auch im Vergleich der Organisationspläne von Januar 1946 und Juli 1945: ${ }^{163}$

160 OMGBR: Functional History 27.4.1945 - 30.6.1946, I, S. 18f.; Organisationspläne in 6/83-2/5 und 5/372-3/16. Ein ausführlicher Organisations- und Geschäftsverteilungsplan für Bremen Port Command vom 30.1.1946 zeigt die Militärregierung als 13. und letzte der Funktionseinheiten Headquarters Command, Security Force, Task Force, Staging Area Command, Transportation Service, 17 th Major Port, Motor Transport, Engineer Service, Quartermaster Service, Ordnance Service, Signal Service, Medical Service. Außer dem Bremen Port Command gab es in der Enklave noch Stützpunkte für Luftwaffe und Marine sowie die Detachments der britischen Militärregierung (5/41-1/18).

161 OMGBR: Functional History 27.4.1945 - 30.6.1946, I, S. 19. Im Februar - wohl in dem Zusammenhang - wurde auch der Kommandeur des Hafenkommandos, Generalmajor Vaughan, abgezogen, ohne gleichrangig ersetzt zu werden; siehe Schreiben des Konsuls Altaffer an Murphy vom 24.7.1946 (POLAD 814/33); für Altaffer war die nachfolgende Auflösung des Hafenkommandos ein schwerer Schlag für die örtliche Besatzungsverwaltung.

162 OMGBR: Functional History 27.4.1945 - 30.6.1946, I, S. $19 \mathrm{f}$.

163 Siehe OMGUS-Hb, Bremen, Übersicht 3 und 4. 
Ubersicht 4: Organisation des Office of Military Government for Bremen, 15. Januar 1946 (nach 6/83-2/5)

\begin{tabular}{|c|c|c|c|c|c|c|c|}
\hline \multicolumn{8}{|c|}{$\begin{array}{c}\text { Commanding Off. } \\
\mid \\
\text { Executive Off. }\end{array}$} \\
\hline \multicolumn{8}{|c|}{ Administration } \\
\hline \multicolumn{4}{|c|}{$\begin{array}{l}\text { Headquarters } \\
\text { Commandant }\end{array}$} & \multicolumn{2}{|c|}{$\begin{array}{c}\text { Civil } \\
\text { Administration }\end{array}$} & & \\
\hline $\begin{array}{l}\text { Internal } \\
\text { Affairs } \\
\text { ansportation, } \\
\text { Public } \\
\text { Safety. } \\
\text { Legal) }\end{array}$ & $\begin{array}{l}\text { Trade \& } \\
\text { Industry }\end{array}$ & $\begin{array}{l}\text { Denazifi- } \\
\text { cation }\end{array}$ & Labor & $\begin{array}{l}\text { Information } \\
\text { (Education, } \\
\text { \& Religion, } \\
\text { Youth } \\
\text { Activities, } \\
\text { Political } \\
\text { Intelligence) }\end{array}$ & $\begin{array}{l}\text { Public } \\
\text { Health }\end{array}$ & $\begin{array}{c}\text { Fiscal \& } \\
\text { Property } \\
\text { Control }\end{array}$ & $\begin{array}{l}\text { DP's \& } \\
\text { Public } \\
\text { Welfare }\end{array}$ \\
\hline
\end{tabular}

Von den nach wie vor neun Fachreferaten sind nur zwei (Civil Administration, Fiscal \& Property Control) im Titel unverändert bestehen geblieben. Sonst findet sich Teilung (Public Health, Public Welfare) und Zusammenlegung (Internal Affairs) von Referaten, Neueinrichtung (Denazification) und Neubenennung (Information).

Der Organisationsplan vom November $1946^{164}$ weist eine weiterhin konstante Zahl von neun Fachbereichen - nun Abteilungen genannt - unter dem Leitungs- und Verwaltungsbereich auf, von denen sich sechs in ähnlicher Form bereits im Sommer 1945 finden (Public Health \& Welfare, Public Safety, Economics, Transport, Legal, Finance \& Property Control), während nur ein einziger (Finance \& Property Control) seine Entsprechung im zuvor beschriebenen Plan vom Jahresanfang 1946 hat. Der Rückgriff auf fruhere bzw. allgemein gebräuchliche Formen in der Stabilisierungsperiode ab April 1946 nach der Unruhe der Umstrukturierungen des Winters wird deutlich. Nach einem Besuch des Control Officer David L. Robinson bei der Bremer Militairregierung muBte sich Direktor Welker im Juni 1946 deutliche Kritik an der Verwaltungsstruktur gefallen lassen: Die Verwaltung sei kopflastig, trotzdem fehle es an Koordination und Kontrolle; besonders die Finanz- und Personalplanung liege so im Argen, daß schnellstens Abhilfe geschaffen werden mulsse, was Welker versprach. ${ }^{165}$ Die 1946 entwickelte Organisationsstruktur erwies sich bis in den Herbst hinein als erfreulich dauerhaft: „The functional organization was practically undisturbed during the report year“, heißt es rückschauend im Sommer 1947, „since very fortunately the earlier organization made possible a structure which followed closely the make-up of the Bremen Senate which has resumed activities following the October elections of $1946 " .{ }^{166}$ Die bereits 1945 festgestellte bewuBte Anpassung an die Geschäftsverteilung im Senat fand also ihre Fortsetzung. Der als Beispiel herausgegriffene Organisationsplan vom 23. Oktober $1947^{167}$ zeigt zwei Fachabteilungen mehr als im Vorjahr: Bildung und Entnazifizierung. Außerdem ist das Bremerhavener Detachment nun wie eine Fachabteilung angegliedert.

164 Siehe OMGUS-Hb, Bremen, Übersicht 5.

165 Schreiben vom 14.6. und Antwort vom 18.6.1946 (5/372-3/16 und AG 1945-46/64/9).

166 OMGBR: Functional History 1.7.1946 - 30.6.1947, I, S.3.

${ }^{167}$ Siehe OMGUS-Hb, Bremen, Übersicht 6. 


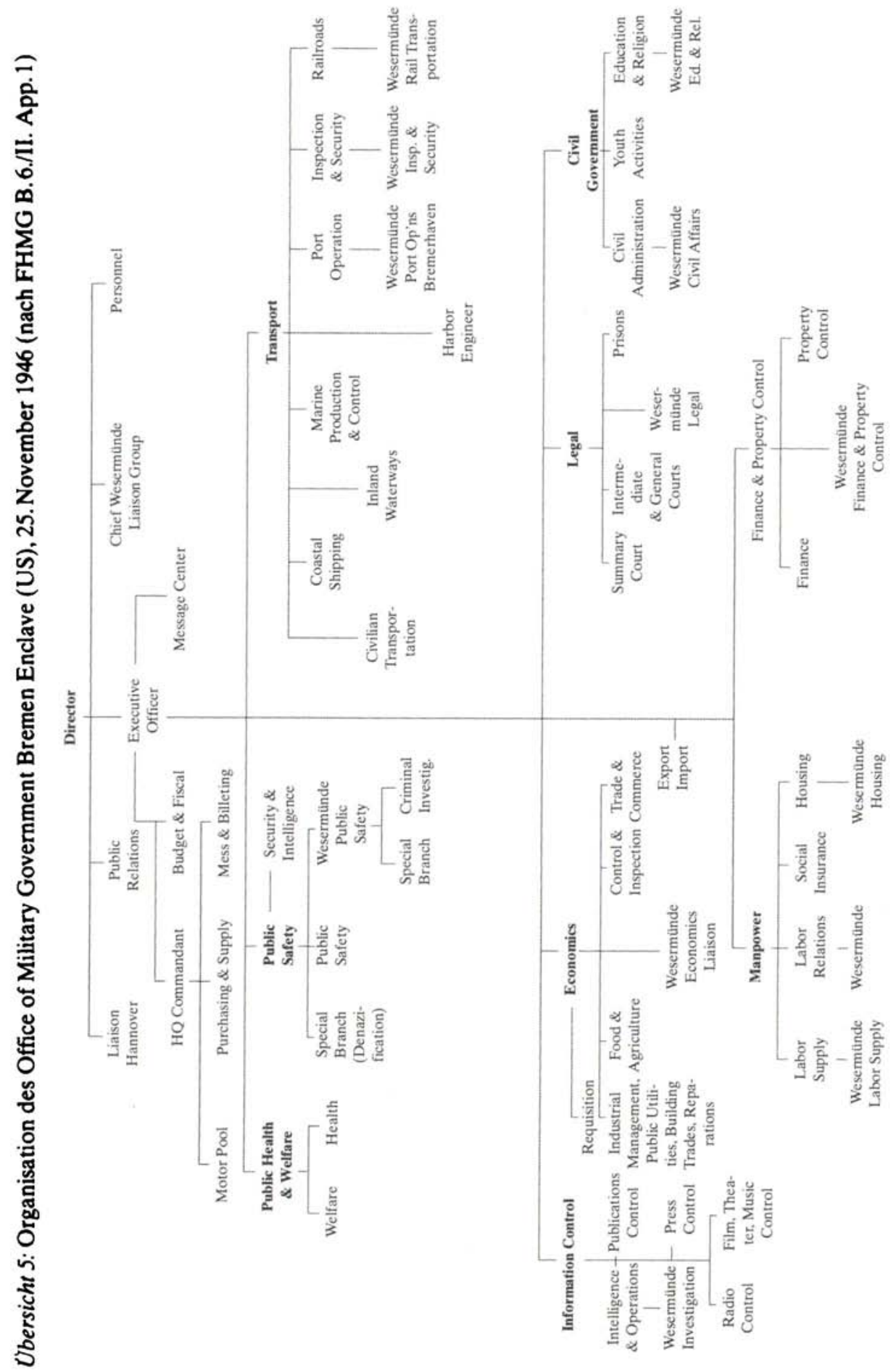


Übersicht 6: Organisation des Office of Military Government Bremen. 23. Oktober 1947 (nach 6/67-1/21)

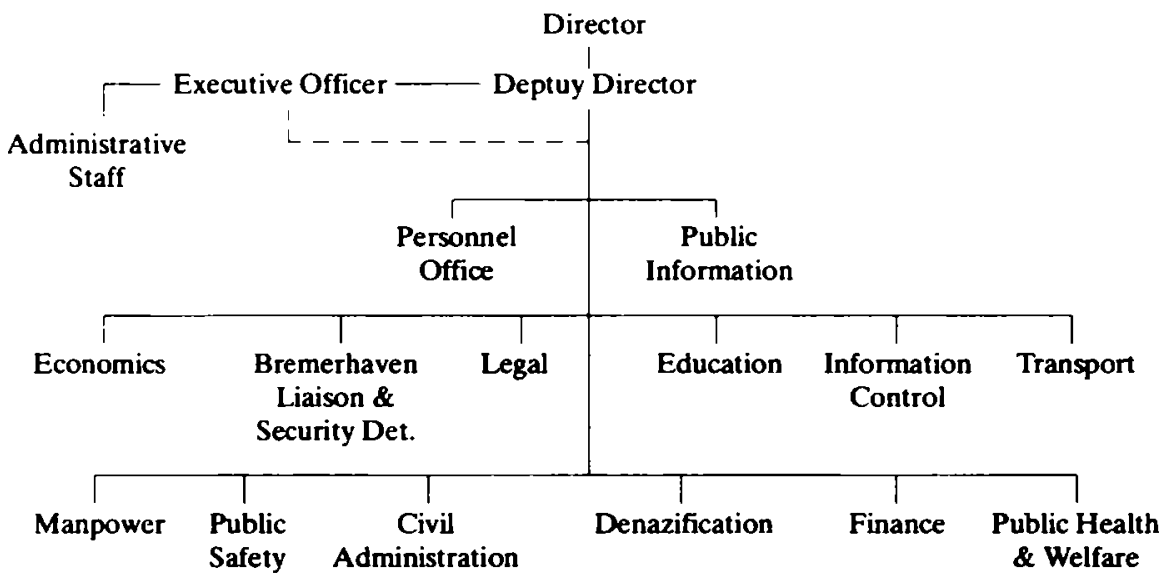

Funktionen im Haushalts- und Rechnungswesen wurden einschlieBlich Personal im Sommer 1947 an Bremerhaven Port of Embarkation abgegeben, die Nachfolgeorganisation von Bremen Port Command. ${ }^{168}$

Im Januar 1948 verselbständigte sich die bis dahin der Wirtschaftsabteilung angegliederte Mannschaft der JEIA und gründete eine eigene Bremer Zweigstelle, die jedoch verwaltungsmäBig weiter mit der Militärregierung in Verbindung blieb. Administrativ betreut werden mußte auch ein Meinungsforschungsteam von OMGUS, das seit dem 13. Januar 1948 in der Hansestadt tätig war, die behördliche Reiseagentur Combined Travel Board und die bizonalen Stellen verantwortlichen Fachbereiche, 2. B. Post und Bahn und die Weser River Field Organization. ${ }^{169}$ Die Aufsicht über den Schiffbau ging am 2. Mai 1948 auf BICO über, Handel, Industrie und Fischereiwesen folgten bis Jahresende. Diese Verlagerungen von Zuständigkeiten verbunden mit drastischem Personalabbau ${ }^{170}$ machten organisatorische Eingriffe größeren Umfangs unumgänglich. Mit Wirkung vom 15.September 1948 wurden deshalb anstelle der dreizehn bestehenden Fachabteilungen sechs neue gebildet, auf die alle verbliebenen Aufgaben verteilt waren. Damit kehrte jedoch keine Ruhe ein, denn bereits am 29. September 1948 wurden die Militärgerichte der Aufsicht der örtlichen Militärregierung entzogen und OMGUS unterstellt, was der Legal Division die Existenzberechtigung nahm. ${ }^{171}$ Die Organisationsstruktur Ende November $1948^{172}$ veranschaulicht die Auflösungserscheinungen der Militärregierung: Es gab Abteilungen ohne sachlichen Zusammenhang, die nur noch als Sammelbecken für Restfunktionen dienten.

168 OMGBR: Functional History 1.7.1947 - 30.9.1947, I, S. 1 .

169 OMGBR: Functional History 1.1.1948 - 31.12.1948, 1, S. 5 ff.; vgl. OMGUS-Hb, Bremen B.7.

170 Siehe OMGUS-Hb, Bremen B.6.

171 OMGBR: Functional History 1.1.1948 - 31.12.1948, I, S.9.

172 Siehe OMGUS-Hb, Bremen, Übersicht 7. 
Ubersicht 7: Organisation des Office of Military Government Bremen, 30. November 1948 (nach 6/1-2/1)

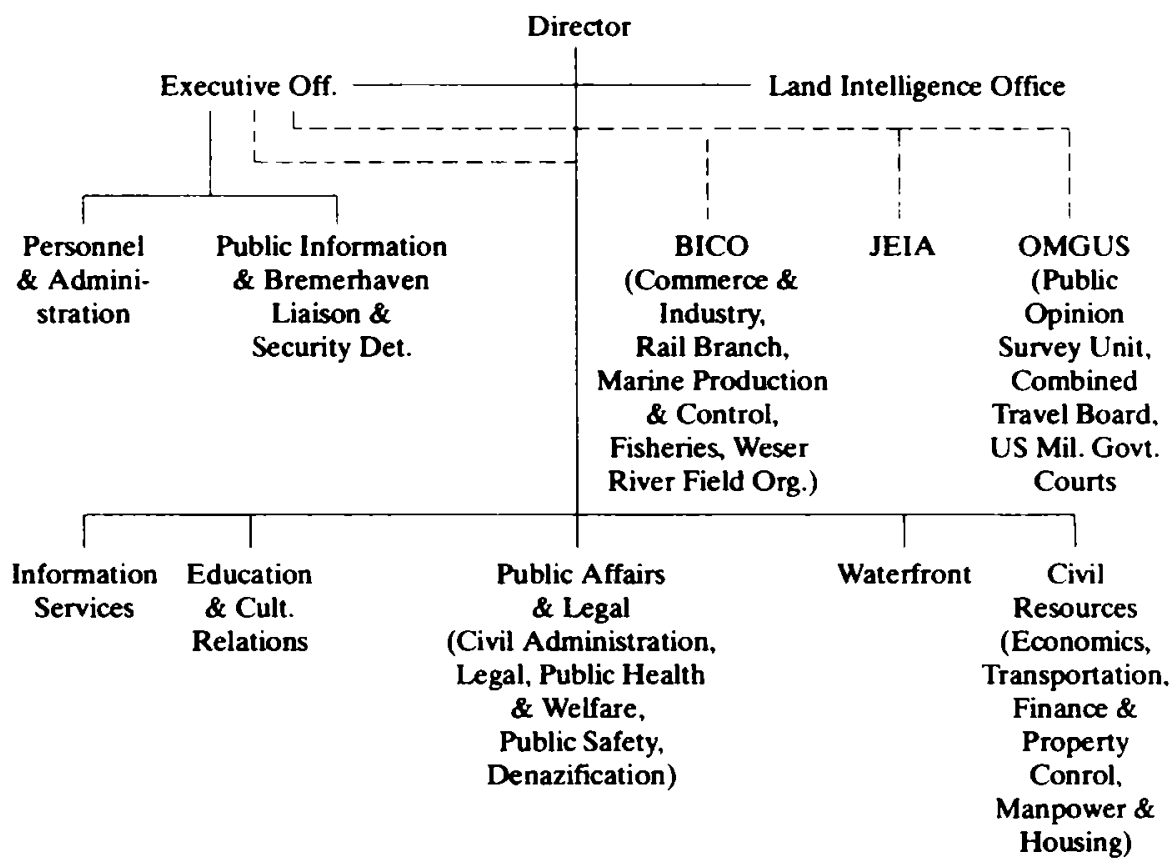

Dieser Zustand bestand bis März 1949 praktisch unverändert fort. Den administrativ liierten OMGUS-Einheiten wuchs derzeit ein Referat für zivilen Luftverkehr zu. ${ }^{173}$ Danach blutete die Bremer Militärregierung weiter aus. Die Information Services Division wurde aufgelöst, die Zuständigkeit für Rundfunk und Informationszentren findet sich am 1. Juli 1949 bei den liierten OMGUS-Einheiten. ${ }^{174}$ Die Zahl der Abteilungen insgesamt blieb nur deshalb unverändert, weil die Public Affairs \& Legal Division in zwei Abteilungen geteilt wurde, von denen die eine als Legal Division firmierte, die andere als Civil Administration \& Land Intelligence Division. Hinter solch bedeutungsvoll klingenden Namen verbarg sich zu dem Zeitpunkt nur noch ein einziger amerikanischer Offizier mit Sekretärin und insgesamt sieben deutschen Mitarbeitern. ${ }^{175}$

\section{b) Die Personalentwicklung}

Beim Einmarsch in Bremen am 26./27. April 1945 bestand Detachment E2C2 aus 28 Offizieren und 60 Soldaten; das Wesermünder Detachment G1C2 verfügte zu Beginn seiner Arbeit über sieben Offiziere, einen Zivilisten im Offiziersrang und 18 Soldaten. Es waren somit insgesamt 114 Amerikaner, die die Militärregierung in der Bremer Enklave in Angriff nahmen - eine Gesamtzahl, die schon im Herbst 1946 zeitweise wieder unterschritten wurde.

${ }^{173} \mathrm{Vgl}$. Organisationsplan vom 1.3.1949 (6/58-1/19).

$174 \mathrm{Vgl}$. Organisationsplan vom 1.7.1949 (6/2-1/27).

$175 \mathrm{Vgl}$. Organisationsplan der Abteilung (6/2-1/24). 
Die Personalstärke des Bremer Detachments wurde zunächst kontinuierlich aufgestockt. Am 31. Mai 1945 zählte es 38 Offiziere, am 30. Juni 51 und am 30. September 101 Offiziere (davon drei Zivilbedienstete) sowie 147 Soldaten, ferner 80 eingestellte DPs und 200 deutsche Mitarbeiter. Damit waren die Amerikaner selbst bereits zahlenmäßig in die Minderheit geraten - eine Tendenz, die sich rasch verstärkte.

Das Wesermünder Detachment wuchs im Sommer 1945 auf 26 Offiziere (davon ein Zivilist) und 33 Soldaten. Die übrigen Detachments blieben kleine Außenposten: In Osterholz-Scharmbeck waren seit Ende Mai 1945 fünf Offiziere und zehn Mann stationiert, in Loxstedt und Brake Ende Mai drei, später vier Offiziere plus sechs Mann, in Nordenham ebenfalls vier Offiziere mit fünf Mann. Nach dem Abkommen vom 10. Dezember 1945 wurden diese Kräfte frei, und der Stellenabbau konnte beginnen. ${ }^{176}$

Ende Januar 1946 waren laut Personalbericht bei der Bremer Militärregierung beschäftigt: 163 Amerikaner (86 Offiziere, 77 Soldaten), 511 Deutsche sowie 98 nichtdeutsche Ausländer. Der Personalstand bei Einrichtung des Office of Military Government for Bremen Enclave (US) am 15. April 1946 zeigt einerseits schon eine erhebliche Reduzierung des US-Personals, andererseits eine starke Zunahme der deutschen Mitarbeiter: 142 Amerikaner (75 Offiziere, 59 Soldaten, 8 US-Zivilisten) standen 604 Deutschen gegenüber. ${ }^{177}$ Ende Juni 1946 waren es 51 Offiziere, 47 Soldaten und 35 US-Zivilisten, ${ }^{178}$ im Juli über 700 deutsche Mitarbeiter.

Am 27. April 1946 hatte es ein Essen gegeben zu Ehren derjenigen Offiziere, die vor Jahresfrist beim Einmarsch dabei gewesen waren und noch Dienst taten: Es waren noch sieben von damals 35 in der Enklave aktiv, also genau $20 \%$ des vorher speziell für die Aufgabe geschulten Führungspersonals. ${ }^{179}$

Am 1.September 1946 wies der Stellenplan 130 US-Positionen aus, von denen allerdings nur 105 besetzt waren (30 Offiziere, 21 Soldaten und 54 US-Zivilisten). Die Überleitung zahlreicher Funktionen der Besatzungsverwaltung in die Hănde ziviler Bediensteter war in vollem Gange. Die Zahl der bei der Militärregierung beschäftigten Deutschen erreichte mit 775 ihr Maximum.

Im Herbst 1946 wurde die 40-Stunden-Woche eingefürt bei gleichzeitiger Einschränkung der Überstundenvergütung. Direktor Gordon Browning beantragte am 5. Okto-

${ }^{176}$ Siehe OMGBR: Functional History 27.4.1945 - 30.6.1946, I, S. 20ff., OMGBR: Functional History 27.4.1945 - 30.6.1946, II, Appendix 6, OMGBR: Functional History 26.4.1945 30.9.1945, II, Appendix 1, sowie 6/105-1/4.

177 Für 1946 siehe OMGBR: Functional History 27.4.1945 - 30.6.1946, I, S.22 f., OMGBR: Functional History 1.7.1946 - 30.6.1947, I, S.2f., OMGBR: Functional History 1.9.1946 31.12.1946, I, S. 1 ff., sowie 6/67-1/21 und 5/372-3/18.

178 OMGBR: Functional History 27.4.1945 - 30.6.1946, 1, S. 22 nennt offensichtlich irrtümlich 320 deutsche Mitarbeiter für Ende Juni - gemeint waren vielleicht 620, da die Zahl im Juli bereits über 700 liegt und derartig starke kurzfristige Schwankungen im Beschäftigungsverhältnis einer besonderen Erklärung bedurft hätten.

179 Es handelt sich um Col. Bion C. Welker, Kommandeur des Detachments E2C2; Maj. Harold R. Bechtel, Branch Chief der Fiscal Branch; Maj. Marion A. Haguewood, zunächst Administrative and Executive Officer, später Leiter der Internal Affairs Branch, dann in der Public Safety Branch; Maj. John C. Sager, für Gesundheitswesen im Wesermünder Detachment zuständig; Capt. Blackburn W. Johnson, ebendort für Nahrungsmittelversorgung zuständig; Lt. Arthur L. Ballin, ebenfalls im Wesermünder Detachment zunächst Legal Officer, dann für Civil Administration zuständig; Lt. Arthur J. Waterman, zunächst in der Trade \& Industry Branch, dann in der Civil Administration Branch tätig. Vgl. OMGBR: Functional History 27.4.1945-30.6.1946, I, S.22f. 
ber 1946 bei OMGUS mit detaillierter Begründung die künftige Vermehrung der Planstellen für die Enklave auf 187 - vergeblich. Es blieb bei 130 Stellen, die bis zum Jahresende immerhin bis auf fünf besetzt werden konnten ( 32 Offiziere, 12 Soldaten, 81 US-Zivilisten). Erste Einsparungen wurden bei den deutschen Mitarbeitern vorgenommen, deren Zahl bis zum 31.Dezember 1946 auf 683 zurückging. ${ }^{180}$

Die aus der zweiten Jahreshälfte 1947 vorliegenden Zahlen zeigen eine verhaltene Abwärtsbewegung bei den US-Positionen, aber starke Rückgänge beim deutschen Personal. ${ }^{181}$ Am 1.Oktober 1947 waren noch 321, am 31. Dezember 1947 noch 292 Deutsche bei der Bremer Militärregierung beschäftigt - weniger als die Hälfte im Vergleich zum Vorjahr. Die US-Stellen wurden im Juli auf 119 gekürzt und blieben auf diesem Stand bis zum Jahresende, doch hatte man wieder mit Unterbesetzung zu kämpfen. Eine Aufstellung vom 31. Dezember 1947 weist 16 Vakanzen aus, das sind immerhin $13,5 \%$ der vorhandenen Stellen. Der Personalbestand setzte sich danach zusammen aus 30 Militärs und 73 US-Zivilisten. Auf Bremerhaven entfielen von den 119 Stellen nur 13 (oder $11 \%$ ).

In der ersten Jahreshälfte von 1948 beschleunigte sich der personelle Substanzverlust der Militärregierung: 102 Stellen am 1.März, 84 am 1. Mai, 61 am 15. Juli - noch am Vorjahresende waren es beinahe doppelt so viele gewesen. ${ }^{182}$ Die Zahl der deutschen Mitarbeiter sank weniger spektakulär von 289 Anfang März auf 223 Mitte Juli. Im Zusammenhang mit der für Juli 1948 in Aussicht gestellten Übernahme der Besatzungsverwaltung durch das State Department hatte OMGUS darauf gedrängt, das verbliebene militärische Personal durch ziviles zu ersetzen. Ende Juni 1948 standen nur noch fünf Militärs im Dienst der Militärregierung, am 27. Oktober hatten alle ausgedient bis auf einen: Charles R. Jeffs, Captain der US Navy und vom 30 . November an Chef der Militärregierung in Bremen. Am 30. November 1948 weist der Stellenplan noch 55 Positionen für Amerikaner und 201 für Deutsche aus, doch lag die tatsächliche Personalstärke nur bei 49 bzw. 178 Mitarbeitern, eine Unterbesetzung von ca. $11 \%$. Weniger Probleme mit der Stellenbesetzung hatten die ausgegliederten, aber verwaltungstechnisch der Bremer Militärregierung weiterhin verbundenen örtlichen Dienststellen von JEIA, BICO und OMGUS, an die man auch Personal hatte abgeben müssen. Vielleicht wurde dort besser bezahlt. Diese zugeordneten Dienststellen jedenfalls verfügten Ende November 1948 über 58 Positionen für Amerikaner und 118 für Deutsche, von denen nur eine bzw. sieben vakant waren. Am 1. Juli 1949 arbeiteten bei den zugeordneten Dienststellen in der Bremer Enklave 30 Amerikaner und 96 Deutsche - alle vorhandenen Stellen waren damit besetzt. Die Militärregierung selbst verfügte zu dem Zeitpunkt zwar über 40 Positionen für Amerikaner, hatte aber nur 33 unter Vertrag eine Fehlquote von 17,5\%. Für deutsche Mitarbeiter gab es noch 119 Stellen, von denen 113 besetzt waren.

Einige Auffälligkeiten zum Schluß: Klagen über mangelndes Verständnis für die Probleme der Enklave an höherer Stelle wurden auch auf dem Personalsektor laut. Anfangs monierte man monatelang ausbleibende Beförderungen und Auszeichnun-

180 OMGBR: Functional History 1.9.1946-31.12.1946, I, S. 2 f.; nach OMGBR: Functional History 1.7.1946 - 30.6.1947, I, S. 3 war allerdings die Zahl von über 700 deutschen Mitarbeitern im Juli bereits zum Jahresende halbiert worden; es ist anzunehmen, daB dieser Angabe ein MiBverständnis zugrunde liegt, z. B. Kalenderjahr statt richtig Berichtsjahr.

181 Für 1947 vgl. OMGBR: Functional History 1.7.1947-30.9.1947, I, S. 1; OMGBR: Functional History 1.10.1947-31.12.1947, I, S. 1, sowie 6/67-1/21.

182 Für 1948/49 vgl. OMGBR: Functional History 1.1.1948-31.12.1948, I, S. 5 ff., sowie Organisations- und Stellenpläne in 6/1-1/23, 6/1-2/1, 6/2-1/27, 6/58-1/19, 6/67-2/1. 
gen, ${ }^{183}$ später das Ausmaß von Stellenkürzungen und -herabstufungen. Daß man bei OMGUS Vergleiche mit dem amerikanischen Sektor von Berlin anstellte, wurde in Bremen mit spürbarer Entrüstung zur Kenntnis genommen, fühlte man sich doch mit Aufgaben eines Kalibers konfrontiert, das eher den Vergleich mit den süddeutschen Flächenstaaten zugelassen hätte. ${ }^{184}$ Wiederholt ist von der Schwierigkeit die Rede, unter diesen Voraussetzungen geeignetes Fachpersonal zu gewinnen und tatsächlich blieben ja zeitweise $10 \%$ und mehr der verfügbaren Stellen unbesetzt. Das mußte auf die Effektivität der Arbeit ebenso Auswirkungen haben wie die phasenweise starke Personalfluktuation, die allerdings kein Bremer Spezifikum darstellt. ${ }^{185}$ Schließlich sei noch einmal nachdrücklich darauf hingewiesen, daB bei jeder Bewertung der Tätigkeit und Wirkung der US-Militärregierung die große Zahl deutscher Mitarbejter berücksichtigt werden muB, Mitarbeiter, die nicht nur mit einfachen Dienstleistungen das Funktionieren des bürokratischen Apparates gewährleisteten, sondern z. B. als Sachbearbeiter Entscheidungen vorbereiten und durchaus beeinflussen konnten.

Ubersicht 8: Beschäftigtenzahlen im Überblick, OMGBR, 1946-1949

\begin{tabular}{rrr}
\multicolumn{1}{l}{ Datum } & US & Dt. \\
15.4 .1946 & 142 & 604 \\
1.9 .1946 & 130 & 775 \\
31.12 .1946 & 130 & 683 \\
1.10 .1947 & 119 & 321 \\
31.12 .1947 & 119 & 292 \\
1.3 .1948 & 102 & 289 \\
15.7 .1948 & 61 & 223 \\
31.12 .1948 & 57 & 201 \\
1.3 .1949 & 57 & 130 \\
1.7 .1949 & 40 & 119
\end{tabular}

183 OMGBR: Functional History 27.4.1945 - 30.6.1946, I, S. 35 .

184 Herbst 1947, OMGBR: Functional History 1.10.1947-31.12.1947, I, S.1.

185 Vgl. Gulgowski: American Military Government, S.257, 259. 


\section{B. Systematische Übersicht}

\section{Die einzelnen Aufgabenbereiche der Militärregierung in Bremen}

\section{Leitung und interne Verwaltung der Militärregierung}

\section{a) Der Direktor, sein Stellvertreter und sein Referent (Executive Officer)}

Kommandeur des Bremer Detachments E2C2 vom Zeitpunkt seiner Entstehung (27.Januar 1945) an und Militärgouverneur der Enklave war bis zum 20.September 1946 Lt.Col., dann Col. Bion C. Welker.' Er stammte aus Dauphin, Pennsylvania, und war im Zivilberuf Herausgeber einer Zeitung und leitender Mitarbeiter einer Rundfunkstation gewesen. ${ }^{2}$ Mit Ruhm bedeckt hat er sich in Bremen nicht. Nach einer kritischen Presseveröffentlichung des amerikanischen Journalisten Russell Hill in der Pariser Ausgabe des New York Herald Tribune entsandte der Kontrollrat im Juli 1945 eine Untersuchungskommission nach Bremen unter Leitung von Luther Steven Smith, Direktor der Abteilung für Zivile Verwaltung, die nach eingehenden Zeugenverhören die im Hinblick auf Senatsbildung, Entnazifizierung und Öffentlichkeitsarbeit erhobenen Vorwürfe allerdings nicht bestätigt fand. ${ }^{3} \mathrm{Zu}$ Weihnachten gab es gar ein Belobigungsschreiben für die in Bremen geleistete Arbeit vom Kommandierenden General der 7. Armee, Generalleutnant Geoffrey Keyes. ${ }^{4}$ Im April 1946 kam Welker um seine Entlassung ein, weil er mit der vorgesehenen Rückstufung zum Oberstleutnant nicht einverstanden war, und resümierte seine Bremer Erfahrungen in einem genau am 27. April. dem Jahrestag der Machtübemahme, datierten Schreiben an Clay, das alles im rosigsten Licht erscheinen läßt. Aus Clays Antwort sprechen Anerkennung und das Bestreben, ihn für die Militärregierung zu halten, was letztlich auch gelang. Die mit General Order Nr. 28, OMGUS, vom 7. Mai 1946 bekanntgegebene Ernennung von Robert K. Phelps zum Direktor der Bremer Militärregierung und Nachfolger Welkers war jedenfalls eine unbedeutende Episode, wenn sie überhaupt je wirksam geworden ist. ${ }^{5}$ In der Überlieferung der Bremer Militärregierung hat Phelps keine Spuren hinterlassen, und wenig später findet man Welker wieder im Amt.

Unregelmäßigkeiten und Unzulänglichkeiten im dienstlichen wie außerdienstlichen Verhalten führten jedoch gegen Ende seiner Amtszeit zu neuen Untersuchungen, die Col. Pearson vom USFET-Hauptquartier durchführte und deren Ergebnis den Bre-

${ }^{1}$ OMGBR: Functional History 27.4.1945 - 30.6.1946, I, S.1; OMGBR: Functional History 1.9.1946 - 31.12.1946, II, Appendix 1 b. Unter Berufung auf ein Telegramm von Clay vom 20.9.1946 als Zivilist an das OMGUS-Hauptquartier versetzt, Special Order Nr. 74, OMGBR, vom 23.9.1946 (6/69-2/2).

2 6/125-2/10; Special Report, Juli 1945, S. 47 (StA Bremen 16, 1/4); geb. 30.6.1894, gest. 17.11.1978 (Auskunft National Personnel Records Center, St. Louis).

3 Verhöre vom 21. - 24.7.1945 (StA Bremen 16, 1/4). Der Untersuchungsauftrag wurde erteilt und spezifiziert am 15.7.1945 vom Chief of Staff Bryan L. Milburn (AG 1945-46/79/7).

4 AnläBlich des Wechsels der Militärregierung zu Bremen Port Command, OMGBR: Functional History 27.4.1945 - 30.6.1946, II, Appendix 5.

5 5/358-3/9, 5/372-3/18 und AG 1945-46/67/5. 
mer Amtsnachfolger Gordon Browning zur Anklageerhebung veranlaßte. Die Anklage wurde später zurückgezogen. Nach einem Bericht der Bremer Criminal Investigations Division befanden sich die Beweisstücke mit der Mehrzahl der an den Vorkommnissen Beteiligten - Zeugen wie Beschuldigten - mittlerweile in den Vereinigten Staaten, so daß für eine Verurteilung ausreichende Beweise nicht beizubringen waren. Ende Januar 1947 lag Welker in einem Bremer Krankenhaus und wartete auf seinen Abtransport in die Heimat. ${ }^{6}$

Sein Executive Officer Joseph W. Shamel trat ähnlich unrühmlich hervor. Ende März 1945 zum Detachment gekommen, avancierte er im Sommer 1945 vom Major zum Lt.Col. und wurde während eines längeren Heimaturlaubs von Welker zu dessen Stellvertreter ernannt (23. November 1945 - 12. Februar 1946). ${ }^{7}$ Am 3. September 1946 erneut zum kommissarischen Vertreter des Direktors berufen, ${ }^{8}$ stand er am Ende des Monats bereits unter Hausarrest und wurde unter der Anklage, Teile des Bremer Ratssilbers unterschlagen zu haben, im Dezember vor ein Kriegsgericht gestellt. Wegen Mangels an Beweisen freigesprochen, wurde er mit anderen Beteiligten in die USA zuruickgeschickt und aus der Armee entlassen.9

Bis etwa Oktober 1945 hatte Lt.Col. Douglas W. Meservey als Stellvertreter Welkers fungiert. ${ }^{10}$ Als Stellvertreter und designierter Nachfolger wird am 20 . April $1946 \mathrm{Col}$. Pendleton bezeichnet. ${ }^{11}$ Am 23. August 1946 wird Col. John J. Burns in der Stellvertreterposition genannt. ${ }^{12}$

Lt.Col. Gordon Browning $\mathrm{CAC},{ }^{13}$ von Haus aus Jurist und Politiker, ubernahm am 20. September 1946 das Bremer Kommando. ${ }^{14}$ Er blieb nur bis zum 10. Dezember 1946, um dann in den USA ein Amt als Richter anzutreten. ${ }^{15}$ Abgelöst wurde er von Thomas F. Dunn, der bereits seit dem 1. Dezember 1946 als Stellvertreter amtierte. ${ }^{16}$ Dunn kam aus der War Shipping Administration und hatte schon im Juni 1945 an Ver-

${ }^{6}$ Die Zeitschrift Stars \& Stripes berichtete in Nr. 297 vom 26.10.1946 von dem Verfahren gegen Welker u. a. wegen Behinderung der Justiz, ungebührlichen Verhaltens, Schädigung des Ansehens der Armee durch Trunkenheit und MiBbrauch von Hilfsgütersendungen des Roten Kreuzes (6/125-2/10). Die Vorfälle erwähnt auch Gulgowski: American Military Government, S.242f. Die übrigen Einzelheiten enthält ein Bericht des Chief of Staff C.K. Gailey vom 23.1.1947 (AG 1947/19/4).

${ }^{7}$ OMGBR: Functional History 27.4.1945 - 30.6.1946, I, S.2, 17, 19; Nachweise für den 1.7.1945 und 15.1.1946 OMGUS-Hb, Bremen, Übersicht 3 und 4.

${ }^{8}$ General Order Nr. 3, OMGBR, vom 3.9.1946 (6/69-2/1).

9 6/125-2/10; Shamel kam aus Mount Caroll, Illinois (ebenda). Der gröBte Teil des Ratssilbers konnte sichergestellt werden, doch waren 26 Silberteller und etwa ebenso viele Mokkalöffel als ungeklärter Verlust zu buchen (StA Bremen 9, S O-2602).

$10 \mathrm{Vgl.} \mathrm{z.} \mathrm{B.} \mathrm{Personalliste} \mathrm{vom} \mathrm{31.5.1945} \mathrm{(6/105-1/4).}$

11 Report of Trip to Bremen (5/372-3/16). Pendleton war noch im Januar 1946 Leiter der Internal Affairs \& Communications Division, OMGUS.

12 General Order Nr.2, OMGBR, vom 23.8.1946 (6/69-2/1). Burns schied am 7.9.1946 in Bremen aus (OMGBR: Functional History 1.9.1946 - 31.12.1946, II, Appendix 1 b).

${ }^{13}$ Geboren 22.11.1889 in Carroll Co., Tennessee; KongreBabgeordneter (Demokraten), dann Gouverneur von Tennessee 1937 - 1939 und wieder ab 1949; vgl. OMGBR: Functional History 1.9.1946 - 31.12.1946, I, S. 1 und Who's Who in United States Politics and American Political Almanac, S. 51 .

14 General Order Nr. 4, OMGBR, vom 20.9.1946 (6/69-2/1).

15 OMGBR: Functional History 1.9.1946 - 31.12.1946, I, S. 1; General Order Nr.6, OMGBR, vom $10.12 .1946(6 / 69-2 / 1)$.

${ }^{16}$ Ebenda; Special Order Nr. 88, OMGBR, vom 19.11 .1946 (6/2-3/4). 
handlungen in Bremen teilgenommen. ${ }^{17}$ Er war also ein Schifffahrtsexperte, dem die örtlichen Verhältnisse zumindest nicht fremd waren. Dasselbe gilt für Capt. Charles $R$. Jeffs USN, der am 6. März 1947 zum stellvertretenden Direktor emannt wurde. ${ }^{18}$ Der Marineoffizier hatte seit Herbst 1945 den amerikanischen Flottenstützpunkt Bremen befehligt und wurde frei für neue Aufgaben, als wesentliche Funktionen der Marine in den Bereichen Werftenkontrolle und Sicherung der Schiffahrtswege auf OMG Bremen übergegangen waren. ${ }^{19}$ Das Gespann Dunn/Jeffs harmonierte gut mit Wilhelm Kaisen $^{20}$ und brachte viel Verständnis auf für die Interessen der bremischen Häfen und Werften. Dunn stellte am 30. November 1948 sein Amt zur Verfügung, um einen Posten in der Privatwirtschaft zu übernehmen, so daß nun Jeffs an die Spitze der Bremer Militärregierung trat, ${ }^{21}$ der künftig ohne einen fest bestallten Vertreter auskam. Er blieb bis 1952 - schlieBlich als Rear Admiral und Landeskommissar - führender Vertreter der amerikanischen Besatzungsmacht in Bremen, nahm dann bei der Marine seinen Abschied, heiratete 1953 in dritter Ehe eine Bremerin und ließ sich für die folgenden Jahre als Repräsentant einer kalifornischen Firma in der Stadt nieder, die er gerne als seine zweite Heimat bezeichnete. Hier ereilte ihn 1959 auch der Tod. ${ }^{2}$ Als Executive Officer des Direktors Dunn diente Lt.Col. James R. Case, ${ }^{23}$ als dessen Nachfolger Joseph L. Payette. ${ }^{24}$

${ }^{17}$ StA Bremen 4. 116-6; geb. 27.5.1903, gest. 26.10.1964 bei einem Besuch in Bremen. Dunn war nach 1948 als Schiffsmakler tätig (StA Bremen 3-R.1.m.Nr.117 [2]). Die War Shipping Administration verfügte über ein eigenes Büro und erheblichen EinfluB in Bremen; sie war dem State Department unterstellt (5/372-3/16).

${ }^{18}$ Special Order Nr.17, OMGBR, vom 6.3.1947 (6/2-3/5); er amtierte offenbar schon vorher, seit Januar 1947, vgl. OMGBR: Functional History 1.7.1946 - 30.6.1947, I, S. 1 f.

19 Siehe OMGUS-Hb, Bremen B.7.

$20 \mathrm{Vgl}$. Zuversicht und Beständigkeit, S. $89 \mathrm{f}$.; Begegnungen mit Kaisen, S. $183 \mathrm{ff}$. Das Verhältnis zu Welker war nicht so gut gewesen - Kaisen warf ihm seine Zusammenarbeit mit Vagts und seinen herrischen Befehlston vor (Kaisen: Meine Arbeit, S. 186 und 204 f.).

${ }^{21}$ General Order Nr. 10, OMGBR, vom 30.11 .1948 (6/69-2/1); OMGBR: Functional History 1.1.1948-31.12.1948, I, S. 10 .

22 StA Bremen 3-R.1.m.Nr.351 [14]. Jeffs, geb. 20.1.1893 in Brooklyn, New York, machte Karriere bei der Marine, diente im 1. Weltkrieg in Irland und danach bei der U-Bootwaffe; erwarb ein Ingenieurdiplom, mit dem er zum Leitenden Ingenieur des Schlachtschiffes „California“, dann einer Marinewerft aufstieg. 1938 - 1942 war er im Fernen Osten im Einsatz, zunächst als Kommandant eines Kanonenbootes, dann als Stabschef bei der 8 . Flotte. Nach zweijähriger Unterbrechung kehrte er als Kommandant des Flaggschiffes „Appalachian" auf den pazifischen Kriegsschauplatz zurück. Im Juli 1945 nach Europa kommandiert, kam Jeffs am 10.8.1945 nach Bremen, um vier Wochen später das Kommando der US Naval Advanced Base Bremen zu übernehmen (Bremer Biographie 1912 - 1962, S. 260f.). Das vorherrschende Interesse von Jeffs an Schiffahrtsfragen machte der ehemalige Leiter der Entnazifizierungsabteilung, Joseph F. Napoli, in einem Gespräch mit dem Verf. am 13.6.1980 durch die scherzhaft-hintersinnige Bemerkung deutlich, der (politische) Weitblicks Jeffs' sei eben der eines U-Bootfahrers gewesen - auf Tauchfahrt!

${ }^{23}$ Kam am 8.10.1946 zur Bremer Militärregierung, OMGBR: Functional History 1.9.1946 31.12.1946, II, Appendix 1 b; wurde am 15.9.1947 zu OMG Bavaria versetzt, OMGBR: Functional History 1.7.1947 - 30.9.1947, I, S.1.

${ }^{24}$ Kam als Zivilist am 19.9.1946 zur Bremer Militärregierung (OMGBR: Functional History 1.9.1946 - 31.12.1946, II, Appendix 1 b), und Ubernahm die Leitung der Civilian Transportation Branch, Civilian Services Division (6/23-2/7); seit dem 15.9.1947 für Case Executive Officer (OMGBR: Functional History 1.7.1947 - 30.9.1947, I, S. 1). 


\section{b) Pressestelle (Public Information Office)}

Beinahe zwei Jahre lang mußte die Bremer Militärregierung ohne einen hauptamtlichen Presseoffizier auskommen. Zweifel an ihrer Öffentlichkeitsarbeit konnten bei der Untersuchung im Juli 1945 durch den Hinweis zerstreut werden, daß sowohl der Kommandeur persönlich als auch ein Assistent des Exekutivoffiziers, Thomas P. Headen, über langjährige Berufserfahrungen im Pressewesen verfügten. ${ }^{25}$ So erscheint die Position eines Fachoffiziers für Public Relations erstmals im November 1946 im Bremer Organisationsplan; ${ }^{26}$ die Stellenbesetzung zog sich dann noch bis in den Februar 1947 hin. Robert B. Redlich, erster Stelleninhaber, war zunächst der Information Control Division zugeordnet, wurde aber gegen Ende Mai 1947 dem Direktor unmittelbar unterstellt. Seine Amtsbezeichnung lautete, wie üblich, Public Information Officer. ${ }^{27}$ Redlich konnte die Zusammenarbeit mit der Presse - gemeint ist vor allem die amerikanische - deutlich verbessern. Er verlieB Bremen zum 30 . Juni $1948^{28}$ und wurde ersetzt durch Howard W. Calkins, der bis zum Sommer 1949 die Pressestelle leitete. Sie blieb von der Reorganisation der Militärregierung im Herbst 1948 beinahe unberührt. ${ }^{29}$ Am 30 . Juni 1949 wurde verfügt, daß die Stelle des Public Information Officer künftig wieder nebenamtlich besetzt werden sollte..$^{30}$

Bei der Pressestelle war auch die vorgeschriebene Berichterstattung über die Arbeit der Militärregierung angesiedelt, aus der die periodischen, teils recht umfangreichen Tätigkeitsberichte hervorgingen. ${ }^{31}$

\section{c) Interne Verwaltung, Haushalt, Personal}

Nach der Planung vom März 1945 sollten für die innere Verwaltung des Bremer Detachments der Headquarters Commandant und ein Administrative Officer Sorge tragen. Der „Quartiermeister“ sollte sich um Personalfragen, Verpflegung und Versorgung, den Kraftfahrzeugpark u. ä. kummern, der Verwaltungsoffizier Telefonzentrale, Registratur und Bibliothek betreuen, die Schreibkräfte mit Bürobedarf versorgen und die interne Kommunikation in Gang halten (Message Center). ${ }^{32}$ Seine Rolle erinnert an einen Bürovorsteher. Die Gliederung in diese zwei Bereiche bildete im tatsächlich realisierten Verwaltungsaufbau lange Zeit die organisatorische Grundstruktur.

Im ersten Jahr schwankt die personelle Besetzung beider Bereiche zwischen insgesamt drei und fünf Offizieren. Lt. Paul E. Roche, als Headquarters Commandant Anfang Juni 1945 genannt, hatte am 1. Juli zwei weitere Offiziere an seiner Seite, im Januar 1946 noch einen: Lt. Robert G. Moorhead, der die Sache Anfang März dann wieder allein machte. In der Verwaltung war Lt. Robert T. Wright 1945 zunächst zweiter Mann, um im Frühjahr

${ }^{25}$ Special Report, Juli 1945, Conclusions (StA Bremen 16, 1/4); siehe OMGUS-Hb, Bremen B, Anm. 2 (Welker) und Anm. 100 (Headen).

${ }^{26}$ Siehe OMGUS-Hb, Bremen A, Übersicht 5.

${ }^{27}$ OMGBR: Functional History 1.7.1946 - 30.6.1947, I, S. 172.

${ }^{28}$ Empfehlungsschreiben vom 1.7.1948 (6/46-3/15).

${ }^{29} \mathrm{Sie}$ wird in General Order Nr.7, OMGBR, vom 14.9.1948, ausdrücklich als unveränderte Organisationseinheit genannt, erscheint aber auf dem dazugehörigen Organisationsplan erstmals mit dem Bremerhavener Liaison \& Security Detachment graphisch zusammengefügt. Außerdem ist der Executive Officer jetzt unmittelbarer Vorgesetzter (6/69-2/1).

${ }^{30}$ General Order Nr. 12, OMGBR, vom 30.6.1949 (ebenda).

31 Siehe dazu ausführlich Röpcke: Dienstberichte, S. 312.

32 Siehe OMGUS-Hb, Bremen A, Übersicht 2. 
1946 ein Dreier-Team anzuführen. ${ }^{33}$ Im Juni meldete Welker nach Berlin, daB der bisherige Verbindungsoffizier in Hannover, Lt.Col. Brown, den Lt. Smith in der Verantwortung für Verwaltung und Finanzen abgelöst habe. Ein Besuch des Kontrolloffiziers hatte Mängel in diesem Bereich zutage gefördert. ${ }^{34}$ Im Sommer 1946 erhielt der Verwaltungschef die Bezeichnung „Adjutant“. Mit der Ernennung von Moorhead zum Adjutanten und Leiter der Administrative Services Division am 20. August 1946 erfolgte eine erste organisatorische Zusammenfassung der beiden Bereiche, ${ }^{35}$ die aber den Weggang des Abteilungsleiters am 12. Oktober $1946^{36}$ nicht überstand: Der Organisationsplan vom November 1946 zeigt eine Zersplitterung in vier Segmente, in dem neben dem Headquarters Commandant das Personalburo, die Nachrichtenzentrale und das Haushalts- und Rechnungswesen jeweils gesondert aufgefuhrt werden. ${ }^{37}$

Fur ein gutes halbes Jahr standen dann Personnel Office, Adjutant's Office und Fiscal \& Supply Branch nebeneinander, ${ }^{38}$ bis im Juni 1947 Versorgung und Bewirtschaftung einschließlich Fachpersonal an die Spezialeinheit in Bremerhaven abgegeben wurden. ${ }^{39}$ Danach war mit gewissen Modifikationen der alte Dualismus von Personal- und Verwaltungschef wiederhergestellt. Der Gesamtbereich gehörte mit 19 von 130 USStellen Ende 1946 zu den personalstärksten der Militärregierung und konnte diese Position trotz des Aderlasses im Sommer 1947 mit 14 von 106 US-Stellen (ohne Bremerhaven) Ende 1947 in etwa behaupten.40

Das schrittweise Ausgliedern des militärischen Personals in der ersten Jahreshälfte von 1948 machte eine Sektion des Personalbüros überflüssig, und auf dem Organisationsplan vom 1.Juni 1948 sind Personal und Verwaltung erstmals graphisch zusammengefaBt. ${ }^{41}$ Die offizielle Zusammenlegung zur Personnel \& Administrative Branch erfolgte mit der großen Reorganisation am 15. September 1948, wobei Military Personnel Branch und Adjutant's Office aufgelöst wurden. ${ }^{42}$ Anfang 1949 entstand daraus noch einmal eine Abteilung, die Administration \& Personnel Division, ${ }^{43}$ unter der Leitung von Robert L. R. Marshall, der gleichzeitig als Budget \& Fiscal Officer fungierte. ${ }^{44}$ Diese letztere Aufgabe hatte vom 6. November 1946 bis 31 . Juli 1947 auch Joseph F. Napoli wahrgenommen, ehe er zum Leiter der Bremer Entnazifizierungsabteilung avancierte. ${ }^{45}$ Später regelte er die Haushaltsbelange nebenamtlich. ${ }^{46}$

${ }^{33}$ Vgl. Personalliste vom 1.6.1945 (6/105-1/4); OMUGS-Hb, Bremen A, Übersicht 3 und 4; Telefonverzeichnis vom 1.3.1946.

34 AG $1945-46 / 64 / 9$ und 5/372-3/16.

35 OMGBR: Functional History 1.7.1946 - 31.8.1946, I, S. 1. Detaillierter Personal- und Organisationsplan der Abteilung in 6/46-2/19.

36 OMGBR: Functional History 1.9.1946 - 31.12.1946, II, Appendix $1 \mathrm{~b}$.

37 OMGUS-Hb, Bremen A, Übersicht 5.

38 Zuletzt auf dem Organisationsplan vom 1.7.1947 (6/67-1/21).

39 OMGBR: Functional History 1.7.1947 - 30.9.1947, I, S. 1; dieser Verschiebung fielen zahlreiche Stellen für deutsche Mitarbeiter zum Opfer (ebenda).

${ }^{40}$ OMGBR: Functional History 1.9.1946-31.12.1946, I, S. 2; 6/67-1/21.

41 Ebenda.

${ }^{42}$ Letzteres erst am 30.10.1948, General Order Nr. 7 und 8, OMGBR, vom 14.9. und 29.10.1948 (6/69-2/1).

43 Auch: Administrative \& Personnel Division; erscheint auf dem Organisationsplan vom 1.3.1949 (6/58-1/19) und im April 1949 im OMGUS Information Bulletin; offiziell bekannt gemacht erst mit General Order Nr. 12, OMGBR, vom 30.6.1949 (6/69-2/1).

44 OMGUS Information Bulletin, April 1949, S.8.

45 OMGUS-Hb, Bremen B.3.

${ }^{46}$ Seit 1.6.1948 auf den Organisationsplänen vermerkt (6/67-1/21). 


\section{Inneres (Civil Administration, Public Safety, Intelligence, Information [Control])}

\section{a) Civil Administration}

Die beiden beim Einmarsch für Regierung und Verwaltung Bremens zuständigen Offiziere, Capt. Erwin W. Bard und sein Vertreter, Capt. John A. André, gehörten zur Kernmannschaft des Detachments, die bereits das Trainingsquartier in Frankreich gemeinsam absolviert hatte. Der Planung nach sollten sie direkt dem stellvertretenden Kommandeur Meservey verantwortlich sein. Formal wurde das Referat dann zwar den anderen gleichgestellt, doch blieben von der Aufgabenstellung her enge Beziehungen zum Kommandeur erhalten, da Bard praktisch als Verbindungsoffizier zum Präsidenten des Bremer Senats fungierte und sich von August 1945 an täglich mit diesem besprach. ${ }^{47}$ In den schwierigen Fragen der ersten Regierungsbildung hatte allerdings der Anfang Mai angereiste Prof. Walter L. Dorn, Sonderbeauftragter von USFET G-5-Chef General Adcock, wichtige Personalentscheidungen vorbereitet und den Kommandeur beraten. ${ }^{48}$ Als von August bis November 1945 ein Bremen Operations Team vom für die ganze Enklave zuständigen Personal abgesondert wurde, gehörte Bard mit seinem Assistenten dazu. Supervisionsaufgaben auf Enklavenebene erhielt Major Harold H. Crabill. ${ }^{49}$ Anfang Oktober 1945 wurde Civil Administration mit der neugeschaffenen Denazification Branch zusammengefaBt, um Ende November mit der direkten Zuordnung zum Kommandeur nahezu in die Ausgangslage zurückzukehren. ${ }^{50}$ Bard, seit Dezember 1945 Major, erscheint zwar noch als Leiter der Civil Administration Branch auf dem Organisationsplan vom 15. Januar 1946, ${ }^{51}$ doch führte die Geschäfte seit Mitte Dezember 1945 bereits sein Vertreter Lt. Arthur J. Waterman, der dann bis Oktober 1947 verantwortlicher Fachoffizier blieb. ${ }^{52}$

Einen organisatorischen Einschnitt gab es Ende Februar 1946, als die Civil Administration Branch zur City Administration Section umgewandelt wurde und zusammen mit dem Kulturbereich die Civil Government Branch unter Capt. J. H. Baynard bildete. Das Referat wurde bereits einen Monat später zur Abteilung erhoben, die nun Major John C. Sager leitete, bis im Mai Harold H. Crabill, inzwischen Oberstleutnant, aus den USA zurückkehrte und die Leitung übernahm. ${ }^{53}$ Ende November 1946 hatte die Civil Administration Branch ihre Bezeichnung wieder. ${ }^{54}$ Am 7. Juni 1947 wurde die Civil Government Division aufgelöst und aus ihren beiden Hauptbestandteilen eigene Abteilungen gebildet, die Civil Administration Division und die Education Division. ${ }^{55}$

${ }^{47}$ OMGBR: Functional History 27.4.1945 - 30.6.1946, I, S. 1 und 51 f.; vgl. OMGUS-Hb, Bremen A, Übersicht 2 und 3; Protokolle der Besprechungen in StA Bremen 3-R.1.m.Nr.390.

48 Vgl. Dorn: Inspektionsreisen, S. 39 ff;; Begegnungen mit Kaisen, S. 179 f.

49 OMGBR: Functional History 27.4.1945 - 30.6.1946, I, S. 51.

So Ebenda, S. 52 .

51 6/83-2/5. Bard machte Anfang April 1946 beim Kontrollrat Dienst (StA Bremen 16, 1/3-5); der in dieser Beziehung nicht immer zuverlässige Wulff: Im Jahrfünft, S.9, bezeichnet ihn als "Professor fúr politische Wissenschaften“.

52 OMGBR: Functional History 27.4.1945 - 30.6.1946, I, S.52; Waterman kam im September 1945 ins Referat; anfangs gehörte er dem Bereich Trade \& Industry des Bremer Detachments an $(6 / 105-1 / 4)$.

53 OMGBR: Functional History 27.4.1945 - 30.6.1946, I, S. $53 \mathrm{f}$.

54 OMGUS-Hb, Bremen A, Übersicht 5.

55 General Order Nr. 5, OMGBR, vom 7.6.1947 (6/69-2/1). 
Diese Regelung hatte ein gutes Jahr Bestand. Mit Wirkung vom 20. Juli 1948 wurde die Abteilung aufgelöst, der Civil Administration Adviser geriet mit den Bereichen Gesundheit, Wohlfahrt, Sicherheit und Entnazifizierung in eine Abteilung, die zunächst Governmental Affairs, wenig später dann Public Affairs \& Legal Division genannt wurde. ${ }^{56}$ An die Funktionen des Fachoffiziers für zivile Verwaltung als Verbindungsmann zum Bremer Senat knüpfte man Ende $1947^{57}$ und noch einmal Ende 1948 nachdrücklich an, indem den Fachabteilungen untersagt wurde, auf direktem Wege den deutschen Fachbehörden Anweisungen zu erteilen; vielmehr sollte der Dienstweg über den Direktor der Militärregierung und den Senat eingehalten werden, wobei die Kontakte zum Senat über den Civil Administration Adviser zu laufen hätten. ${ }^{58}$

Aus einer Zusammenfassung mit dem nachrichtendienstlichen Bereich entstand am 30. Juni 1949 noch einmal eine Civil Administration \& Intelligence Division, ${ }^{59}$ die jedoch nur noch in der Person des Abteilungsleiters und seiner Sekretärin amerikanisches Personal aufzuweisen hatte, während alle übrigen Aufgaben der zwei Fachbereiche und diversen Sektionen von sieben deutschen Angestellten wahrgenommen wurden. ${ }^{60}$ Abteilungsleiter Clarence $P$. Oakes war erst 1949 nach Bremen gekommen, blieb aber als politischer Berater des Landeskommissars noch bis $1952 .^{61}$ Nachfolger von Waterman war im Herbst 1947 Ernest A. Flotow geworden, ${ }^{62}$ der am 2. Juni 1948 ausschied und die Abteilungsleitung an Dale D. Clark abgab. ${ }^{63}$ Dieser hat noch Ende November 1948 das Amt des Civil Administration Adviser bekleidet, ${ }^{64}$ den Jahresbericht für 1948 verfaßte Anfang 1949 jedoch bereits ein Vertreter. ${ }^{65}$ Noch im April 1949 war die Position vakant, bis mit Clarence P. Oakes ein neuer Mann gewonnen werden konnte.

so General Order Nr. 7 und 9, OMGBR, vom 14.9. und 30.11.1948 (ebenda).

57 "In order to bring about the greatest degree of coordination, the CAD was designated as the channel for all important communication to the German authorities, such as Military Government Regulations and important correspondence" (OMGBR: Functional History 1.10.194731.12.1947, I, S.2.

58 OMGBR: Functional History 1.1.1948 - 31.12.1948, I, S. 11.

59 General Order Nr. 12, Change 1, OMGBR, vom $13.7 .1949(6 / 69-2 / 1)$.

${ }^{60} 6 / 2-1 / 24$.

${ }^{61}$ Begegnungen mit Kaisen, S. 189; Oakes stammt aus Independence, Kansas, und saß für die Republikaner im Senat von Kansas. Er war schon vor dem Krieg mehrfach in Bremen gewesen und hatte in Heidelberg studiert. 1945/46 als Marineoffizier in Bremen; rege Teilnahme am gesellschaftlichen Leben (Ehrenmitglied des „Plattdütschen Vereen“, Präsident des Deutsch-Amerikanischen Clubs, Mitglied der Carl-Schurz-Gesellschaft und des Rotary Club); verlieB Bremen Ende März 1952 51jährig, um in Washington D.C. neue Aufgaben zu übernehmen (Weser-Kurier 21.3.1952, Bremer Nachrichten 25.12.1952); 1970 am Institute for American Strategy in Chicago tätig (StA Bremen WA 1970/76).

62 Traf am 20.9.1946 aus den USA ein, um in der Civil Government Division zu arbeiten (6/217; OMGBR: Functional History 1.9.1946 - 31.12.1946, II, Appendix 1 b); kommt aus New Lenox, Illinois, und war in der öffentlichen Schulverwaltung beschäftigt; übernahm am 10.10.1946 die Education \& Religious Affairs Branch (Clifton: Reform of Education, S. 143). erscheint Ende November 1947 als kommissarischer Leiter der CAD, im Januar 1948 als Leiter (6/90-1/5).

${ }^{63}$ OMGBR: Functional History 1.1.1948-31.12.1948, I, S.8.

64 So am 27.11.1948 (StA Bremen 3-R.1.m.Nr.117).

${ }^{65}$ Der Nachrichtendienstoffizier Nicholas Metal; siehe OMGBR: Functional History 1.1.1948 31.12.1948, I, S. 10. 


\section{b) Public Safety}

Die Public Safety Branch mit Polizei und Feuerwehr als den wichtigsten Zuständigkeitsbereichen bezog nach dem Einmarsch Quartier im Polizeihaus Am Wall. Die Aufrechterhaltung von ,law and order' stand nach eigenem Bekunden in der ersten Zeit im Vordergrund. ${ }^{66}$ Ende Mai 1945 gab es außer den zwei Sicherheitsoffizieren in Bremen zwei in Wesermünde und drei weitere in den kleineren Detachments der Enklave. ${ }^{67}$ Major E. Russel Kennedy, der das Sachgebiet in Bremen anfangs leitete, wurde am 5.Juni 1945 von Major Marion A. Haguewood abgelöst, ${ }^{68}$ der wie sein Vorgänger schon seit der Vorbereitungsphase zur Kernmannschaft des Detachments gehörte.$^{69} \mathrm{Im}$ August wurde Haguewood auf Enklavenebene für die öffentliche Sicherheit zuständig, im Januar 1946 erscheint er als Leiter der Internal Affairs Branch, in dem Post-und Verkehrswesen, Justiz und öffentliche Sicherheit zusammengefaBt waren, um schließlich die Leitung der Internal Affairs \& Communications Division zu übernehmen, die nach der Heraustrennung des Verkehrswesens Ende April 1946 hauptsächlich aus Legal Branch und Public Safety Branch bestand. ${ }^{70}$ Letztere hatte als Nachfolger Haguewoods Major John O. Dale von Ende August bis Mitte September 1945 geführt; er übernahm die Aufgabe erneut am 13. März 1946 und behielt sie bis zu seiner Versetzung am 13. Mai 1947. ${ }^{71}$ Zwischenzeitlich waren im September 1945 noch einmal Major Kennedy und im Anschluß daran Capt. Ellis L. Forrester Leiter des Bereichs Public Safety. ${ }^{\text {2 }}$

Bei der Auflösung der Internal Affairs \& Communications Division im Sommer 1946 entstand neben der Legal Division auch eine Public Safety Division mit den zwei Bereichen Entnazifizierung und öffentliche Sicherheit. Abteilungsleiter wurde der schon als Mitarbeiter von Major Haguewood erprobte Major John W. Boyd. ${ }^{73}$ Ende 1946 gehörte die Abteilung mit 18 von 130 vorhandenen Stellen für Amerikaner zu den größten in der Bremer Militärregierung. ${ }^{74}$

Die Verantwortlichkeit für die Sicherheit auch im Hafengebiet Bremens war im April 1946 an die deutsche Polizei zurückgegeben worden; ${ }^{75}$ das von den Ausländerlagern, insbesondere den Polen, ausgehende Sicherheitsproblem entschärfte sich. ${ }^{76}$ Vorläufig

${ }^{66}$ OMGBR: Functional History 27.4.1945 - 30.6.1946, I, S.91.

${ }^{67}$ Personalliste vom $31.5 .1945(6 / 105-1 / 4)$.

68 OMGBR: Functional History 27.4.1945 - 30.6.1946, II, Appendix 27.

${ }^{69}$ OMGBR: Functional History 27.4.1945 - 30.6.1946, I, S. 1.

${ }^{70}$ OMGBR: Functional History 27.4.1945 - 30.6.1946, II. Appendix 27; Organisationsplan vom 15.1.1946 (6/83-2/5); Organisationsplan (6/37-2/10).

71 OMGBR: Functional History 27.4.1945 - 30.6.1946, II, Appendix 27; OMGBR: Functional History 1.7.1946 - 30.6.1947, I, S.51.

72 OMGBR: Functional History 27.4.1945 - 30.6.1946, II, Appendix 27; Forrester wurde am 12.3.1946 nach Bremerhaven/Wesermünde beordert, wo er am 20.2.1948 das Amt des Port Security Officers übernahm, siehe OMGBR: Functional History 1.1.1948- 31.12.1948, I, S. 21. Kennedy hat trotz seiner relativ kurzen Amtszeiten als zuständiger Polizeioffizier - zwischendurch war er im Transportwesen beschäftigt - auf deutscher Seite nachhaltig beeindruckt. Brandt: Antifaschismus, S. 126, charakterisiert ihn als rigorosesten Vertreter eines repressiven Kurses gegen die organisierten Antifaschisten, und Erich Vagts, dem das ja nur recht gewesen wäre, bezeichnet ihn rückblickend als großen „Deutschenfresser, der gegen jeden und jedes lediglich MiBtrauen hatte" (StA Bremen 7,29-5, S.11).

${ }^{73}$ General Order Nr.5, OMGBR, vom 10.10.1946 (6/69-2/1), siehe OMGUS-Hb, Bremen A, Übersicht S).

${ }^{74}$ OMGBR: Functional History 1.9.1946 - 31.12.1946, I, S. 3.

75 OMGBR: Functional History 27.4.1945 - 30.6.1946, I, S. 102 f.

${ }^{76}$ Ebenda, S. 98 f. 
verbliebene Aufgaben wie die nach britischen Richtlinien erforderliche Genehmigung politischer Versammlungen und die Erteilung von Reisegenehmigungen ließen sich routinemäBig abwickeln. ${ }^{77}$

Nach der Etablierung einer eigenen Entnazifizierungsabteilung am 22. März $1947^{78}$ umfaBte die Abteilung im Sommer 1947 nur noch die Public Safety Branch, die daraus abgespaltene Fire Fighting Branch und zwei Offiziere für Port Security. ${ }^{79}$ Letztere wurden zusammen mit der Marine Security Branch, der Kontrollstelle für die Wasserschutzpolizei, die erst am 15. Dezember 1947 von der Transport Division an die Public Safety Division überwiesen worden war, mit Wirkung vom 1. Mai 1948 in die neue „Abteilung Waterkant", die Waterfront Division, eingebracht. Die Auflösung der Public Safety Division erfolgte allerdings erst mit der Reorganisation der Militärregierung am 15.September 1948. Der Public Safety Adviser, der Berater für Fragen der öffentlichen Sicherheit, fand sich mit Kollegen aus den Bereichen zivile Verwaltung, Entnazifizierung, Gesundheit und Wohlfahrt in einer Abteilung wieder, die zunächst den Namen Governmental Affairs Division erhielt, ${ }^{80}$ aber schon Ende November unter Hinzufuigung des Justizbereichs zur Public Affairs \& Legal Division umgestaltet wurde, wobei dem Public Safety Adviser die Aufsicht über das Gefängniswesen als neue Aufgabe zufiel. ${ }^{81}$ Diese Konstruktion, die an das Konglomerat der Internal Affairs Branch Anfang 1946 erinnert, hatte bis zum 30.Juni 1949 Bestand; dann wurden Abteilung und Position des Public Safety Adviser aufgelöst. Der Sachbereich wurde in der Folge nur noch nebenamtlich im Rahmen der neukonstituierten Civil Administration \& Intelligence Division betreut. ${ }^{82}$ Seinen Dienst in Bremen beendete damit auch John S. Baber, der als ziviler Bediensteter am 4.September 1946 in die Bremer Public Safety Branch eingetreten war und deren Leitung als Nachfolger von Major John O. Dale vom 13. Mai 1947 an übernommen hatte. ${ }^{83}$

\section{c) Intelligence}

Der nachrichtendienstliche Bereich - Beschaffung und Auswertung wichtiger Informationen - bietet organisatorisch in Bremen ein unruhiges Bild. Eine eigene Dienststelle für diesen Zweck, ein Land Intelligence Office, gab es nur für gut vier Monate im Jahr 1948.

Nach dem Einmarsch mußte man sich zunächst auf britische Hilfe, dann auf die Abwehrspezialisten der 29. Infanteriedivision verlassen. Am 6.Juni 1945 traf ein erster Nachrichtenoffizier aus dem Information Services Control Command ein, der sich vor allem um die Entnazifizierung im Bereich der öffentlichen Medien kümmerte. ${ }^{84}$ Dem

77 Ebenda, S. 105; OMGBR: Functional History 1.7.1946-30.6.1947, I, S. 5 und 60.

78 General Order Nr.2, OMGBR, vom 22.3.1947 (6/69-2/1)

${ }^{79}$ Organisationsplan vom 1.7.1947 (6/67-2/21).

${ }^{80}$ General Order Nr.7, OMGBR, vom 14.9.1948 und vorher Nr.7, OMGBR, vom 12.12.1947 (6/69-2/1); Organisationsplan vom 27.7.1948 (6/1-2/1).

81 General Order Nr. 9, OMGBR, vom 30.11.1948 (6/69-2/1).

82 General Order Nr. 12, OMGBR, vom 30.6.1949 (ebenda); Organisationsplan in 6/2-1/24.

${ }^{83}$ OMGBR: Functional History 1.7.1946 - 30.6.1947, I, S. S1. Die Stelle des Abteilungsleiters wurde nach dem Ausscheiden von Boyd 1947 nicht wieder besetzt; auf dem Organisationsplan vom 1.7.1947 erscheint sie noch als vakant, später gar nicht mehr (6/67-1/21), denn vom 2.9.1947 fungierte Capt. Jeffs, der Stellvertreter des Direktors, nebenbei als Abteilungsleiter der Public Safety Division, siehe OMGBR: Functional History 1.7.1947 - 30.9.1947, I, S. 1.

84 OMGBR: Functional History 27.4.1945 - 30.6.1946, I, S. 78f. und 286. 
Fachoffizier in der Information Branch, später Information Control, wuchs in der Folge schwerpunktmäBig die nachrichtendienstliche Berichterstattung zu in Zusammenarbeit mit den Fachkräften aus dem Entnazifizierungs- und Zivilverwaltungsbereich, die auch auf diesem Sektor tätig waren. ${ }^{85}$ Eine „vorrangige Verantwortlichkeit“ des Referats für Informationskontrolle für den Sektor legte ein Brief Clays vom 1. März 1946 fest, und das unter diesem Datum erschienene Telefonverzeichnis der Bremer Militärregierung verweist mit dem Stichwort „Intelligence“ nur auf George Freimarck $^{86}$ von Information Control. Ein Kooperationsabkommen vom 9. März 1946 mit dem britischen Sicherheitsdienst und Bremen Port Command sollte die Arbeitsvoraussetzungen verbessern. ${ }^{87}$ Im Sommer 1946 war der Fachoffizier rückblickend mit dem Geleisteten ganz zufrieden. Die Arbeit der drei beteiligten Stellen sei frühzeitig erfolgreich koordiniert worden. Probleme habe hauptsächlich der akute Personalmangel bereitet ${ }^{88}$ Andere sahen das anders. Unter den im ersten Besatzungsjahr gewonnenen Erfahrungen wird an anderer Stelle desselben Sammelberichtes als erster Punkt das Fehlen einer eigenen Sektion für politischen Nachrichtendienst angeführt und beklagt: „various security agencies were barging around in a hundred different directions without uniform procedures and with primary emphasis on their own activities and Military Government needs were often far in the background". 89 Geplant war ursprünglich die Ansiedlung beim Executive Officer zusammen mit dem Kulturbereich. ${ }^{90}$ Die Information Branch wies im Januar 1946 eine derartige Zusammensetzung auf, ${ }^{91}$ nur war eben der Nachrichtenoffizier dort nicht allein zuständig und zentral verantwortlich, sondern mußte sich mit seinen Kollegen in den Bereichen Zivilverwaltung und Entnazifizierung abstimmen. Diese Ausgangslage bestand im wesentlichen unverändert bis zum Frühahr 1947 fort. Ein informelles „intelligence committee" diente der Abstimmung der beteiligten Stellen untereinander und der Koordination mit der Arbeit der Briten und des amerikanischen CIC.

Im Februar 1947 schließlich erhielt die Research Branch der Information Control Division zentrale Zuständigkeiten und die Funktion eines Land Intelligence Office neben ihren sonstigen Fachaufgaben - eine in keinem anderen Land der amerikanischen Zone getroffene Regelung. ${ }^{92}$ Bis Juni 1948 bestand die zentrale Ansiedlung in dieser Abteilung, dann erfolgte die Verselbständigung als dem Direktor unmittelbar verantwortliches Landesamt, welche bereits zum 30 . November 1948 mit der Einordnung in die Public Affairs \& Legal Division wieder ihr Ende fand. ${ }^{93}$

${ }^{85}$ Ebenda, S. 285.

${ }^{* 6}$ Er war noch bis Mitte Dezember 1946 Leiter der Intelligence \& Operations Branch, ICD (6/46-2/22). Nachfolger wurde N. Metal, siehe OMGUS-Hb, Bremen B, Anm. 96. Die Annahme von Brandt: Antifaschismus, S. 126, daB Freimarck aufgrund seiner linksliberalen Einstellung zur Gruppe der KGF-freundlichen Offiziere in der Militärregierung gehört haben dürfte, stößt insofern ins Leere, als Freimarck noch im Januar 1946 nicht als Mitglied der Bremer Militärregierung erscheint, also erst hier tätig wurde, als sich die KGF schon aufgelöst hatte; von Eckardt: Lebenserinnerungen, $S .125$ bezeichnet ihn als persönlichen Freund.

${ }^{87}$ OMGBR: Functional History 27.4.1945 - 30.6.1946, I, S. 289 f.

88 Ebenda, S. 292 und 285. Intelligence Officer am 8.7.1946 war John Boyd (3/157-1/3).

89 OMGBR: Functional History 27.4.1945 - 30.6.1946, 1, S.32.

90 Siehe OMGUS-Hb, Bremen A, Übersicht 2.

91 Organisationsplan vom 15.1.1946 (6/83-2/5).

92 OMGBR: Functional History 1.7.1946 - 30.6.1947, I, S.39f.

${ }^{93}$ OMGBR: Functional History 1.1.1948 - 31.12.1948, I, S.61; General Order Nr. 9, OMGBR, vom $30.11 .1948(6 / 69-2 / 1)$. 
Zum 30. Juni 1949 wurden die verbliebenen nachrichtendienstlichen Aufgaben mit denen der Zivilverwaltung in der Civil Administration \& Intelligence Division zusammengefaBt. ${ }^{94}$ Leiter dieser Division war der Neuzugang Clarence P. Oakes. ${ }^{95}$ Als Land Intelligence Officer altgedient war in Bremen zuvor Nicholas Metal, der am 12. November 1946 in den Dienst der Militärregierung trat und das Amt bis 1949 bekleidete..

\section{d) Information Control}

Die Kontrolle der Informationsmedien begann in Bremen unter der Regie von 6871st District Information Services Control Command (DISCC), einer separaten Organisation unter Direktiven von ICD, USFET. ${ }^{97}$ Erst Ende Januar 1946 entstand eine Information Control Branch als Bestandteil der Militärregierung,98 die gut drei Monate später zur Abteilung erhoben wurde. Sie umfaBte die Sachgebiete Film, Theater und Musik, Presse, (sonstige) Veröffentlichungen, Radio Bremen und Nachrichtendienst. Das relative Gewicht der Abteilung nahm von Ende 1946 (12 von 130 US-Stellen) bis Ende 1947 (13 von 119 US-Stellen) zu. ${ }^{99}$ Abteilungsleiter war zumindest seit August 1946 Major Thomas P. Headen. ${ }^{100}$ Er wurde ungefähr ein Jahr später abgelöst von Duncan D. MacBryde, der die Position bis 1949 innehatte. ${ }^{101}$

Zum 1.Juni 1948 verselbständigte sich das Land Intelligence Office; das betroffene Referat wurde umbenannt zu Research \& Reorientation Branch. Die Überwachung des Theater- und Musiklebens wechselte wenig später auf höhere Empfehlung in die Kulturabteilung, ${ }^{102}$ und der Name der Abteilung änderte sich zu Information Services

94 General Order Nr. 12, OMGBR, vom 30.6 .1949 (ebenda).

95 Siehe OMGUS-Hb, Bremen B, Anm. 61.

\% OMGBR: Functional History 1.9.1946 - 31.12.1946, II, Appendix 1 b; seit Mitte Dezember 1946 für Intelligence verantwortlich (6/46-2/22); noch in Personallisten des OMGUS Information Bulletin von April 1949.

97 OMGBR: Functional History 27.4.1945 - 30.6.1946, 1, S. 286; 5/243-1/24.

98 5/243-1/24. Die Abstimmung mit den Briten erfolgte durch eine Vereinbarung vom 31.1.1946; vgl. auch das Telefonverzeichnis der Bremer Militärregierung vom 1.3.1946. Referatsleiter war Capt. Alex Saron, der später das Sachgebiet Film. Theatre \& Music Control betreute, vgl. Organisationsplan vom 1.10.1946 in 6/46-2/34.

99 OMGBR: Functional History 1.9.1946-31.12.1946, I, S. 3; 6/67-1/2.

${ }^{100}$ Geb. 9.8.1903, noch einmal befördert zum 1.6.1947 (6/47-1/16). Im Zivilberuf seit 15 Jahren Reporter und Journalist bei der New York Sun; vor der Bremer Zeit zehn Monate in Frankreich als Public Relations Officer tätig, siehe Special Report, Juli 1945, S. 40 (StA Bremen 16, 1/4). Am 1.7.1945 Assistent des Bremer Exekutivoffiziers Shamel, nach dem 10.12.1945 Exekutivoffizier der neuen G-5 Sektion von Bremen Port Command, Ende Januar 1946 in die USA (OMGBR: Functional History 27.4.1945 - 30.6.1946, I, S.18f.). Im August als Abteilungsleiter ICD genannt (General Order Nr.2, OMGBR, vom 23.8.1946 [6/69-2/1]). Im Herbst 1946 Lt.Col., dann Zivilbediensteter (6/46-2/34).

101 Schreibung vereinzelt auch: Duncan F. McBryde; 1942 - 1944 als Militärattaché in Syrien und Libanon, danach Chef einer Auslandspresseabteilung im War Department; 9.5.1947 Deputy, Plans \& Directives Branch, OMGUS (5/261-3/6); im Sommer 1947 nach Bremen, ab Oktober 1949 Leiter der Abteilung für öffentliche Angelegenheiten, im Januar 1951 Abberufung ans State Department. „Er war bei uns nicht als ,Okkupationsbeamter', sondern als Freund tätig“ (Bremer Nachrichten 6.1.1951). von Eckardt: Lebenserinnerungen, S. 125 zählte ihn zu seinen Freunden, und den Abschiedsbrief an Kaisen schloB McBryde mit den Worten „Ihr junger Verehrer und Freund" (Begegnungen mit Kaisen, S. 189).

102 Special Order Nr. 22, OMGUS, vom 23.6.1948. 
Division. ${ }^{103}$ In dieser Form überstand sie den Herbst 1948. Ihre Auflösung erfolgte zum 30. Juni 1949, wobei die verbliebenen Aufgaben an OMGUS übergingen. ${ }^{104}$

\section{Entnazifizierung (Denazification)}

Besondere organisatorische Vorkehrungen zur Durchführung der Entnazifizierung wurden zu Beginn der Besatzungszeit von der Bremer Militärregierung nicht getroffen. Die Verantwortung lag beim jeweils zuständigen Fachoffizier, der die notwendigen Informationen von Spezialeinheiten bezog - anfangs der British Field Security des 30. Corps, danach von der Counter Intelligence Branch (CIB) der 29. Infanteriedivision. Special Branch, Public Safety, bestand nur aus zwei deutschen Mitarbeitern, die unter der Aufsicht des für Gefängnisse zuständigen Offiziers die ausgewerteten Fragebogen aus dem Bereich des öffentlichen Dienstes verwalteten. ${ }^{105}$ Erst Ende Juli/Anfang August 1945 trafen speziell für Entnazifizierung ausgebildete Offiziere in der Enklave ein: Major John W. Boyd ${ }^{106}$ und 1st Lt. Jesse S. Morse. ${ }^{107}$ Sie verständigten sich mit der 29. Infanteriedivision dahingehend, daB das von der CIB aufgebaute Bremen Document Center zunächst weiter fungieren und mit Informationen versorgt werden sollte. Ausgewählte deutsche Mitarbeiter wurden umgehend zu Schulungskursen nach Bad Orb geschickt, so daß schon am 27. August 1945 die Arbeit mit den neuen, 131 Fragen enthaltenden Fragenbogen beginnen konnte. Im Oktober waren fünf Offiziere und 39 geschulte deutsche Mitarbeiter in der Special Branch tätig. ${ }^{108}$ Am 1.Oktober 1945 wurde die Special Branch aus dem Bereich Public Safety herausgenommen und zur Denazification Branch verselbständigt - eine MaBnahme, die im März 1946 wieder rückgängig gemacht wurde. ${ }^{109}$ Mit Public Safety vorübergehend der Internal Affairs \& Communications Division zugeordnet, arbeitete die Special Branch unter Captain Morse im Herbst 1946 wieder als Teilbereich von Public Safety, nun eine Abteilung fur sich. Zu der Zeit wurde die kleine Review Board Branch integriert, die seit November 1945 Berufungsfälle und Beschwerden in Entnazifizierungssachen zu klären hatte. ${ }^{110}$ Die seit dem 30 . August 1945 von Lt. Sydney Malkin geführte Investigation Section wurde nach dessen Ausscheiden im August 1946 bis Januar 1947 mit gutem Erfolg kommissarisch von einem Deutschen geleitet." "1

Um künftigen Aufgaben im Zusammenhang mit dem in Vorbereitung befindlichen Gesetz zur Befreiung von Nationalsozialismus und Militarismus ${ }^{112}$ besser gerecht zu

${ }^{103}$ Die Umbenennung erfolgte vor Mitte September 1948, siehe General Order Nr. 7, OMGBR, vom 14.9.1948 (6/69-2/1).

104 General Order Nr. 12, OMGBR, vom 30.9 .1949 (ebenda).

105 OMGBR: Functional History 27.4.1945 - 30.6.1946, I, S. 78 f.

106 VerläBt Bremen am 31.1.1946 in Richtung USA zu einem Erholungsurlaub (ebenda, S. 82), tritt danach nicht mehr in Erscheinung.

107 Leiter der Operations Section; 23.10.1945 - 30.1.1946 Erholungsurlaub in den USA, im März 1946 Chief of Special Branch (ebenda, S. 82); am 22.3.1947 Leiter der Denazification Division, scheidet zum 31.7.1947 aus.

108 OMGBR: Functional History 27.4.1945 - 30.6.1946, I, S.80f. Am 1.7.1946 hatte die Special Branch 40 deutsche Mitarbeiter (6/95-2/15).

109 OMGBR: Functional History 27.4.1945 - 30.6.1946, I, S.81 f.

${ }^{110}$ Ebenda, S.84f.; OMGBR: Functional History 1.7.1946-30.6.1947, I, S. 41.

111 Alfred Göbel, vgl OMGBR: Functional History 1.7.1946-30.6.1947, I, S.48 und OMGBR: Functional History 27.4.1945 - 30.6.1946, I, S.81.

112 Erlassen am 9.5.1947 (Gesetzblatt der Freien Hansestadt Bremen 1947, S.67 ff). 
werden, wurde am 22. März 1947 die Denazification Division geschaffen ${ }^{113}$ mit Special Branch Bremen, Special Branch Bremerhaven, Inspection Branch und Investigation Branch. Abteilungsleiter Jesse S. Morse versah seinen Dienst noch bis zum 31. Januar 1947, war also zwei entscheidende Jahre lang in verantwortlicher Position für die Entnazifizierung in Bremen tätig. Sein Nachfolger Joseph F. Napoli behielt die Zuständigkeit für Entnazifizierungsfragen bis 1949,114 allerdings nach Auflösung der Abteilung mit Wirkung vom 15. September 1948 nur noch als Denazification Adviser im Rahmen der Governmental Affairs Division, ${ }^{115}$ die kurz darauf zur Public Affairs \& Legal Division umstrukturiert wurde. ${ }^{116}$ Zum 30 . Juni 1949 wurde das Amt des Denazification Adviser bei der Bremer Militärregierung aufgelöst. ${ }^{117}$ Verbliebene Aufgaben wie die Anfragen beim Berliner Document Center übernahm später die Political Affairs Division beim Landeskommissar.

\section{Justiz (Legal)}

Der im März 1945 konzipierte Organisationsplan sah eine Legal Branch vor, die für Gesetze und Verordungen, das Amtsblatt, Gerichte und Rechtsfragen überhaupt zuständig sein sollte. ${ }^{18}$ Nach dem Einmarsch bezogen drei Offiziere unter Leitung von Major James B. Watson Quartier im nur teilweise zerstörten Gerichtsgebäude, wo am 9. Mai 1945 die erste Militärgerichtsverhandlung stattfand. Einer der drei, Lt. Arthur L. Ballin, wechselte noch im Mai zum Wesermünder Detachment und wurde durch $\mathrm{Lt}$.

113 General Order Nr.2, OMGBR, vom 22.3.1947 (6/69-2/1); OMGBR: Functional History 1.7.1946-30.6.1947, I, S. 41; vgl. auch 6/96-1/43.

114 Geb. 24.9.1914 in New York, Studium der Politikwissenschaften an der Ohio State University; danach Tätigkeit im Handels- und Arbeitsministerium; zur US Army 1943, Nordafrika und Italien (persönliche Auskünfte vom 13.6.1980 und 4.12.1983); stieß am 28.10.1946 zur Bremer Militărregierung, zunăchst Tătigkeit im Rechnungswesen (Budget \& Fiscal) - Ernennung zum 6.11.1946 (Special Order Nr. 86, OMGBR, vom 6.11.1946 [6/2-3/4]). Leiter der Denazification Division 1.8.1947 - 15.9.1948, Denazification Adviser bis 19.6.1949. Am 11.5.1948 schriftliche Belobigung von Clay für außerordentlichen Einsatz, 1949 kritische Äußerungen über den Effekt des Entnazifizierungsprogramms auch in der Öffentlichkeit, siehe Artikel "Denazification from an American's Viewpoint" in: Annals, Philadelphia 1949, und eine Pressekonferenz am 13.5.1949, vgl. Weser-Kurier vom 14.5.1949. Siehe „Denazification“, S. 66-84. Meyer-Braun: Bremer SPD, S. 47 ff., behandelt die Pressekonferenz und den Artikel; ihr entging, daB der Artikel bereits im Juli 1949 in den USA erschien, also von Napoli noch in Bremen verfaßt worden war; erst im Mai 1950 erhielt der Bremer Senat davon Kenntnis. Vgl. auch Begegnungen mit Kaisen, S. 189 ff. Wulff: Im Jahrfünft, S. 15 erwähnt im Zusammenhang mit den Säuberungen im Herbst 1945 Napoli irrtümlich als Leiter der Special Branch, die eine noch traurigere Berühmtheit erlangt habe als 1933 der Leiter der nationalsozialistischen „Abbaukommission“. Es bleibt bei dieser fragwürdigen Etikettierung unklar, ob Napoli uberhaupt gemeint ist oder eher Morse, der zu der Zeit bereits in der Special Branch tätig war. - Napoli heiratete eine Bremerin. Nach 1949 in NATO-Diensten in Italien, dann in der amerikanischen Bundesverwaltung bis 1975.

115 General Order Nr. 7, OMGBR, vom 14.9.1948 (6/69-2/1).

116 Zum 30.11.1948, vgl. OMGBR: Functional History 1.1.1948-31.12.1948, I, S.9.

117 Order Nr.12, OMGBR, vom 30.6.1949, mit Bezug auf ein Schreiben von OMGUS vom 16.5.1949 (6/69-2/1).

${ }^{118}$ Siehe OMGUS-Hb, Bremen A, Übersicht 2. 
Gross ersetzt; der andere, Capt. Robert L. Guthrie, rückte Anfang September 1945 in die Führungsposition als Enclave Legal Officer. ${ }^{119}$

Am 9. Juli 1945 etablierte sich ein dreiköpfiger Untersuchungsausschuß (Review Board) zur Überprüfung der Gefängnisinsassen zwecks Freilassung zu Unrecht Inhaftierter. Mitglied war neben Watson und Guthrie der Gerichtsoffizier Capt. Donald J. Zimmermann, der wegen seines privaten Umgangs später von der Entnazifizierungsabteilung als schlechtes Beispiel herausgestellt wurde. ${ }^{120}$

Im Januar 1946 waren im Justizbereich, der seine Eigenständigkeit verloren hatte und nun zu Internal Affairs zählte, sieben Offiziere in Bremen tätig, dazu einer in Bremerhaven/Wesermünde. ${ }^{121}$ Von den „Männern der ersten Stunde“ war niemand mehr dabei. Der erst im Februar 1946 zur Sektion stoßende Capt. A. T. Benton wurde noch Chief Legal Officer vor seiner Rückversetzung in die Vereinigten Staaten im Juni 1946. Mit Robert W. Johnson, ziviler Bediensteter und Rechtsanwalt von Beruf, schloB sich dann Anfang Mai 1946 der Mann den Rechtsexperten der Bremer Militärregierung an, dem bereits im Juni 1946 die fachliche Verantwortung für den Bereich zufiel $^{12}$ und bis zum Ende der OMGUS-Periode erhalten blieb.

Wie der Entnazifizierungsbereich, so war auch die Justiz 1946 vorübergehend in der Internal Affairs \& Communications Division untergebracht, ${ }^{123}$ um noch im Sommer des Jahres eigene Abteilung zu werden. ${ }^{124}$ Nach dem Stellenschlüssel vom Jahresende 1946 war sie mit zehn von insgesamt 130 vorhandenen Stellen für Amerikaner ausgestattet. ${ }^{125}$ Aufgabenschwerpunkte der Abteilung waren im November 1947 weiterhin die Militärgerichtsbarkeit und die Aufsicht uber die deutsche Rechtsprechung, nachrangig folgten rechtsberatende Funktionen, Prüfung der Gesetzgebung, Gefängnisverwaltung und Begnadigungen. ${ }^{126}$ Mit der Ausgliederung der Militärgerichte in eine eigene Organisation am 28. September 1948 ging der Legal Division mit Ausnahme des Abteilungsleiters das gesamte Fachpersonal verloren. Die Auflösung der Abteilung war die logische Konsequenz. Sie erfolgte zum 30. November 1948. Johnson wurde als Rechtsberater Leiter der neuen Public Affairs \& Legal Division. ${ }^{127}$ Der Schrumpfungsproze $B$ der Militärregierung ergab am 1 .Juli 1949 noch einmal eine eigenständige Legal Division mit den gewohnten Aufsichtsfunktionen für Gesetzgebung und Rechtspflege sowie dem Bereich rechtliche Beratung, besetzt mit zwei amerikanischen Rechtsanwälten, ${ }^{128}$ das Ende der OMGUS-Periode keine drei Monate später setzte der Wirksamkeit der Neuschöpfung jedoch enge Grenzen.

119 OMGBR: Functional History 27.4.1945 - 30.6.1946, I, S.220f. Zur Position Guthries siehe auch Wenzlau: Wiederaufbau der Justiz, S. 117, Anm. 5 und S. 178, Anm.8.

120 "dessen Beziehung zu einer übel beleumundeten und politisch belasteten Frau in der Bevölkerung heftigen Unwillen erregt “, Bericht A. Göbel (1948), S. 4 (6/92-1/13).

121 Siehe Organisationsplan vom 15.1.1946 (6/83-2/5); vgl. OMGUS-Hb, Bremen A, Übersicht 4.

122 OMGBR: Functional History 27.4.1945 - 30.6.1946, I, S.221.

$123 \mathrm{Vgl}$. Organisationsplan in 6/37-2/10.

124 Bekanntgabe von Johnson als Abteilungsleiter durch General Order Nr.2, OMGBR, vom 23.8.1946(6/69-2/1).

125 OMGBR: Functional History 1.9.1946 - 31.12.1946, I, S. 3.

126 6/62-2/33.

127 OMGBR: Functional History 1.1.1948 - 31.12.1948, I, S.9f. und 61 f.; General Order Nr.9, OMGBR, vom 30.11.1948 (6/69-2/1).

128 6/64-1/10; General Order Nr. 12, OMGBR, vom 30.6.1949(6/69-2/1). 


\section{Finanzen (Finance)}

Das Konzept vom März 1945 sah je einen Fachbereich für Finanzen und Vermögenskontrolle vor, während in der Praxis dann beide zur Fiscal \& Property Control Branch zusammengefaßt wurden. ${ }^{129}$ Ende Mai/Anfang Juni 1945 waren Major Harold R. Bechtel als Fiscal Officer und Capt. George W. Knepper und Capt. Henry Feinstein in der Vermögenskontrolle tätig, letzterer beim Wesermünder Detachment. ${ }^{130}$ Major Bechtel erhielt im Juli einen Assistenten zugeteilt, ${ }^{131}$ und im Januar 1946 gab es je zwei Offiziere für Finanzen und Vermögenskontrolle im Referat, das unter Bechtels Leitung stand, sowie zwei weitere in Bremerhaven/Wesermünde. ${ }^{132}$ In der Sektion für Vermögenskontrolle wechselte das Personal häufiger. ${ }^{133}$ Die Bearbeitung der Restitutionen (Restitution Branch) wurde mit dem 30. Juli 1946 an die Wirtschaftsabteilung abgegeben, die Einrichtung des Amtes für Vermögenskontrolle am 15. Oktober 1946 unter deutscher Leitung brachte weitere Entlastung. ${ }^{134}$ Der Amtsleiter war dem Senator für Finanzen verantwortlich, unterlag aber der Überwachung und Kontrolle durch den zuständigen amerikanischen Offizier. Die Abteilung änderte ihren Namen im Herbst 1946 von Fiscal \& Property Control Division zu Finance \& Property Control Division, um dann 1947 nur noch als Finance Division 24 firmieren. ${ }^{135}$ Der Stellenschlüssel vom Jahresende 1946 wies ihr sechs der 130 verfügbaren amerikanischen Stellen zu, Ende 1947 waren es noch drei von insgesamt 119 Stellen $^{136}$ - ein kleiner Fachbereich also. Abteilungsieiter Major Bechtel war am 19. November 1946 aus dem Dienst geschieden. ${ }^{137}$ Sein Nachfolger wurde Major William H. Goehring, der die fachliche Leitung des Bereichs dann als Zivilist bis zum Ende der OMGUS-Periode behielt. ${ }^{138}$

Am 24. April 1947 wurde die Zuständigkeit für die Vermögenskontrolle im Lande Bremen zentralisiert, eine Aufgabe, mit der vom 1. Juni 1947 an der zivile Bedienstete Lawrence T. Schwarz betraut war. ${ }^{139}$ Zum 1. April 1948 wurde die volle Verantwortung für die Durchführung der Vermögenskontrolle der deutschen Behörde überlassen, so daß auch auf diesem Sektor den Vertretern der amerikanischen Besatzungsmacht nur eine allgemeine Aufsichtsfunktion blieb. ${ }^{140}$

Den Reorganisationen im Herbst 1948 fiel auch die Finance Division zum Opfer: Sie wurde am 15.September 1948 aufgelöst. Der Finance \& Property Control Adviser gehörte mit den Fachbereichen Arbeit, Wirtschaft und Verkehr zu einer Abteilung, die zunächst Bipartite Affairs Division genannt, aber bereits am 30. November $1948 \mathrm{zu}$

${ }^{129} \mathrm{Vgl}$. OMGUS-Hb, Bremen A, Übersicht 2 und 3.

${ }^{130} 6 / 105-1 / 4$.

131 OMGBR: Functional History 27.4.1945 - 30.6.1946, I, S. 352.

132 Organisationsplan vom $15.1 .1946(6 / 83-2 / 5)$.

133 OMGBR: Functional History 27.4.1945 - 30.6.1946, I, S. 358 nennt von Ende April 1945 bis 1.7.1946 fünf verschiedene Namen.

134 OMGBR: Functional History 1.7.1946 - 30.6.1947, I, S.225f.; vgl. StA Bremen 4, 145 Amt für Vermögenskontrolle, Findbucheinleitung von K. Schwarz, 1983.

${ }^{135}$ Siehe OMGUS-Hb, Bremen A, Übersicht 5 und 6, sowie General Order Nr. 2. OMGBR, vom 23.8.1946 (6/69-2/1).

136 OMGBR: Functional History 1.9.1946 - 31.12.1946, I, S. 3; 6/67-1/21.

137 OMGBR: Functional History 1.9.1946 - 31.12.1946, II, Appendix 1 b.

138 6/65-1/13. Er war noch 1950 für den Landeskommissar in Bremen tätig.

139 OMGBR: Functional History 1.7.1946 - 30.6.1947, I, S. 225.

140 OMGBR: Functional History 1.1.1948 - 31.12.1948, I, S. 166. 
Civil Resources Division umbenannt wurde. ${ }^{141} \mathrm{Zu}$ seinen Aufgaben gehörten die Überwachung des Staatshaushalts, der Banken und Versicherungen, der Vermögenskontrolle und der Besatzungskostenabrechnung. ${ }^{142}$ Ein Schreiben von OMGUS vom 12. Mai 1949 entzog die Vermögenskontrolle der lokalen Militärregierung, so daß zum 30. Juni 1949 noch einmal eine Umbenennung in Finance \& Property Adviser erfolgte. ${ }^{143}$

\section{Wirtschaft (Economics)}

Nach der Vorausplanung vom März 1945 sollte die Bremer Wirtschaftsabteilung nicht nur für Handel und Industrie, Landwirtschaft und Fischerei, Kleidung und Lebensmittel zuständig sein, sondern auch für die Bereiche Arbeit, öffentliche Versorgungseinrichtungen und Verkehr. ${ }^{144}$ In dieser Form wurde die Umsetzung in die Praxis gar nicht erst versucht. Trotz Aufteilung in die zwei Gebiete Public Works \& Utilities (einschließlich Transport) und Economics (einschlieBlich Labor) blieb der Wirtschaftsbereich mit sieben Offizieren und einem Zivilisten das gröBte Fachreferat, so daB man sich entschloB, auch noch den Bereich Arbeit herauszunehmen. Am 1.Juli 1945 findet sich eine Drittelung in Economics, Utilities \& Labor, sowie Transportation. ${ }^{145}$

Lt.Col. Rupert F. Anderson, der das Bremer Wirtschaftsreferat aufzubauen hatte, war nach dem Kommandeur und seinem Vertreter der ranghöchste Offizier des Detachments. Er hatte bereits an der Vorbereitungsphase in Frankreich teilgenommen. Sein Weggang Anfang Juli 1945 führte zur Auflösung der Economics Branch, die als solche erst im Februar 1946 wieder etabliert wurde. ${ }^{146}$

Nach der Aufteilung in Lokal- und Enklavenverwaltung Anfang August 1945 war für das Bremer Wirtschaftsleben die Trade \& Industry Branch unter Major Alex B. McDonald verantwortlich. Am 1. September 1945 wurde ferner die Kontrolle der industriellen Produktion als Aufgabe der Militärregierung festgeschrieben. Die 7. Armee úberstellte zu dem Zweck drei Offiziere, darunter Major William H. Goehring, die sich der Sache annahmen. ${ }^{147}$ Goehring erscheint auf dem Organisationsplan vom 15. Januar 1946 als Leiter der Trade \& Industry Branch, ${ }^{148}$ doch bei der Neukonstituierung der Economics Branch am 4. Februar 1946 erhielt Major Osborne M. Taylor die Leitungsfunktion. ${ }^{149}$ Er diente als verantwortlicher Fachoffizier für den Wirtschaftsbereich in Bremen noch nach dem Ende der OMGUS-Zeit unter dem Landeskommissar.

141 General Orders Nr.7 und 9, OMGBR, vom 14.9. und 30.11.1948 (6/69-2/1).

$1426 / 64-3 / 14$.

143 General Order Nr. 12, OMGBR, vom 30.6.1949 (6/69-2/1).

144 6/125-3/24; siehe OMGUS-Hb, Bremen A, Übersicht 2.

145 6/105-1/4; siehe OMGUS-Hb, Bremen A, Übersicht 3.

146 OMGBR: Functional History 27.4.1945 - 30.6.1946, I, S. 1 und 294. Anderson ging zur Kontrollkommission nach Berlin.

${ }^{147}$ Ebenda.

148 6/83-2/5; Goehring fehlt im Telefonverzeichnis vom 1.3.1946, erscheint aber ab Mai 1946 wieder als Leiter der Industrial Management Branch und Mitarbeiter von Taylor, was einen Rollentausch gegenüber der Aufgabenverteilung im Januar bedeutet; er übernahm am Jahresende 1946 die Finanzabteilung der Bremer Militärregierung (siehe OMGUS-Hb, Bremen B 5).

149 OMGBR: Functional History 27.4.1945 - 30.6.1946, I, S. 295; Taylor war seit Anfang Juni 1945 in dem Bereich Bremen tätig (ebenda, S.294) und leitete seit Anfang Oktober die neu geschaffene Industrial Control Section (StA Bremen 4,92- W.1.a.26 ${ }^{1}$ ). Er kam aus dem Air Corps (11/39-3/2). 
Spätestens im April 1946 zur Abteilung erhoben, ${ }^{150}$ umfaßte die Economics Division im Sommer 1946 die Sachgebiete Industrial Management, Building Trades, POL \& and Solid Fuels, Reports \& Statistics, Trade \& Commerce, Requisitions \& Allocations, Public Utilities, Food. ${ }^{151}$ Ende Juli kam die Bearbeitung der Restitutionen hinzu. ${ }^{152}$ Mit 17 von 130 Stellen für Amerikaner Ende 1946 und 21 von 119 Ende 1947 gehörte die Wirtschaftsabteilung deutlich zu den gröBten der Bremer Militärregierung. ${ }^{153}$ Umso steiler war ihr Abstieg in der ersten Jahreshälfte 1948. Personalund Kompetenzverluste u.a. an die neugeschaffenen örtlichen Büros der JEIA in Bremen und Bremerhaven und an BICO-Dienststellen lieBen die Abteilung zusammenschrumpfen. Mitte Juli 1948 verblieben ihr als Aufgabengebiete nur noch Nahrungsmittel und Landwirtschaft sowie Reparationen, Restitutionen und Dekartellisierung. ${ }^{154}$

Die Auflösung der Abteilung erfolgte zum 15. September 1948. Die verbliebenen Funktionen nahm nun das Amt des Economics Adviser wahr, der mit den Bereichen Finanzen, Verkehr und Arbeit zunächst in der Bipartite Affairs Division, dann in der Civil Resources Division untergebracht war, ${ }^{155}$ die jeweils von Capt. Jeffs als Stellvertreter bzw. dann als Direktor der Bremer Militärregierung kommissarisch geleitet wurde. ${ }^{156}$ Diese Regelung war bis September 1949 keinen wesentlichen Veränderungen mehr unterworfen.

\section{Häfen, Schiffahrt und Verkehr (Transport)}

Die Bremer Enklave verdankte dem amerikanischen Wunsch nach einem eigenen Nachschubhafen im besetzten Deutschland ihre Existenz, doch hatte die dort eingesetzte Militärregierung mit dem Hafenbetrieb zunächst nichts zu tun. Eine eigens zu dem Zweck geschaffene deutsche Behörde, die Bremen Civil Port Authority, später Weserhafenbehörde, ${ }^{157}$ operierte unter Spezialeinheiten des Bremen Port Command, das für die Häfen zuständig war. ${ }^{158}$ Einige Aufgaben - so die Überwachung der Lotsen- und Schlepperdienste, der Seezeichen, der Werften - nahm in Absprache die USNavy wahr. ${ }^{159}$ Die der Militärregierung auf dem Verkehrssektor verbleibenden Aufgaben wurden nicht hoch eingeschätzt - Transportation war im vorab entworfenen Organisationsplan eine Sektion von vielen im Wirtschaftsreferat. ${ }^{160}$ Anfangs gab es zwei Fachoffiziere im Bremer Detachment - Capt. James H. Schack und Capt.

$1506 / 43-2 / 21$.

151 Organisationsplan in 6/37-2/10.

152 Siehe OMGUS-Hb, Bremen B 5.

153 OMGBR: Functional History 1.9.1946-31.12.1946, I, S. 3; 6/67-1/21.

154 Organisationsplan vom 15.7.1948 in 6/67-2/1; vgl. OMGBR: Functional History 1.1.1948 31.12.1948, I, S.5.

155 General Orders Nr.7 und 9, OMGBR, vom 14.9. und 30.11 .1948 (6/69-2/1).

156 Siehe Organisationspläne in 6/1-2/1, 6/2-1/27 und 6/58-1/19.

157 Vgl. StA Bremen, Vorwort zu Bestand 4, 116 von Hartmut Müller, 1969.

158 Vgl. History of Bremen Port Command 1945 May - Sept und Report of Operations of Bremen Port Command 1945 Oct - Dec in StA Bremen 16,1/4.

159 Abkommen vom 30.6.1945 zwischen US Naval Advanced Base Bremen und Bremen Port Command über die Zuständigkeiten im Häfen- und Schiffahrtsbereich (StA Bremen 4, 11620). Das Bremer Detachment E2C2 erscheint nicht einmal auf dem Verteiler des Abkommens.

160 Siehe OMGUS-Hb, Bremen A, Übersicht 2. 
Raphael M. Stein -, doch bald erwies sich die Einrichtung einer Transportation Branch als zweckmäßig, die mit drei Offizieren besetzt war. ${ }^{161}$ Nach der Aufgliederung in Enklaven- und Lokalverwaltung im August 1945 arbeitete auf Enklavenebene Lt.Col. Emest $\mathrm{H}$. Hicks mit vier Offizieren und Zuständigkeiten für den Verkehr auf der Schiene, der Straße und den Binnenwasserstraßen. Das lokale Bremer Team wurde von Major Stein geleitet, und auch in Bremerhaven/Wesermünde, OsterholzScharmbeck, Loxstedt und Brake gab es fachlich zuständige Offiziere. ${ }^{162}$ Der Organisationsplan nach dem Abkommen vom 10. Dezember 1945 weist einen Transportoffizier in Wesermünde aus und eine Gruppe von fünf Offizieren in Bremen, die sich im Rahmen der Internal Affairs Branch um Unterhaltung und Betrieb des Verkehrsnetzes kümmerten. ${ }^{163}$ Als die Zuständigkeit für Verkehrswege von überregionaler Bedeutung (Bahn, Binnenwasserstraßen) an zentrale Instanzen abgegeben worden war, ${ }^{164}$ schrumpfte Transportation zu einer kleinen Sektion nun in der Civilian Services Branch unter Lt.Col. Golon B. Harris. ${ }^{165}$ Der Umschwung kam noch Ende März 1946 mit der Ankündigung Clays, die an die Zentrale abgegebenen Kompetenzen im Verkehrsbereich sollten zum 1. April 1946 an die Bremer Militärregierung zuruckfallen. Gleichzeitig fiel ihr die Aufsicht uber den Hafenbetrieb in Bremen zu. ${ }^{166}$ Bremen Port Command, das gesonderte Hafenkommando, wurde Anfang Mai 1946 aufgelöst. ${ }^{167}$ Die Hafentruppe 17th Major Port bezog ihr Hauptquartier in Bremerhaven, wo sich die Abwicklung des militärischen Nachschubs konzentrierte. ${ }^{168}$ Das schuf Raum in den bremischen Häfen für den seit November 1945 stark angewachsenen Umschlag ziviler Güter einschließlich der UNRRA Versorgungsgüter. ${ }^{169}$ Organisatorisch fanden die neuen Aufgaben ihren Platz in der Civilian Services Branch, die am 10. April 1946 zur Abteilung erhoben ${ }^{170}$ und am 27. April von den Sektionen Housing, Food and Welfare befreit wurde. ${ }^{171}$ Eine neue Fachabteilung für Häfen, Schifffahrt und Verkehr war entstanden mit den Referaten Railroads, Inland Waterways, Port Operations, Coastal Shipping and Civil Transportation, wobei letzteres der Deutlichkeit halber besser „Highways \& Highway Transport“ geheißen hătte. Ihr wurden im Juni und November 1946 auch die bisher von der US-Navy wahrgenommenen Aufga-

${ }^{161}$ Personalliste vom 31.5.1945 (6/105-1/4); auf dem Organisationsplan vom 1.7.1945 (siehe OMGUS-Hb, Bremen A, Übersicht 3) ist Major Kennedy, vorher Public Safety, hinzugekommen.

162 Organisationsplan in 6/22-1/22; Hicks war spăter (15.1.1946) Executive Officer der Militärregierung in Bremerhaven (6/83-2/5). Capt. Schack war, wie noch im Januar 1946, für Binnenschiffahrt zuständig; Major Stein erscheint zuletzt als Leiter der Transportation Section, Civilian Services Branch, im Telefonverzeichnis vom 1.3.1946.

163 Organisationsplan vom 15.1.1946 (6/83-2/5).

164 Die Binnenschiffahrt z. B. wurde im März 1946 von einem lokalen Büro der Transport Division, OMGUS, aus überwacht, vgl. 6/33-2/4, Mitteilung vom 13.3.1946.

165 Telefonverzeichnis vom 1.3.1946.

166 Schreiben Clays vom 27.3.1946 (StA Bremen 4, 116-12); aufgeführt werden die Bereiche Rail, Civil Port, Inland Waterways, Coastal Shipping.

${ }^{167}$ OMGBR: Functional History 27.4.1945 - 30.6.1946, I, S. 435.

${ }^{168}$ Ebenda, S. 369, vgl. auch OMGUS-Hb, Bremen B, Anm. 157.

169 OMGBR: Functional History 27.4.1945 - 30.6.1946, I, S. $366 \mathrm{f}$.

${ }^{170}$ So Abteilungsleiter Harris in einem Memo vom 19.4.1946 (6/19-2/15); vielleicht fehlte dieser Umbenennung noch der Segen von oben, denn die OMGBR: Functional History 27.4.194530.6.1946, I, S. 368 nennt den 25.4.1946 als Entstehungstag der Abteilung.

171 Memo vom 27.4.1946 (6/43-2/21). 
ben übertragen, für die zusätzlich eine Inspection \& Security Branch ${ }^{172}$ sowie eine Marine Production \& Control Branch für die Werftenaufsicht ${ }^{173}$ eingerichtet wurden. Weiter trat eine kleine Rivers \& Harbors Engineering Branch hinzu. ${ }^{174}$

Am 10. Oktober 1946 erfolgte die Umbenennung in Transport Division. ${ }^{175}$ Sie war Ende 1946 mit 22 von 130 US-Positionen deutlich die größte Abteilung der Bremer Militärregierung. ${ }^{76}$ Der Berliner OMGUS-Zentrale waren die Bremer Verhältnissc ein Dorn im Auge. Am 7. Februar 1947 klagte der Leiter der Transportabteilung, OMGUS, in einem Schreiben an den Stabschef darüber, daß Bremen das einzige Land der amerikanischen wie britischen Zone sei, das Schiffs- und Eisenbahnverkehr direkt kontrolliere. Hier sei Änderung geboten. ${ }^{17}$ Diese Auffassung setzte sich durch und fand Ausfluß in einer Anordnung vom 7. März 1947, mit der die Bereiche Rail, Inland Waterways, Coastal Shipping, Rivers \& Harbors Engineering und Inspection an die Transportabteilung von OMGUS überführt wurden. Der Bremer Abteilung verblieben die Bereiche Port Operations, Marine Production \& Control, Civil Transportation and Security. ${ }^{178}$ Letzterer - er beinhaltete v. a. die Aufsicht über die Wasserschutzpolizei - wurde am 4. Juni 1947 zu Marine Security umgetauft und am 15. Dezember 1947 in die Public Safety Division überführt, von wo er am 1. Mai 1948 in die Waterfront Division wanderte. ${ }^{179}$ Die OMGUS unterstellte Bremer Rail Branch ging Anfang 1948 auf BICO über. ${ }^{180}$

Im Zusammenhang mit Plänen zur Reduzierung des militärischen Personals der Hafentruppe 17th Major Port in Bremerhaven erfolgte im Juli 1947 die Überführung des Hafenbetriebs dort vorbehaltlich weniger Ausnahmen in die Verantwortlichkeit der Militärregierung. Das war der letzte Kompetenzzuwachs der Bremer Transportabteilung, und er hatte nicht mehr viel zu bedeuten. Der Hafenbetrieb vollzog sich am Ende des Jahres 1947 nach Einschätzung des zuständigen Amerikaners fast hundertprozentig in deutscher Verantwortung, so daB nur gewisse Aufsichtsfunktionen blieben. ${ }^{181}$

Zum 1. Mai 1948 wurde das Werftenreferat ausgegliedert und BICO unterstellt. Die Leitung der Restabteilung übernahm kommissarisch der Direktor. ${ }^{182}$ Ihre Auflösung erfolgte im Zuge der großen Reorganisation am 15. September 1948, wobei sie zunächst geschlossen als Amt des Transportation Adviser zusammen mit Economics, Manpower und Finance in die Bipartite Affairs Division eingebracht, kurz darauf (30. November 1948) dann aber doch noch aufgeteilt wurde: Der Straßenverkehr blieb in der Abteilung, die die neue Bezeichnung Civil Resources erhielt, die Hafenaufsicht

172 Geschaffen am 24.6.1946 (OMGBR: Functional History 27.4.1945-30.6.1946, II, Appendix 103).

${ }^{173}$ Am 15.11.1946 samt Leiter, Capt. Paulsen USN, von der Marine übernommen (17/161-2/5).

174 Am 15.7.1946 eingerichtet, Leiter: A. E. Redifer (6/30-1/16).

175 Memo von Abteilungsleiter Harris (6/30-1/40). Die am selben Tag mit General Order Nr.5, OMGBR, vom 10.10.1946, bekanntgegebene Umbenennung in Port and Transportation Division ist nicht zum Tragen gekommen (6/69-2/1).

${ }^{176}$ OMGBR: Functional History 1.9.1946 - 31.12.1946, I, S. 3.

17 StA Bremen 4, 116-12, mit ausführlichen Organisationsanalysen.

178 General Order Nr. 17, OMGUS, 1947 (6/17-2/2).

$179 \mathrm{Vgl}$. General Orders Nr. 3, 4 und 7, OMGBR, vom 25.4., 4.6. und 12.12.1947, Nr. 7, OMGBR, vom 14.9.1948 (6/69-2/1).

$180 \mathrm{Vgl}$. Organisationsplan vom 1.5.1948 (6/67-2/1).

181 SiA Bremen 4, 116-11 und 29, auch 6/25-1/20.

182 Wie OMGUS-Hb, Bremen B, Anm. 179; nach OMGBR: Functional History 1.1.1948 31.12.1948, I, S. 7 am 2.5.1948. 
wurde in die Waterfront Division eingegliedert, in der nun die verbliebenen Aufgaben im Bereich Häfen und Schiffahrt zusammengefaßt waren. ${ }^{183}$

OMGUS bildete aus den am 7.März 1947 übernommenen Referaten Inland Waterways, Coastal Shipping und Rivers \& Harbors Engineering die Weser Field Organization mit Sitz in Bremen, die der Water Branch der Transport Division unterstand, administrativ aber mit der Bremer Militärregierung in Verbindung blieb. ${ }^{184}$ Ihr Leiter Kenneth E. McGregor hatte vorher das Bremer Binnenschiffahrtsreferat geführt. ${ }^{185}$ Im Januar 1948 übernahm die Watertransport Branch von BICO die Organisation, die sich nun Weser River Field Organization nannte. ${ }^{186}$ Diese Organisation wurde zum 1.Juni 1949 wieder aufgelöst. ${ }^{187}$ Ihre Funktionen im Bereich Binnen- und Küstenschiffahrt fielen an die Bremer Militärregierung zurück und wurden dem Hafenreferat der Waterfront Division zugeschlagen. ${ }^{188}$ Im Juli 1949 verteilten sich also die Bestandteile der ehemaligen Transportabteilung wie folgt: ${ }^{189}$

$\begin{array}{ll}\text { OMG Bremen: } & \begin{array}{l}\text { Waterfront Division - Port Supervision } \\ \text { Inland Water Transport \& Coastal Shipping Branch } \\ \text { Marine Security Branch }\end{array} \\ & \begin{array}{l}\text { Civil Resources Division - Civilian Transportation } \\ \text { Rail Branch }\end{array} \\ \text { BICO: } & \text { Marine Production \& Control Branch }\end{array}$

Vom leitenden Personal des Ressorts sollen die folgenden hervorgehoben werden: Lt.Col., dann Col. Golon B. Harris, der sich 1945 zunächst bei der Versorgung der DPs in der Enklave hervorgetan hatte, im Januar 1946 die DPs \& Public Welfare Branch leitete und deren schrittweise Umgestaltung in eine Fachabteillung für Häfen, Schiffahrt und Verkehr mitvollzog, stand bis zum 2. September 1947 an der Spitze der Abteilung. ${ }^{190}$ Er war eine kraftvolle Persönlichkeit, dem bürokratisch Kleinkariertes nicht lag. Die Abteilungsleitung ging nach seinem Ausscheiden auf den Direktor uber. Robert J. Siebenmorgen fungierte deshalb vom Herbst 1947 bis 1 . Mai 1948 nicht als Abteilungsleiter, sondern als Chefkoordinator der Abteilung. ${ }^{191}$ Er war als Fachmann fur Küstenschiffahrt seit 1946 Branch Chief in Bremen und vertrat das Gebiet auch beim Häfen- und Küstenschiffahrtskomitee in Hamburg. ${ }^{12}$ Große Verdienste um die bremischen Häfen erwarb sich Stanley A. Clem, der nach der Überführung des Hafenbetriebs in den Verantwortungsbereich der Militärregierung 1946 das Referat Port Operations und damit die fachliche Verantwortung übernahm. ${ }^{193}$ Clem blieb bis 1951 in Bremen. Mit Hafensenator Hermann Apelt verband ihn persönliche Freundschaft. ${ }^{194}$

183 General Orders Nr. 7 und 9, OMGBR, vom 14.9. und 30.11.1948 (6/69-2/1).

184 Einrichtung zwischen dem 13.3. und 9.4.1947 (6/28-1/8).

185 OMGBR: Functional History 27.4.1945 - 30.6.1946, I, S. 368.

186 Organisationsplan in 6/28-3/6.

187 Mitteilung von McGregor an Wasserstraßendirektion vom 25.5.1949 (StA Bremen 5,6I. A.23).

188 General Order Nr. 12, OMGBR, vom 30.6.1949 (6/69-2/1).

$189 \mathrm{Vgl}$. Organisationsplan vom 1.7.1949 (6/2-1/27).

$190 \mathrm{Vgl}$. OMGBR: Functional History 27.4.1945 - 30.6.1946, I, S.473; 6/83-2/5 (15.1.1946); General Order Nr.2, OMGBR, vom 23.8.1946 (6/69-2/1). Er wurde zu OMGUS versetzt, vgl. OMGBR: Functional History 1.7.1947 - 30.9.1947, I, S. 1 .

$191 \mathrm{Vgl}$. Organisationspläne in 6/67-1/21 und 6/1-1/23.

192 OMGBR: Functional History 27.4.1945 - 30.6.1946, I, S.368; StA Bremen 4, $116-11$.

193 OMGBR: Functional History 27.4.1945 - 30.6.1946, I, S. 368

194 So Apelt: Reden und Schriften, S. 280 ff. selbst 1958. Clem, geb. 8.3.1898 in Illinois, war väterlicherseits deutscher Abstammung, von Beruf Ingenieur; diente bei der britischen Flotte, kam 


\section{Arbeit (Manpower)}

Der Labor Officer des Bremer Detachments war beim Einmarsch zunächst - wie geplant - dem Wirtschaftsreferat angegliedert. ${ }^{195}$ Bereits im Juni 1945 erfolgte die Umsetzung in die Utilities \& Labor Branch, ${ }^{196}$ aus der nicht viel später eine eigene Labor Branch hervorging. Mehrfacher Personalwechsel begleitete die organisatorischen Veränderungen. Major Carlton K. Lewis war der erste Amtsinhaber; er wurde schon am 20. Mai 1945 nach Wesermünde versetzt und von dem Zivilbediensteten Emil Skarda abgelöst, der seinerseits am 25. Juni 1945 Major J. W. Marshall als Labor Officer Platz machte. ${ }^{197}$ Dieser gab sein Amt am 29. August 1945 dann an Lt.Col. George R. Mursell ab, welcher mit einer kurzen Unterbrechung im Winter 1945/46 der verantwortliche Fachoffizier der Bremer Militärregierung bis 1949 blieb. ${ }^{198}$

Die Labor Branch, die im Januar 1946 neben dem Einsatz von Arbeitskräften, der Kontrolle der Arbeitsbedingungen und der Betreuung von Gewerkschaften und Betriebsräten auch für den Sozialversicherungsbereich zuständig war, wurde am 27 . April 1946 mit der Housing Branch zur Manpower Division zusammengefaßt. ${ }^{199}$ Die Abteilung verfügte Ende 1946 über 9 von 130, Ende 1947 über 7 von 119 Stellen für Amerikaner. ${ }^{200}$ Sie schrumpfte in der ersten Jahreshälfte 1948 zusammen, bis nur noch der Abteilungsleiter ubbrig blieb und wurde zum 15. September 1948 aufgelöst. ${ }^{201}$ Der Manpower \& Housing Adviser teilte von da an das organisatorische Schicksal der Berater für Wirtschaft, Finanzen und Verkehr. ${ }^{202}$

\section{Gesundheit und Wohlfahrt (Public Health \& Welfare)}

Die Verbindung von Gesundheits- und Wohlfahrtswesen in der Public Health \& Welfare Branch ergab sich - anders als geplant - im Bremer Detachment bereits im Mai 1945. ${ }^{203}$ Mit den Fachkräften der Briten und der 29. Infanteriedivision wurde enger Kontakt gepflegt, der zeitweise seinen Ausdruck in gemeinsamen wöchentlichen Seminaren zu gesundheitspolitischen Themen fand. Das medizinische Personal war der Militärregierung anfangs nur beigeordnet; es gehörte einer besonderen medizinischen Organisation mit Hauptquartier in Süddeutschland an. Dies wurde als Nachteil emp-

1945 nach Berlin, 1946 nach Bremen, wo er bis 1951 blieb; danach Dienst in Kaiserslauten und Livorno. 1953 für zwei Jahre im Holzhandel, dann zurück zur Armee. Starb am 16.3.1958 in Orléans.

195 OMGBR: Functional History 27.4.1945 - 30.6.1946, I, S.420; siehe OMGUS-Hb, Bremen A, Übersicht 2. Zu den Aufgaben der Detachment-Arbeitsoffiziere allgemein siehe Fichter: Besatzungsmacht und Gewerkschaften, S.96ff.

196 Siehe OMGUS-Hb, Bremen A, Übersicht 3.

197 OMGBR: Functional History 27.4.1945 - 30.6.1946, I, S. 417 und $420 \mathrm{f}$.

198 Marshall hatte im Zivilberuf vier Jahre beim US Employment Service verbracht; er kam am 20.8.1945 nach Bremen, wurde zunächst für Bremen, dann für die ganze Enklave zuständig (OMGBR: Functional History 27.4.1945 - 30.6.1946, I, S. 424); befristete Abordnung in die USA ca. Dezember 1945 - Februar 1946 (ebenda, S. 430).

199 Organisationsplan vom 15.1 .1946 (6/83-2/5); Memo vom 27.4.1946 (6/43-2/21).

200 OMGBR: Functional History 1.9.1946-31.12.1946, I, S. 3; 6/67-1/21.

201 Vgl. Organisationsplan vom 15.7 .1948 (6/67-2/1); General Order Nr.7, OMGBR, vom 14.9.1948(6/69-2/1).

$202 \mathrm{Vgl}$. OMGUS-Hb, Bremen B 5, 6, und 7.

203 Vgl. Personalliste vom 31.5.1945 (6/105-1/4); siehe OMGUS-Hb, Bremen A, Ubersicht 3. 
funden und mit dem Abkommen vom 10. Dezember 1945 korrigiert. ${ }^{204}$ Der Organisationsplan vom 15. Januar 1946 weist dann ungefähr die Aufteilung in Public Health und DPs \& Public Welfare auf, die die ursprüngliche Planung vorgesehen hatte. ${ }^{205} \mathrm{Im}$ Wohlfahrtsreferat waren zu dem Zeitpunkt auch die Sektionen Food und Housing angesiedelt. Ende Februar 1946 erhielt das Referat die Bezeichnung Civilian Services und schloB nun auch den Transportsektor mit ein. ${ }^{206}$ Mit Wirkung vom 27. April - beide Bereiche waren inzwischen Abteilungen geworden - erfolgte eine Umstrukturierung, die Civilian Services ein neues Gesicht in Gestalt einer Verkehrsabteilung gab, während das Wohlfahrtswesen herausgenommen und wieder der Gesundheitsabteilung zugeschlagen wurde. ${ }^{207}$ In dieser Zusammensetzung bestand die Public Health \& Welfare Division bis zu ihrer Auflösung 1948. ${ }^{208}$

Beim Einmarsch in Bremen war Major Abraham Gelperin MC verantwortlicher Fachoffizier für Gesundheits- und Wohlfahrtswesen. Er schied am 4. Dezember 1945 aus dem Dienst. Sein Mitarbeiter John C. Sager SnC war bereits am 4. Mai zum Wesermünder Detachment beordert und durch Major John E. Merriken, Med. Adm. Corps, ersetzt worden. Als Sager im Januar 1946 andere Aufgaben erhielt, muBte Merriken vorübergehend das Gesundheitswesen in Bremen und Bremerhaven/Wesermünde beaufsichtigen. ${ }^{209}$ Er blieb als verantwortlicher Fachoffizier für Bremen bis August 1946 im Amt. ${ }^{210}$ Das Wohlfahrtswesen betreute nach Gelperin Major Rainwater, danach Capt. Kenneth R. Moul unter der Referatsleitung von Lt.Col. Golon B. Harris, der fur DPs zuständig war. ${ }^{211}$ Harris blieb Branch Chief nach der Erweiterung des Referats und der Umbenennung in Civilian Services, während das Wohlfahrtswesen nun von Lt. James R. Bartholomew betreut wurde. 212

Die Abteilung fur Gesundheit und Wohlfahrt war Ende 1946 mit funf von 130 USStellen die kleinste der Bremer Militărregierung; ${ }^{213}$ sie verbesserte sich zwar auf acht von 119 Stellen am Jahresende von 1947, doch OMGUS gab Ende Januar 1948 Programme zur Einschrănkung der Aktivităten in diesen Bereichen heraus. ${ }^{214}$ Dr. med. John D. Winebrenner, der am 10. Oktober 1946 zum Abteilungsleiter ernannt worden war, ${ }^{215}$ bezeichnete im April 1948 die Abteilung in ihrer Zusammensetzung als administrative Anomalie britischen Ursprungs und beantragte angesichts des bevorstehen-

204 OMGBR: Functional History 27.4.1945 - 30.6.1946, I, S. 130 und 132.

205 Siehe OMGUS-Hb, Bremen A, Übersicht 2 und 4.

206 Telefonverzeichnis der Bremer Militärregierung vom 1.3.1946, S. $11 \mathrm{f}$.

${ }^{207}$ Memo vom 27.4.1946 (6/43-2/21). Abweichend hiervon und zweifellos falsch datiert OMGBR: Functional History 1.7.1946-30.6.1947, I, S.62 f. die Zusammenlegung der Bereiche in den Juli 1946; sie wird als Analogiebildung zur Geschäftsverteilung im Bremer Senat erläutert. Die DPs Branch war bereits am 15.4.1946 mit der Welfare Branch verschmolzen worden (OMGBR: Functional History 27.4.1945 - 30.6.1946, I, S. 476).

208 General Order Nr. 7, OMGBR, vom 14.9.1948 (6/69-2/1).

${ }^{209}$ OMGBR: Functional History 27.4.1945 - 30.6.1946, I, S. $130 \mathrm{ff}$.

210 6/42-3/22. Der Organisationsplan vom 15.1.1946 (6/83-2/5) nennt Capt. Oscar A. Nelson als Public Health Officer neben Merriken. Der Name taucht später nicht mehr auf.

211 Ebenda und OMGBR: Functional History 27.4.1945 - 30.6.1946, I, S. 156.

212 Telefonverzeichnis vom 1.3.1946, S.11. Die Darstellung in OMGBR: Functional History 27.4.1945 - 30.6.1946, I, S.156, nach der Bartholomew den Bereich erst im April 1946 übernahm, muß demnach irrig sein.

213 OMGBR: Functional History 1.9.1946 - 31.12.1946, I, S.3.

214 6/67-1/21; OMGBR: Functional History 1.1.1948-31.12.1948, I, S.33.

215 General Order Nr. 5, OMGBR, vom 10.10.19461946 (6/69-2/1) (dort versehentlich John $B$. Winebrenner); amtierte als Public Health Officer bereits im September 1946 (6/42-3/22). 
den wie bereits vollzogenen Personalabbaus ihre Auflösung. ${ }^{216}$ Dazu kam es dann erst mit Wirkung vom 20. Juli 1948, ${ }^{217}$ wenngleich bereits Anfang Juni nur noch je eine Fachkraft für den Gesundheits- und Wohlfahrtsbereich den Restbestand der Abteilung ausgemacht hatten. ${ }^{218}$ Winebrenner gab am 20. September 1948 sein Amt auf und kehrte in die USA zurück. Seine Stelle als Public Health Adviser nahm seine frühere Vertreterin, die Krankenschwester Olga B. Edwards ein, als Public Welfare Adviser fungierte Melba M. Foltz. ${ }^{219}$ Beide Frauen arbeiteten zunächst im Rahmen der Governmental Affairs Division, dann der Public Affairs \& Legal Division bis Ende Mai 1949. Zum 1.Juni wurden ihre Funktionen noch einmal auf andere Stellen der Bremer Militärregierung übertragen, zum 30. Juni 1949 schlieBlich wurden die Ämter des Public Health Adviser und Public Welfare Adviser in Bremen ganz aufgelöst. ${ }^{220}$

\section{Bildung und Kultur (Education \& Cultural Relations)}

Das Organisationskonzept vom März 1945 hatte den Bereich Bildung, Wissenschaft und Kunst zusammen mit dem politischen Nachrichtendienst und der Berichterstattung über die Aktivitäten der Militärregierung dem Executive Officer zugeordnet eine eigenartige Einteilung, die auch nicht zum Zuge kam. ${ }^{221}$ Die stattdessen getroffene Regelung führte allerdings ebenfalls zu einer Aufgabenhäufung, die effektives Arbeiten in allen Bereichen praktisch unmöglich machte. Bildung wurde zusammen mit Religion, Kunst, Jugend und Sport Teil der Civil Administration Branch, die Capt. Erwin W. Bard leitete. ${ }^{22}$ Bard, neben seinen vordringlichen Verpflichtungen in der $\mathrm{Zi}$ vilverwaltung beim Aufbau eines neuen Bremer Senats für den gesamten Kulturbereich zuständig, konnte den überall anstehenden Problemen unmöglich gerecht werden. ${ }^{223}$ Bei der Aufgliederung in Lokal- und Enklavenverwaltung im August 1945 blieb Bard beim Bremer Team, während auf höherer Ebene Major Harold H. Crabill die Belange von Zivilverwaltung und Kultur wahrnahm. ${ }^{224} \mathrm{Er}$ wurde auf amerikanischer Seite die prägende Gestalt im Bremer Bildungswesen der Nachkriegszeit.

Crabill war im Zivilberuf Pädagoge. ${ }^{25}$ Im November 1945 übernahm er das Erzie-

${ }^{216}$ Schreiben vom 12.4.1948 an Director, OMG Bremen (6/1-2/1).

217 General Order Nr. 7, OMGBR, vom 14.9.1948 (6/69-2/1).

218 Siehe Organisationsplan vom 1.6.1948 (6/67-1/21).

219 OMGBR: Functional History 1.1.1948-31.12.1948, 1, S. 33.

220 General Order Nr.7 und 9, OMGBR, vom 14.9. und 30.11.1948; Nr. 11 und 12, OMGBR, vom 27.5. und 30.6.1949 (6/69-2/1). Zum gesamten Komplex vgl. Britta im Sande: Gesundheitsund Sozialpolitik in Bremen unter amerikanischer Besatzung im Spiegel der Akten der Besatzungsbehörden 1945-1949, Hamburg 1991 (Ms. im StA Bremen).

221 Siehe OMGUS-Hb, Bremen A, Übersicht 2. Vgl. zum folgenden auch OMGUS-Hb. Bremen B 2.a.

222 Aufstellung vom 1.6.1945 (6/105-1/4); OMGBR: Functional History 1.10.1945 - 10.12.1945, I, S. 43 .

${ }^{223}$ OMGUS-Hb, Bremen A, Übersicht 3 weist eine eigene Organisationseinheit aus für Education \& Religion, Monuments \& Arts, Historian (die Bereiche Jugend und Sport inbegriffen) - verantwortlich: Capt. Bard. Der ganze Komplex war für längere Zeit von Bard mit Hilfe eines einzigen Soldaten zu bewältigen (OMGBR: Functional History 1.10.1945 - 10.12.1945, I, S. 43).

${ }^{224}$ OMGBR: Functional History 27.4.1945-30.6.1946, I, S. 51 und 195.

225 Nach Wulff: Im Jahrfünft, S. 20, geb. 1905, deutsche Vorfahren, mangelhafte deutsche Sprachkenntnisse. Schüler von J. Dewey und W. Kilpatrick. Wirkte "in seiner ein wenig quellenden leiblichen Fülligkeit ... wie ein wortkarger sizilianischer Taverne-Wirt". Im Zivil- 
hungswesen und die Bereiche Jugend und Sport in Bremen auch auf lokaler Ebene und machte sich um die Beschaffung von Schulbüchern verdient. ${ }^{226}$ Ende Dezember wurde er in dieser Funktion abgelöst und als Leiter der Information Branch eingesetzt, in der - beinahe so wie im März 1945 geplant - der Kultursektor zusammengefaßt war mit Jugendangelegenheiten, politischem Nachrichtendienst und der Berichterstattung in eigener Sache. ${ }^{227}$ Bei der nächsten Reorganisation Ende Februar 1946 griff man jedoch auf die Konstellation des Vorjahres zurück und führte Zivilverwaltung und Kultur wieder zusammen in der Civil Government Branch, die in Abwesenheit von Crabill Capt. Joseph H. Baynard leitete. ${ }^{228}$

Ende März 1946 erfolgte die Umwandlung zur Abteilung, die nun Major John C. Sager führte, bis Crabill - inzwischen Lt.Col. - Anfang Mai zurückkehrte und die Leitung übernahm. ${ }^{229}$ Die Abteilung bestand aus Education, Religious \& Cultural Affairs Branch (Leitung: Capt. Carvel Busey), ${ }^{230}$ City Administration Branch sowie History \& Reports Branch. ${ }^{231}$ Letztere fehlt auf dem Organisationsplan Ende November 1946. ${ }^{232}$

leben Lehrtätigkeit am Department of Education, Indiana University, besonders im Bereich visuelle Unterrichtsmittel; vgl. hierzu auch Clifton: Reform of Education, S. 143; Kennan: Memoirs, S. 438 erhielt vom amerikanischen Konsul in Bremen 1949 die Auskunft, Crabill sei Lehrer an einer High School in Indiana gewesen. Nach seiner Bremer Zeit kaufte Crabill eine Farm in Middletown, Virginia, wo er Wilhelm Kaisen auf dessen Amerikareise Anfang Mai 1950 beherbergte. Kaisen erwähnt den Besuch in seinen Erinnerungen (Meine Arbeit, S. 304) und schildert seine Eindrücke von der Farm, verliert jedoch über die Person Crabills, dessen unflexible Haltung in schulpolitischen Fragen er Kennan gegenüber beklagt hatte, kein weiteres Wort. Crabill, der von einer Rückkehr nach Bremen als Mitarbeiter der geplanten Internationalen Universität träumte, hatte mit dem Besuch Hoffnungen verknüpft, in dieser Sache voranzukommen, die sich nicht erfullten; siehe Brief an W. Berger vom 28.5.1950 (StA Bremen 7,110 NachlaB Berger Nr. 59). Der zitierte Brief läBt auch Distanz zu Jeffs und seinem Executive Officer Payette erkennen, die sicherlich keinen Wert darauf legen würden, ihn wieder bei sich zu sehen, sowie das Gefühl zunehmender Isolierung unter den Fachkollegen der Besatzungstruppe. Das aus der Zusammenarbeit in der Bremer Militärregierung erwachsene Freundschaftsverhältnis zu Wilhelm Berger (1901-1974; Lehrer, ab 1951 Schulrat in Bremen) ist zu diesem Zeitpunkt von Bewunderung für den Deutschen bestimmt. Laut Wulff: Im Jahrfünft, S. 21, war Crabill in Bremen ohne Berger nicht zu denken, der ats Helfer, Berater und Dolmetscher fungierte. Crabill ging 1951-1953 zur Air Force, wo er Unterrichtsmaterialien und Lehrfilme herstellte, war danach zeitweise Versicherungsvertreter, 1957 dann Lehrer an einer High School in Dayton, Ohio, schließlich Dozent am dortigen Sinclair College (StA Bremen 7, 110-59 und 24).

226 OMGBR: Functional History 27.4.1945 - 30.6.1946, I, S. 164 f.; Clifton: Reform of Education, S.143.

227 Siehe OMGUS-Hb, Bremen A, Übersicht 4.

${ }^{228}$ Telefonverzeichnis vom 1.3.1946; in der Sektion für Erziehung erscheint als einer der beiden verantwortlichen Mitarbeiter Wilhelm Berger, der spätere Schulrat; siehe OMGUS-Hb, Bremen B, Anm. 225; Baynard wurde im Januar 1946 als Historian in der Information Branch geführt (6/83-2/5; vgl. auch OMGBR: Functional History 27.4.1945 - 30.6.1946, I, S. 53).

229 Ebenda, S. $53 \mathrm{f}$.

230 In der Nachfolge Crabills seit Ende Dezember 1945 (OMGBR: Functional History 27.4.1945 - 30.6.1946, I, S. 165, so auch Clifton: Reform of Education, S.143); die auf dem Organisationsplan vom 15.1.1946 genannte Joan Packard (6/83-2/5) kann das Amt - wenn überhaupt - nur sehr kurze Zeit innegehabt haben. Busey schied am 1.11.1946 aus (OMGBR: Functional History 1.9.1946 - 31.12.1946, II, Appendix 1 b); Nachfolger wurde Dr. Ernest A. Flotow, siehe OMGUS-Hb, Bremen B.2, Anm. 62.

$231 \mathrm{Vgl}$. Organisationsplan in 6/37-2/10.

232 Siehe OMGUS-Hb, Bremen A, Übersicht 5. Vermutlich wurde sie schlicht vergessen, denn es 
Die beiden verbliebenen Referate verselbständigten sich am 7.Juni 1947 zu eigenen Abteilungen, wobei Crabill die Leitung der Education Division übertragen wurde. ${ }^{233}$ Ihre Aufgabenstellung beschränkte sich auf den Kulturbereich, Jugend und Sport. Die Einrichtung dieser Fachabteilung in Bremen nahm eine Entwicklung vorweg, die sich in anderen Teilen der amerikanischen Zone erst im Frühjahr 1948 vollzog, nachdem von OMGUS am 18. Februar 1948 eine entsprechende Aufforderung ergangen war. ${ }^{234}$ Im Sommer wurde auf allgemeine Anordnung der Zentrale die Überwachung des Theater- und Musiklebens von Information Control auf die Kulturabteilung übertragen, die sich in Bremen etwa seit der Zeit Education \& Cultural Relations Division nannte. ${ }^{235}$

Von den großen Veränderungen im Herbst 1948 blieb die Abteilung unberührt. 1949 umfaßte sie noch Education Branch, Teacher Training Branch, Cultural Relations Branch und Group Activities Branch, wie sich das Referat für Jugendangelegenheiten mit etwas erweitertem Aufgabenfeld nun nannte, ${ }^{236}$ und ungefähr in diesem Zustand erreichte sie das Ende der OMGUS-Periode - allerdings ohne ihren Abteilungsleiter. Harold H. Crabill hatte bereits am 6. Juli 1949 seinen Dienst in Bremen quittiert.

\section{Wesermünde und Bremerhaven}

Das Wesermünder Detachment G1C2 wurde zusammen mit der für Bremen bestimmten Einheit E2C2 am 27. Januar 1945 ins Leben gerufen und rückte gemeinsam mit ihr als Anhängsel des britischen 30. Corps nach Bremen ein. Der Angriff auf Wesermünde begann erst eine Woche nach der Besetzung Bremens. Eine Vorhut des Detachments sondierte am 7. Mai 1945 die Lage in der Stadt, am Tag darauf erfolgte die offizielle Übernahme der Regierungsverantwortung. Am 20. Mai ging die Verantwortung für die Sicherheit der Alliierten von den Briten auf die nachruckende 29. Infanteriedivision über. ${ }^{237}$

Unter dem Kommando von Major Raymond M. Davis standen anfangs insgesamt 26 Mann, von denen acht Offiziersrang hatten. ${ }^{238}$ Ende Mai wurden die sieben Bereiche Property Control, Labor \& Transportation, Economics \& Public Utilities, Public Safety, Food \& Supply, Legal und Displaced Persons betreut, wobei der Sicherheitsbereich

gab sie nach wie vor; Branch Chief war Thomas P. Headen, in Personalunion Abteilungsleiter von Information Control (vgl. Röpcke: Dienstberichte, S.312), so daß ein Wechsel der Branch zur ICD anzunehmen ist.

${ }^{233}$ General Order Nr.5, OMGBR, vom 7.6.1947 (6/69-2/1); Clifton: Reform of Education, S. 143.

234 Auflösung der Internal Affairs \& Communications Division und Einrichtung einer Education \& Cultural Relations Division zum 1.3.1948 (General Order Nr.6, OMGUS, vom 18.2.1948).

235 Special Order Nr.22, OMGUS, vom 23.6.1948; vgl. Organisationsplan vom 15.7.1948 (6/67$2 / 1)$ und vom 15.9.1948 (6/69-2/1).

$236 \mathrm{Vgl}$. Organisationspläne vom 1.3.1949 (6/58-1/19) und vom 1.7.1949(6/2-1/27). Mitarbeiter in der Education Branch war 1949 Floyd Hines, früher Schulaufsichtsbeamter in Cambridge City, Indiana. Hines initiierte in seiner Heimat eine Spendenaktion für Bremen und stand in schriftlichem Kontakt zum Department of Education in Indianapolis und der University of Indiana, Bloomington, die auch in Reise- und Austauschprogrammen eine Rolle spielten (6/56-3/1). Crabill kam ja ebenfalls aus Indiana (siehe OMGUS-Hb, Bremen B, Anm. 225).

${ }^{237}$ OMGBR: Functional History 27.4.1945 - 30.6.1946, I, S. 9 ff.; vgl. OMGUS-Hb., Bremen A 1; zum ganzen Abschnitt vgl. Scheper: Bremerhaven, S. 345-406 (noch ohne Kenntnis der amerikanischen Überlieferung verfaßt).

238 OMGBR: Functional History 27.4.1945 - 30.6.1946, II, Appendix 6, Namensliste. 
als einziger mit zwei Offizieren besetzt war. ${ }^{239}$ Personalverstärkungen ließen im Laufe des Sommers die Zahl der Offiziere auf 26 anwachsen. ${ }^{240}$

Anfangs war das Detachment für Stadt und Landkreis Wesermünde zuständig, doch zeigte sich schnell, daß das nicht zu bewältigen war. Erwünschte Entlastung brachte die Einrichtung des Detachments $110 \mathrm{C} 2$, das am 31. Mai den Landkreis übernahm, doch blieb in einigen Aufgabenbereichen (Public Health, Welfare, DPs, Finance, Property Control, Food) die erweiterte Zuständigkeit des Detachments G1C2 bis zur Übergabe des Landkreises an die britische Besatzungsverwaltung am 10. Dezember 1945 erhalten. ${ }^{241}$

Ferner ist zu beachten, daß der Hafenbetrieb und die Sicherung der Schiffahrtswege zunächst nicht im Aufgabenbereich der Militärregierung lagen, sondern von Spezialeinheiten im Bremen Port Command und der US-Navy besorgt wurden. Als im April 1946 der Hafenbetrieb in Bremen der Zuständigkeit der Militärregierung ubertragen und wieder ganz in deutsche Hände gelegt wurde, verlegte die Hafentruppe 17th Major Port ihr Hauptquartier nach Bremerhaven. Das Bremen Port Command (BPC) wurde aufgelöst, Bremerhaven Port of Embarkation (BPE) trat die Nachfolge an. Ein Schwergewicht der Aufgaben dieses Stützpunktes lag bei der Abwicklung der Truppentransporte und des zivilen Personenverkehrs über See von der Columbuskaje aus, nachdem die Funktionen im Hafenbetrieb Bremerhavens bis Juli 1947 weitgehend an die deutsche Weserhafenbehörde abgegeben worden waren, die unter der Aufsicht der Bremer Militärregierung operierte:242 BPE hatte dafür den Bereich Verpflegung und Versorgung der Militärregierung zusätzlich zu verwalten. ${ }^{243}$

Dem Bremerhavener Detachment brachte die Übernahme der Kontrolle des Hafenbetriebs keinen Kompetenzzuwachs, denn die verantwortlichen Offiziere blieben organisatorisch in die Bremer Transport bzw. Waterfront Division eingebunden. ${ }^{244}$

Ende Juni/Anfang Juli 1945 war dem Kommandeur des Bremer Detachments die in der Praxis schon vorher ausgeubte Befehlshoheit auch uber die ubrigen amerikanischen Detachments der Enklave offiziell zugesprochen worden. ${ }^{245}$ Als Lt.Col. Luther S. Diggs am 7. August 1945 in Bremerhaven/Wesermunde das Kommando ubernahm, war gerade die Aufteilung in Enklavenverwaltung und lokale Einheiten erfolgt. ${ }^{246}$ Nach dem Abkommen vom 10. Dezember 1945 stand Diggs einem Office of Military Government for Stadtkreis Wesermunde \& Bremerhaven vor, das 13 Fachreferate aufwies und mit 21 Offizieren besetzt war. Öfentliche Sicherheit und Fischerei waren mit vier bzw. drei Offizieren am besten ausgestattet. Vertreten wurde Diggs durch Lt.Col. Ernest H. Hicks, für Civil Administration zeichnete Lt. Arthur L. Ballin ver-

\footnotetext{
$2396 / 105-1 / 4$.

240 OMGBR: Functional History 26.4.1945 - 30.9.1945, II, Appendix 1.

241 OMGBR: Functional History 27.4.1945 - 30.6.1946, I, S. 15 und 72.

242 Vgl. OMGUS-Hb, Bremen B.7.

243 OMGBR: Functional History 1.7.1947 - 30.9.1947, I, S. 1 .

244 Die Port Operations Branch, Transport Division, hatte seit November 1946 ein Büro in Bremerhaven, dem der Hafendirektor vorstand. Dieses Amt, dessen Bezeichnungen sich im Laufe der Zeit änderten, bekleidete von November 1946 bis Januar 1947 Major Richard H. Bagley, der spätere Executive Officer des Bremerhavener Detachments (6/109-1/2, April 1947). von Januar 1947 bis 1949 dann John M. Dekreon. Bei den für Hafen- und Wasserschutzpolizei zuständigen Offizieren verhielt es sich im Prinzip ebenso.

$245 \mathrm{Vgl}$. OMGUS-Hb, Bremen, A 2.

246 OMGBR: Functional History 27.4.1945 - 30.6.1946, I, S. 13 und 16.
} 
antwortlich. ${ }^{247}$ Bei der Ablösung von Lt.Col. Diggs als Befehlshaber des Bremerhavener Detachments am 19. Juli $1947^{248}$ wies dieses nur noch die sechs Sektionen Public Safety, Legal, Civil Administration, Denazification, Manpower und Public Health \& Welfare auf, von denen letztere überdies nicht mehr besetzt war. ${ }^{249}$ Die übrigen waren in den vergangenen 18 Monaten in Fortfall geraten. Die Einheit hatte am 23. August 1946 die Bezeichnung Wesermünde Liaison Group erhalten ${ }^{250}$ und war als Folge der Vereinigung von Bremerhaven und Wesermünde ${ }^{251}$ am 28. Februar 1947 umbenannt worden zu Bremerhaven Liaison \& Security Detachment, ${ }^{252}$ eine Benennung, die sich als dauerhaft erwies. Abgelöst wurde Diggs von seinem bisherigen Vertreter, Lt.Col. Alfred L. Haig, ${ }^{253}$ der allerdings im Dezember 1947 versetzt wurde. Lt.Col. Martin P. Wehling nahm am 15. Dezember 1947 zunächst kommissarisch, dann regulär ernannt seine Stelle ein. ${ }^{254}$ Wehling war vorher für den Bereich Zivilverwaltung in Bremerhaven zuständig gewesen und zeichnete sich durch gute Deutschkenntnisse aus. ${ }^{255}$ Auch er blieb nur kurze Zeit im Amt, bis er in die USA zurückbeordert wurde. Am 20. Februar 1948 übernahm Major Alexander F. Leith für ihn das Kommando. ${ }^{256}$ Dieser blieb bis in den Sommer 1948. Das Bestreben, militärisches Personal durch ziviles zu ersetzen, brachte Edward E. Merone an seine Stelle, ${ }^{257}$ der das Amt dann noch für ein gutes Jahr verwaltete.

Der SchrumpfungsprozeB des Detachments hatte 1948 drastische Formen angenommen. Waren Ende 1947 noch 13 US-Stellen für Bremerhaven ausgewiesen, von denen zwölf in den Bereichen Public Safety, Legal, Transport, Manpower und Denazification besetzt waren, so mußte Ed Merone ein Jahr später mit ein paar deutschen Mitarbeitem allein zurechtkommen. ${ }^{258} \mathrm{Er}$ wirkte praktisch nur noch als Verbindungsoffizier

${ }^{247}$ Organisationsplan vom 15.1.1946 (6/83-2/5). Hicks hatte vorher auf Enklavenebene den Bereich Transportation geleitet (6/22-1/22). Ballin war seit dem Einmarsch in Bremen dabei und feierte Ende April 1946 dessen Jahrestag (OMGBR: Functional History 27.4.1945 30.6.1946, II, Appendix 6; OMGBR: Functional History 27.4.1945 - 30.6.1946, I, S. 23). Er soll in Entnazifizierungsfragen besonders scharf und unerbittlich gewesen sein, was man damit erklärte, daß er aus Wien emigrierter Jude war (siehe Wilhelm: Bremerhaven, S. 38).

248 Special Order Nr.53, OMGBR, vom 19.7.1947 (6/2-3/5); das Ende seiner Dienstzeit stand bevor.

$249 \mathrm{Vgl}$. Organisationsplan vom 1.7.1947 (6/67-1/21).

250 General Order Nr. 1, OMGBR, vom 23.8.1946 (6/69-2/1).

251 Am 7.2.1947; zu territorialen Fragen siehe OMGUS-Hb, Bremen, A 4.

252 General Order Nr.1, OMGBR, vom 28.2.1947 (6/69-2/1).

${ }^{253}$ Seit dem 16.9.1946 bei der Bremer Militärregierung (OMGBR: Functional History 1.9.1946 31.12.1946, II, Appendix 1 b); in Bremerhaven für Economics zuständig, Staff Memo Nr. 12, 9.4.1947 (6/109-1/2).

254 General Order Nr.8, OMGBR, vom 15.12.1947 und Nr.2, OMGBR, vom 22.1.1948 (6/692/1).

${ }^{255}$ Er leitete einen Deutschkurs für amerikanisches Personal, Staff Memos Nr. 12 und 13, April $1947(6 / 109-1 / 2)$.

256 General Order Nr.3, OMGBR, vom 7.2.1948 (6/69-2/1); OMGBR: Functional History 1.1.1948-31.12.1948, I, S. 7 .

257 Ebenda, S. 8; Merone war vorher in der Industrial Management Branch der Bremer Economics Division tätig.

258 Stellenplan vom 31.12.1947 (6/67-1/21); OMGBR: Functional History 1.1.1948 - 31.12.1948, I, S. 8 nennt demgegenüber - vermutlich irrig - nur acht Stellen für Ende 1947. Eine Stellungnahme des Direktors der Bremer Militärregierung zu möglichen Personaleinsparungen vom 6.1.1948 brachte höheren Orts eine Reduzierung des Bremerhavener Detachments in Vorschlag (5/354-2/35). 
der Militärregierung zu den deutschen Behörden in Bremerhaven und dem Post Commander von Bremerhaven Port of Embarkation. Eine Aufgabenbeschreibung aus dem Sommer 1949 nennt als eigene Aktivität - dürftig genug - lediglich das Organisieren von Diskussionsveranstaltungen im Rahmen des Reorientation Program. ${ }^{259}$ Im Spektrum der vielfältigen amerikanischen Einrichtungen in Bremerhaven spielte der offizielle Vertreter der Bremer Militärregierung 1949 eine eher unscheinbare Rolle. ${ }^{260}$

${ }^{259}$ General Order Nr. 12, OMGBR, vom 30.6 .1949 (6/69-2/1).

$260 \mathrm{Vgl}$. BPE Telefonverzeichnis vom 1.8.1949. 


\section{Quellenbeschreibung}

\section{Die Akten der Bremer Militärregierung}

Die Akten der amerikanischen Militärregierung in Bremen wurden im März 1951 als eine unter sechzehn Schiffsladungen mit OMGUS-Akten von Bremen in die Vereinigten Staaten verschifft. ${ }^{1}$ In den vor der Verschiffung aufgestellten „shipping lists“, die noch bis vor wenigen Jahren das einzige Findmittel zum Bestand darstellten, bilden die Bremer Akten das Shipment 6, das aus 125 Kisten bestand. Nachträglich hinzugekommene Akten wurden später dem OMGUS-Bestand als Shipment 17 angefügt. Auch unter diesen war Bremer Material, so daB zusammen 141 Kisten der Bremer Militärregierung 1953 im Records Center von Kansas City registriert wurden. Als man in den sechziger Jahren die Kisten nach Alexandria (Va.) verfrachtete und ihren Inhalt in kleinere Kartons umpackte, fehlte bereits ein Teil, der vermutlich einer recht willkürlichen Kassation in Kansas City zum Opfer gefallen ist. ${ }^{2}$ Vom Bremer Bestand wurden 45 Kisten oder ca. $32 \%$ des Materials $1977 / 78$ als fehlend festgestellt. Soweit die Verschiffungslisten erkennen lassen, handelt es sich dabei überwiegend um weniger wertvolle Teile der Überlieferung vor allem aus den Bereichen Interne Verwaltung, Wirtschaft, Transport, öffentliche Sicherheit, Zivilverwaltung und besonders Bremerhaven. 197778 nicht festgestellt wurden ferner die Entnazifizierungsakten, die von Bremen an das Document Center Darmstadt abgegeben worden waren (wie inzwischen bekannt wurde, handelt es sich bei ihnen ausschließlich um Einzelfallakten). Für die Beurteilung der Überlieferung ist die Beobachtung wichtig, daß die Bremer Akten bereits bei der Verschiffung nicht mehr vollständig waren. Neben der vorzeitigen Abgabe an zentrale Sammelstellen, wie sie bei den Entnazifizierungsakten nachweisbar ist, gab es auch den Versuch, wertloses Material (non-record material) auszusondern und zu vernichten. ${ }^{3}$ Man darf getrost davon ausgehen, daß dabei Akten ins Altpapier wanderten, die Forscher heute gern zur Hand hätten. Andere wurden ausgesondert und zurückgehalten, weil sie noch für die Geschäfte des Landeskommissars benötigt wurden. Übrig blieben ca. 100 Regalmeter Akten in 287 records center boxes, die nach groben Schätzungen knapp $5 \%$ der erhaltenen Gesamtmenge von Record Group 260 OMGUS im Washington National Records Center Suitland (Md.) ausmachen.

Die Akten wurden im Rahmen des amerikanisch-deutschen OMGUS-Projektes ${ }^{4}$ $1977 / 78$ von Bremer Archivaren durchgesehen. Von den insgesamt 8127 Einzelakten wurden dabei 2161 ( = 26,6\%) zur Mikroverfilmung bestimmt. Da vielfach gerade die dickeren Bände wichtiges Material enthielten und deshalb zur Verfilmung kamen, dürfte tatsächlich allerdings mehr als $27 \%$ des Bremer Archivgutes im OMGUS-Bestand verfilmt worden sein. Die mikroverfilmten Akten stehen seit einigen Jahren in Form von Mikrofiches im Staatsarchiv Bremen der Nutzung durch die Forschung of-

${ }^{1} \mathrm{Vgl}$. zum folgenden vor allem Abschlußbericht über die Auslandstätigkeit bremischer Archivare im Rahmen des OMGUS-Projekts, 30.6.1978 (StA Bremen Reg.akte 731-01 Bd. 4).

2 Dies ergaben Nachforschungen des amerikanischen Archivars James J. Hastings 1978, siehe StA Bremen Reg.akte 731-01 Bd.4, Anlage 2.

${ }^{3}$ Siehe ebenda, Anlage 5, Memo des Landeskommisars vom 28.4.1950. Auf eine solche Vernichtungsaktion wies ein zufällig erhaltenes verschnürtes und laut Aufschrift zur Vernichtung bestimmtes Bündel von Schriftstücken der Food \& Agriculture Branch aus dem Jahre 1946 die übrigen Akten des Jahres 1946 dieser Provenienz fehlen.

${ }^{4}$ Siehe dazu J. Henke: Das amerikanisch-deutsche OMGUS-Projekt, Sp. 149 - 158. 
fen. ${ }^{5}$ Durch glückliche Umstände gelangte ferner ein vollständiger Satz der Bremer Functional Histories of Military Government im Original an das Archiv, deren beigegebene Fotos und teils farbige Grafiken sich dem Benutzer natürlich besser und vollständiger erschließen als über den Mikrofilm. ${ }^{6}$

Inhaltliche Schwerpunkte des Bestandes sind wie folgt zu skizzieren:

Eine zentrale VerschluBsachensammlung, die 1949 auf höhere Weisung angelegt wurde, ist bei den Akten des Executive Officer überliefert. In ihr finden sich als vertraulich und geheim eingestufte Vorgänge aus verschiedenen Abteilungen, die vor allem das politische Leben betreffen. Vorgänge aus dem nachrichtendienstlichen Bereich machen einen erheblichen Anteil aus. Die Sammlung muB bei jeder intensiveren Benutzung des Bestandes auf einschlägiges Material überprüft werden.

Bei der Pressestelle, der seit 1947 auch der Historian zugeordnet war, hat sich ein vollständiger Satz der schon genannten Functional Histories erhalten. Tages-, Wochenund Monatsberichte, Staff Memos, Organisationspläne und Verwaltungsanweisungen finden sich bei der Abteilung für Verwaltung und Personal.

Die Akten der Civil Administration Division enthalten u. a. Material zu den politischen Parteien und ihren Aktivitäten sowie zur Durchführung der ersten Wahlen nach dem Kriege. Die Überwachung politischer Versammlungen fand hingegen ihren Niederschlag im Bereich Public Safety. Die lange Reihe der Überwachungsberichte gehört zu den wertvollsten Teilen des Bremer OMGUS-Bestandes. Weiterhin ist unter Public Safety Wiederaufbau und Überwachung von Feuerwehr und Polizei dokumentiert, auch Wasserschutzpolizei und Gefängnisverwaltung. Entwicklung und Überwachung von Presse, Rundfunk und Verlagswesen spiegelt sich in dem nicht sehr umfangreichen Aktenbestand der Information Control Division. ${ }^{7}$ Die Entnazifizierungsabteilung hat vor allem Schriftgut zu prozeduralen Fragen, zur Entnazifizierungspolitik und solches statistischer Art hinterlassen. Zur Ergänzung müssen die Entnazifizierungsbetreffe der Fachabteilungen herangezogen werden, die für die praktische Durchführung in diesem Bereich verantwortlich waren.

Bei der Legal Division findet sich Material uber allgemeine Rechts- und Verfassungsfragen des Landes Bremen, über Rechtsprechung, auch Strafvollzug. Bei der Finance Division ist - wenn auch nicht sehr umfangreiches - Quellenmaterial zur Überwachung der Banken, zur Wăhrungsreform und den Besatzungskosten erhalten.

In der Wirtschaftsabteilung ist der Central File des Abteilungsleiters erhalten mit Material über Reparationen und Wiedergutmachung, Ernährung, Landwirtschaft und Fischerei, Industrie und Handel, Bauwesen, Energieversorgung und auch zur allgemeinen Politik gegenüber dem Land Bremen. Weiter finden sich im Zusammenhang mit Reparationsleistungen spezifische Akten über die großen bremischen Industriebetriebe, insbesondere die Demontage der Deschimag ( $A G$ „Weser“), und im Ernährungssektor über die Lebensmittelrationierung und die Wiederaufnahme der Fischerei.

Aus der Transport Division sind vor allem uberliefert der Central File des Abteilungsleiters mit Material zum Wiederaufbau der Häfen und zur Wiederzulassung von

${ }^{5}$ Ein weiterer Satz Mikrofiches befindet sich im Stadtarchiv Bremerhaven, im Institut für Zeitgeschichte, München, und eine Auswahl im Zentralinstitut für sozialwissenschaftliche Forschungen, Berlin.

${ }^{6}$ Ein weiterer, allerdings nicht ganz vollständiger Satz befindet sich beim europäischen Hauptquartier der US-Armee in Heidelberg; er wurde von Brandt (Antifaschismus und Arbeiterbewegung, S. 425) für seine Bremer Studie benutzt; vgl. Röpcke: Dienstberichte der Besatzungsmacht, S.292f.

${ }^{7}$ Vgl. Halefeldt: Akten der Amerikanischen Militärregierung. 
Schiffahrt und Schiffbau, Akten der Port Operations Branch, die die für den Hafenbetrieb zuständige Weserhafenbehörde beaufsichtigte, und Akten der Marine Production \& Control Branch, die Schiffbau und Werften kontrollierte. Angefügt sind Akten zur Binnen- und Küstenschiffahrt, zu Strom- und Hafenbau, die von der Weser River Field Organization und ihren Vorläufern herrühren.

Die Akten der Manpower Division ermöglichen Aussagen über Gewerkschaften und Betriebsräte, Bewirtschaftung des Arbeitsmarktes, Wohnungs- und Sozialversicherungswesen. Die Public Health \& Welfare Division hat überwiegend Material zum Gesundheitswesen hinterlassen (Krankheiten, Ernährungslage, Entnazifizierung), im Wohlfahrtsbereich Akten uber die Tätigkeiten des Jugendamtes und des Wohlfahrtsamtes sowie der Hilfsorganisationen CARE, CRALOG und Rotes Kreuz.

Im Bereich Bildung und Kultur sind nicht nur die Komplexe Schulverwaltung, Schulreform und das Bremer Universitätsprojekt reichhaltig dokumentiert, sondern es finden sich auch Akten über die Kirchen und Religionsgemeinschaften, Theater- und Musiküberwachung, sowie die Zulassung von Vereinen verschiedenster Art. Die Akten des Sachgebiets Jugend und Sport enthalten Material über Jugendförderungsprogramme, Jugendzeitschriften und Jugendclubs, darunter auch die Jugendgruppen politischer Organisationen.

Die Überlieferung des Bremerhavener Detachments enthält Akten fast aus dem gesamten Spektrum der Okkupationsverwaltung, vor allem betreffend Entnazifizierung, Aktivitäten von Parteien, Gewerkschaften, Verbänden und Vereinen sowie Fischereisachen, doch auch Finanzangelegenheiten, Wohnraumbeschaffung, Jugendarbeit u. a. Zusammenfassend ist festzuhalten, $\mathrm{da} B$ die auf Mikrofilm in Deutschland zugänglichen Akten der amerikanischen Militärregierung in Bremen trotz der eingangs geschilderten Verluste und trotz des Umstands, daß die Überlieferung erst gegen Ende 1946 an Dichte gewinnt und bis in den Mai 1945 nur in einzelnen Strängen zurückreicht, eine bedeutsame Verbreiterung der Quellenbasis darstellen, auf der die Erforschung der unmittelbaren Nachkriegszeit aufzubauen hat. Ihre Ergänzung finden sie vor allem in der Überlieferung der deutschen Seite, aber auch in anderen amerikanischen und englischen Archivmaterialien.

\section{Andere amerikanische und englische Archivquellen}

$\mathrm{DaB}$ aus den Akten der regionalen Militärregierungen gewonnene Erkenntnisse durch die Überlieferung der OMGUS-Zentrale abzusichern und abzurunden sind, liegt auf der Hand. Besonders über die britisch-amerikanischen und inneramerikanischen Diskussionen um Statusfragen findet sich wertvolles Hintergrundmaterial, aber auch über organisatorischen Zuschnitt und Verantwortlichkeiten der Bremer Militärregierung 1945/46. Neben Einzelfunden in einigen Fachabteilungen haben sich die Akten des Adjutant General und des Political Adviser in diesen Fragen als ergiebig erwiesen. Gezielt ausgewertet wurden die zentralen Bestände hier insoweit, als sie mikroverfilmt im Institut für Zeitgeschichte, München, greifbar und durch einen Index erschlossen sind.

Von den Marinestützpunkten an der Unterweser und der 29. Infanteriedivision, die die Sicherheit in der Enklave 1945/46 zu gewährleisten hatte, ist bislang so gut wie keine Aktenüberlieferung festgestellt worden. Glücklicherweise fanden sich Akten des Bremer Hafenkommandos, darunter zwei voluminöse Tätigkeitsberichte für 1945, im Historical File der USFET-Akten in Suitland. Dort lagen auch einige nicht so ergiebige Aktenbände der Nachfolgeorganisation Bremerhaven Port of Embarkation und, 
besonders reizvoll, der Bericht einer Untersuchungskommission, die im Juli 1945 die Zustände in Regierung und Verwaltung einer Prüfung unterzog. Mikrofilme dieser Akten befinden sich im Staatsarchiv Bremen. ${ }^{8}$ Weitere Funde dieser Art sind keineswegs ausgeschlossen.

Im AnschluB an das OMGUS-Projekt wurden auch Nachkriegsakten des amerikanischen Konsulats in Bremen gesichtet, jedoch als zu unergiebig nicht zur Verfilmung vorgesehen. Aus dem Bestand Joint Chiefs of Staff wurden die Aktenbände herausgesucht und reproduziert, die sich mit der Frage der Bremer Enklave befassen. Sie sind ebenfalls im Staatsarchiv Bremen benutzbar. 9

Gerade für die Jahre 1945 und 1946 wäre die englische Überlieferung für Bremen von großem Interesse. Leider ist eine endgültige Einschätzung dessen, was von dort zu erwarten ist, zur Zeit [1985] noch nicht möglich. Der Informationsbesuch eines deutschen Archivars im Public Record Office in Kew ergab im Juli 1983, daB eine Überlieferung militärischer Dienststellen, etwa des für Bremen wichtigen 30 . Corps, ausgeschlossen werden kann. Außerdem seien praktisch keine Akten der lokalen Ebene (Stadt- bzw. Landkreise, Regierungsbezirke) erhalten geblieben. Die beim CCG/BE entstandenen Akten sind nach der Besatzungszeit vom Foreign Office übernommen worden, von wo sie nach und nach an das Public Record Office abgegeben werden. Diese Prozedur ist noch nicht abgeschlossen und wird wohl noch einige Jahre in Anspruch nehmen. ${ }^{10}$ Unter den bereits im Public Record Office benutzbaren Akten befinden sich Bremen-Betreffe vorwiegend allgemeiner Art (Status der Enklave u. ä.) in den Control Commission Files, den Control Office Files und der politischen Korrespondenz des Foreign Office 1945. Der Zugang über das Stichwort „Bremen“ erschließt allerdings nur einen Teil des vorhandenen Materials. Das ubrige müBte durch systematische Aktendurchsicht in den einschlägigen Beständen mühsam ermittelt werden. ${ }^{11}$

\section{Deutsche archivalische Überlieferung zur Bremer Besatzungsverwaltung}

Der reichhaltigste und wichtigste Quellenbestand auf deutscher Seite ist die Registratur des Bremer Senats, die, uber Krieg und Kriegsende hinweg kontinuierlich weitergeführt, ohne bedeutende Verluste an das Archiv gelangt ist. ${ }^{12}$ Eine seinerzeit eigens eingerichtete Aktengruppe für den Komplex Zusammenbruch und Machtubernahme durch die Alliierten umfaBt allein 16 Regalmeter Akten; wieviel noch hinzukäme, wenn man das nach Sachbetreff abgelegte einschlägige Schriftgut zusammenzöge, läßt sich nicht einmal schätzen. Aufgrund von Aktenführung und Überlieferungsgeschichte ist die Senatsregistratur dort, wo sie Kontakte und Verhandlungen mit den Ameri-

8 StA Bremen $16,1 / 4$.

9 StA Bremen 16, 1/3.

${ }^{10}$ H. Romeyk: Bericht über den Informationsbesuch im Public Record Office in Kew (StA Bremen Reg.akte 731-15).

11 Auskunft von Patricia M. Barnes, Deputy Keeper of Public Records, 26.9.1983 (StA Bremen Reg.akte 731-15). Ein seit 1987 laufendes spezielles Erschließungsprojekt soll den Zugriff für die deutsche Forschung wesentlich verbessern, siehe Schulze: Das Londoner CCG/BE-Projekt, Sp. $461-474$.

12 Bei Kriegsende verbrannt wurden lediglich die Geheimakten; hierzu und zum folgenden vgl. Übersicht über die Bestände des Staatsarchivs der Freien Hansestadt Bremen. 
kanern dokumentiert, oft vollständiger und ergiebiger als die amerikanische Gegenuberlieferung. Die Senatsregistratur enthält für den in Frage stehenden Zeitraum auch die Ressortakten des Senators für Justiz und Verfassung.

Andere senatorische Behörden, die beachtliche Aktenbestände aus der Besatzungszeit an das Staatsarchiv abgegeben haben, sind der Senator für das Wohlfahrtswesen, der Senator für das Wohnungswesen, der Senator für das Bildungswesen, der Senator für Wirtschaft (dem die Landeswirtschaftsverwaltung bis 1950 unterstand), der Senator für Häfen, Schiffahrt und Verkehr, der Senator für Finanzen und - eine zeitspezifische, kurzlebige Einrichtung - der Senator für politische Befreiung, dessen Ressortakten die umfangreiche Überlieferung der Entnazifizierungsbehörden beigegeben wurde. Als weitere Fachbehörden, von denen einschlägiges Quellenmaterial vorliegt, seien genannt das Landesernährungsamt, das Landesarbeitsamt, die Oberfinanzdirektion und die Wasser- und Schifffahrtsdirektion. Besonders eng waren die Beziehungen der Amerikaner zu den von ihnen für bestimmte Aufgaben eingerichteten Behörden wie dem Amt für Vermögenskontrolle und der Weserhafenbehörde, von denen Aktenbestände vorhanden sind.

Manche Ergänzung zu den Behördenakten findet sich in den Nachlässen der Bremer Bürgermeister und Senatoren Erich Vagts, Wilhelm Kaisen, Theodor Spitta, ${ }^{13}$ Hermann Apelt und Adolf Ehlers, die das Staatsarchiv verwahrt. Von Interesse ist auch der NachlaB Wilhelm Bergers, der zunächst in der Erziehungsabteilung der Militärregierung tätig war, um dann Leitungsfunktionen in der Bremer Schulverwaltung zu übernehmen.

SchlieBlich darf ein Hinweis auf die gut bestückten Plakat- und Bildsammlungen des Staatsarchivs in diesem Zusammenhang nicht fehlen. Teil der Sammlungen ist ein 50minütiger Dokumentarfilm „Bremen '45“, der 1971/72 mit Hilfe britischer und amerikanischer Filmdokumente für das Fernsehen produziert wurde und in verschiedenen Episoden die Militärregierung thematisiert. ${ }^{14}$ Die aus der eigenen beruflichen Tätigkeit erwachsene private Fotosammlung des Bremer Bildberichterstatters Georg Schmidt ist durch zahlreiche Einzelveröffentlichungen von Fotos und zuletzt zwei Bildbände bekannt geworden. ${ }^{15}$ Sie bietet manche ergänzende Bilddokumentation.

Bei wirtschaftsgeschichtlichen Fragestellungen bietet das Archiv der Bremer Handelskammer wertvolles Material, und kirchengeschichtliche Untersuchungen müssen sich mit auf das Archiv der Bremischen Evangelischen Kirche stützen. ${ }^{16}$ Daß Arbeiten, die die Verhältnisse in Bremerhaven zum Gegenstand haben, auf den Beständen des dortigen Stadtarchivs aufbauen müssen, versteht sich von selbst.

${ }^{13}$ Der Nachlaß enthält auch die für die unmittelbaren Nachkriegsjahre wichtigen und schon vielfach zitierten Tagebücher Spittas, deren Edition nach langer Vorbereitungszeit nun vorliegt: Neuanfang auf Trümmern. Die Tagebücher des Bremer Bürgermeisters Theodor Spitta 1945-1947.

${ }^{14}$ Hersteller: Chronos-Film GmbH, Frankfurt. Ausstrahlung vorgesehen für den 18.4.1972 (StA Bremen Reg.akte 763-06/8/1 Bd. 1.)

${ }^{15}$ Schmidt: Bremen nach der Stunde Null; ders.: Als Bremen amerikanisch war.

${ }^{16}$ Ein erstes Beispiel dafür ist Crüsemann: Die Bremische Evangelische Kirche. 